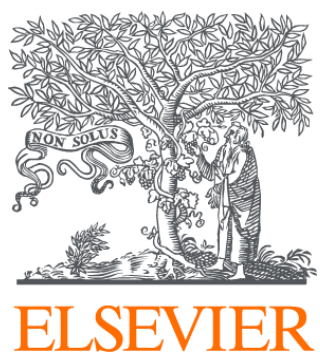

Since January 2020 Elsevier has created a COVID-19 resource centre with free information in English and Mandarin on the novel coronavirus COVID-

19. The COVID-19 resource centre is hosted on Elsevier Connect, the company's public news and information website.

Elsevier hereby grants permission to make all its COVID-19-related research that is available on the COVID-19 resource centre - including this research content - immediately available in PubMed Central and other publicly funded repositories, such as the WHO COVID database with rights for unrestricted research re-use and analyses in any form or by any means with acknowledgement of the original source. These permissions are granted for free by Elsevier for as long as the COVID-19 resource centre remains active. 


\section{"Please doctor, could you tell him that I love him?": Letter from plastic surgeons at the COVID-19 warfront}

\section{Dear Sir,}

How many times have we heard these words in this time? Too many. The COVID-19 pandemic has completely disrupted our normal surgical and clinical routine. In these days, many colleagues of whatever specialty are regularly employed by their hospitals to face COVID-19 emergency in Italy, Europe and worldwide. We are not plastic surgeons anymore. Many of us feel lost, unprepared and inadequate for such an emergency. Here in Bergamo, the centre of the Italian epidemic, we felt small and incompetent at the beginning. ${ }^{1}$ However, we must remember that first of all we are doctors, then plastic surgeons. In these weeks we are putting our willingness at the service of our patients and colleagues.

The numbers of the COVID-19 pandemic in Bergamo are impressive: 8664 positive patients and over official 2000 deaths in about one month. At the same time, the reaction of our hospital, Papa Giovanni XXIII, has been impressive too: over 400 doctors and over 900 nurses entirely dedicated to COVID-19 positive patients; 88 intensive (one of the largest Intensive Care Unit in Europe) and over 400 nonintensive care beds are set aside for those patients. This huge wave of COVID-19 positive patients, forced the hospital management to progressively and rapidly recruit, train and put on ward over 400 physicians of any discipline and 900 nurses from March 6th. Several training programs about COVID-19 infection and management have been scheduled in order to prepare the entire staff. Two Plastic Surgeons of our team (on a total of six) have been fully dedicated on the shifting in COVID medical areas coordinated by a pulmonologist and an intensivist. Main activities focus on patient clinical exam, adjustment of oxygen therapy, regulation of CPAP systems, hemogasanalysis implementation, blood and radiological exam monitoring and consequent therapy modulation, admission, discharge and deaths bureaucracy.

Despite these new clinical fields which are new for a plastic surgeon, we are learning how isolation of patients, due to public health reason, is the most devastating aspect of COVID-19 pandemic. $^{2,3}$ Every single day we phone and update the relatives of those who, because of the worsening of their respiratory condition, are unable to speak and call home. We are sometimes those who communicate the death of his or her beloved but also those who bring words of hope, words of love: "Please doctor, could you tell him that I love him so much?". Some of these patients die without the hug of their families. A plastic surgeon is not usually used to face death because in our surgery it is not so frequent. We would say that the death of a lonely patient also takes a part of us away. It acquires a different hint, touching some inner cord, it makes you feel impotent and lost. As plastic surgeons we often take care of the psychological side of patients and, except for some tumours and traumas, the pathologies we treat - like breast reconstruction - are not fatal diseases.

If we compare the contribution of Plastic Surgery Department in term of numbers, we are like a drop in the ocean. But as Ovid wrote in Epistulae ex Ponto "Gutta cavat lapidem" i.e. "The drop digs the rock". Thanks to our support, a clinical physician is able to evaluate a larger number of patients, focusing on the most critical ones. This is why we keep going on. We want to make our part, working with commitment, dedication and professionalism and assisting all our patients to the best of our in-continueupdating knowledge. We are proud to help Bergamo community to face COVID-19 emergency and trying to make the difference in our wounded city. We hope this letter will help other colleagues not to consider themselves unprepared or unready. The contribute of everyone is crucial to defeat this ongoing pandemic which has not only upset our clinical routine, but it has woken us up from our everyday life. Before COVID-19 everything was scheduled, now there are no plans and we are not sure about our priorities. Only if we behave, as long as necessary, with the awareness of being able to make a difference, we will win this terrible fight against SARS-CoV-2. Only together we will go back to hugging, kissing and loving each other. When the critical phase of this emergency is over, it will be necessary to think deeply about the socioeconomic development strategies to discover new horizons and new opportunities for a better future.

We will never give up!...and what about you? Are you ready to play your part?

\section{Declaration of Competing Interest}

None.

\section{Funding}

This research did not receive any specific grant from funding agencies in the public, commercial, or not-for-profit sectors. 


\section{Acknowledgements}

None.

\section{References}

1. M Nacoti, A Ciocca, A Giupponi, et al. At the epicenter of the COVID-19 pandemic and humanitarian crises in Italy: changing perspectives on preparation and mitigation. doi:10.1056/CAT. 20.0080.

2. Benatti SV. Love in the time of corona. Ann Intern Med 2020 [Epub ahead of print] PubMed PMID:32227245 . doi:10.7326/ M20-1137.

3. C Mario MD, FEBOPRAS; Valdatta, Luigi MD, FACS Plastic Surgery in Coronavirus Disease 2019 Emergencies, Plastic and Reconstructive Surgery - Global Open: May 13, 2020 - Volume Latest Articles - Issue - doi:10.1097/GOX.0000000000002913.

Davide Sallam

Marcello Carminati

Gabriele Mevio

Maurizio Verga

Denis Codazzi

Department of Plastic and Reconstructive Surgery, ASST Papa Giovanni XXIII, Piazza OMS 1, 24127 Bergamo, Italy

E-mail address: davide.sallam@gmail.com (D. Sallam)

(C) 2020 British Association of Plastic, Reconstructive and Aesthetic Surgeons. Published by Elsevier Ltd. All rights reserved.

https://doi.org/10.1016/j.bjps.2020.05.001

\section{What can plastic and reconstructive medical staffs do during the COVID-19 outbreak?}

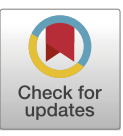

Dear Sir

COVID-19 is a novel coronavirus with increasing outbreaks occurring around the world., ${ }^{1,2}$ During the past 4 weeks, emergence of new cases has gradually decreased in China with the help of massive efforts from society and the government. In addition to those directly working in the respiratory, infectious, cardiology, nephrology, psychology, and ICU departments and COVID-19 patients, all members of the general population may encounter the new coronavirus. Medical staff in plastics, reconstructive, and other departments also have a responsibility to prevent the disease spreading in our community.

In order to protect both patients and medical staff, selective operations and cosmetic treatments were reduced or postponed in the Plastic Surgery Hospital, Beijing, China. Gloves and medical masks were saved and donated to the doctors and nurses in Wuhan as the demand for protective equipment increased significantly. In addition, a standard operation procedure for COVID-19 was proposed in local hos- pitals. Our hospital recommended online consultations to replace face-to-face interactions. Hospital websites and official social media accounts provided updated practical disease prevention information instead of plastic surgery information. Other colleagues also conducted publicity campaigns on disease prevention online via their own social media accounts for relatives and friends, especially for older persons who appeared to have developed a serious illness.

At the early stages of the COVID-19 outbreak in certain areas, the public may not care much about the new disease. As more information about COVID-19 becomes available, people without medical background may be anxious to seek diagnosis, which may result in potential risks of cross infection in the crowded fever clinics. Thus, proper information and guidance can help reduce their panic and anxiety. Moreover, if individuals were exhibiting relevant symptoms with epidemiologic history, they were advised to seek medical care following the directions of local health authority. In general, plastic surgeons are particularly good at introducing novel surgical methods to the public and keeping in touch with a great number of patients. As a result, they may be able to present local health authority advice in the form of straightforward images and accessible videos, as well as promote practical information via personal social media or clinic websites.

In addition to local doctors and nurses from other departments helping in fever clinics and isolation wards, ${ }^{3}$ 42,600 (as of March 8, 2020) members of medical staff from other provinces rushed to help their colleagues in Hubei province. ${ }^{4}$ Plastic surgeons that had completed ICU training in Beijing and other cities supported Wuhan on their own initiative as well. ${ }^{5}$ We suggest that measures should be taken by medical staff from all departments to help slow further spread and to protect health systems from becoming overwhelmed.

\section{Declaration of Competing Interest}

None.

\section{Funding}

None.

\section{References}

1. World Health Organization. Coronavirus. https://www.who. int/emergencies/diseases/novel-coronavirus-2019. [Accessibility verified March 13, 2020]

2. World Health Organization. WHO Director-General's opening remarks at the Mission briefing on COVID-19 - 12 March 2020. https://www.who.int/dg/speeches/detail/ who-director-general-s-opening-remarks-at-the-missionbriefing-on-covid-19-12-march-2020. [Accessibility verified March 13, 2020]

3. Wuhan Union Hospital. Plastic and reconstructive medical staffs in front line. http://www.whuh.com/articles/id/13706.html. [in Chinese] [Accessibility verified March 13, 2020]

4. National Health Commission of the People's Republic of China. Press Conference of the joint Prevention and Control Mechanism of the State Council. http://www.nhc.gov.cn/xcs/fkdt/202003/ a54a40ae28764f3581f36cc31204433c.shtml. [in Chinese] [Accessibility verified March 13, 2020] 
5. Peking Union Medical College Hospital. The second batch of Peking Union Medical College Hospital national medical teams went to Wuhan. https://www.pumch.cn/detail/22594.html. [in Chinese] [Accessibility verified March 13, 2020]

Minlu Huang

Zuoliang Qi

The 16th Department, Plastic Surgery Hospital, Chinese Academy of Medical Sciences (CAMS) and Peking Union Medical College (PUMC), Beijing, China

E-mail address: public_q@163.com (Z. Qi)

(c) 2020 British Association of Plastic, Reconstructive and Aesthetic Surgeons. Published by Elsevier Ltd. All rights reserved.

https://doi.org/10.1016/j.bjps.2020.05.006

\section{Evolution of plastic surgery provision due to COVID-19 - The role of the 'Pandemic pack'}

\section{Dear Sir,}

As COVID-19 spreads quickly from Asia via Europe to the rest of the world, hospitals are evolving into hot zones for treatment and transmission of this disease. With the increasing acceptance that operating theatres are high risk areas for transmission of respiratory infections for both patients and surgeons, ${ }^{1}$ and with our health care systems being generally well-designed to only deal with occasional high-risk cases, there is an obvious need to evolve our practice. Although social media campaigns via the British Association of Plastic, Reconstructive and Aesthetic Surgeons (\#StaySafeStayHome) and British Society for Surgery of the Hand (\#PlaySafeStaySafe) are attempting to raise awareness and reduce preventable injuries, we are still seeing a steady stream of patients present to our plastic surgery trauma service.

We have had to act immediately so our systems can support essential surgical care while protecting patients and staff and conserving valuable resources. As a department we have developed a set of standard operating procedures which cover the full scope of plastic surgery from the facilitation of emergent life and limb saving surgeries, rationalised oncological management to the management of minor soft tissue and bony injuries. We have been cognisant of the need to reduce footfall to the hospital and the stratification into "dirty" and "clean" areas with attempted segregation of non-, suspected and confirmed COVID cases within inpatient clinical areas. This has resulted in displacement of assessment and procedure rooms within the unit. The ward itself has been earmarked as an extended intensive care unit due to its layout and facilities.

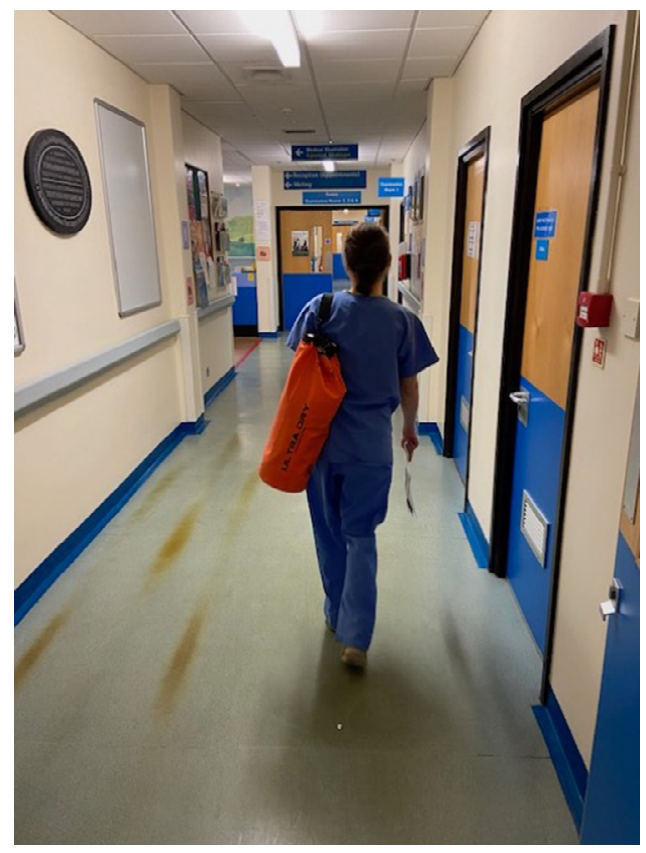

Figure 1 The Pandemic Pack in action.

Standards of practise have changed, with an emphasis on "see and treat" as operating theatre availability has been reduced due to the reduced availability of nurses and theatre staff and their conversion into intensive care areas for ventilated patients.

There is also an emerging assumption that all patients are COVID-19 positive until proven otherwise. ${ }^{2}$ The combination of unfamiliar environments, lack of accessible equipment, requirement to reduce time spent with patients and adherence to social distancing has resulted in the need to provide a more mobile and flexible service.

In order to support our mobile service, we have found that, as in other disaster situations where specialised bags have been deployed, ${ }^{3}$ using a simple bag containing essential equipment and consumables has revolutionised our ability to work at the point of referral and avoid unnecessary trips to theatre.

Despite their simplicity, bags have been fundamental for the development of human civilization, with the word originating from the Norse word baggi and comparable to the Welsh baich (load, bundle)!!! ${ }^{4}$ Our portable "pandemic pack" is now being carried by the first on-call in our department. This pack contains a $10 \mathrm{~L}$ Ultra Dry Adventurer ${ }^{\mathrm{TM}}$, polymer dry bag measuring $36 \mathrm{~cm}(\mathrm{~W}) \times 70 \mathrm{~cm}(\mathrm{~L})$ as shown in Figure 1. The contents are shown in Figure 2 . We have found this adequate for managing most common plastic surgery trauma and emergency scenarios. The bag is easily cleaned with $1000 \mathrm{ppm}$ available chlorine (in accordance with Public Health England guidance) after each patient exposure. We have found it useful to make up two packs in advance so that one is available at handover whilst the other is replenished by the outgoing team.

We are sure that this concept has been used elsewhere, but if it is not common practice in your unit, we would advo- 


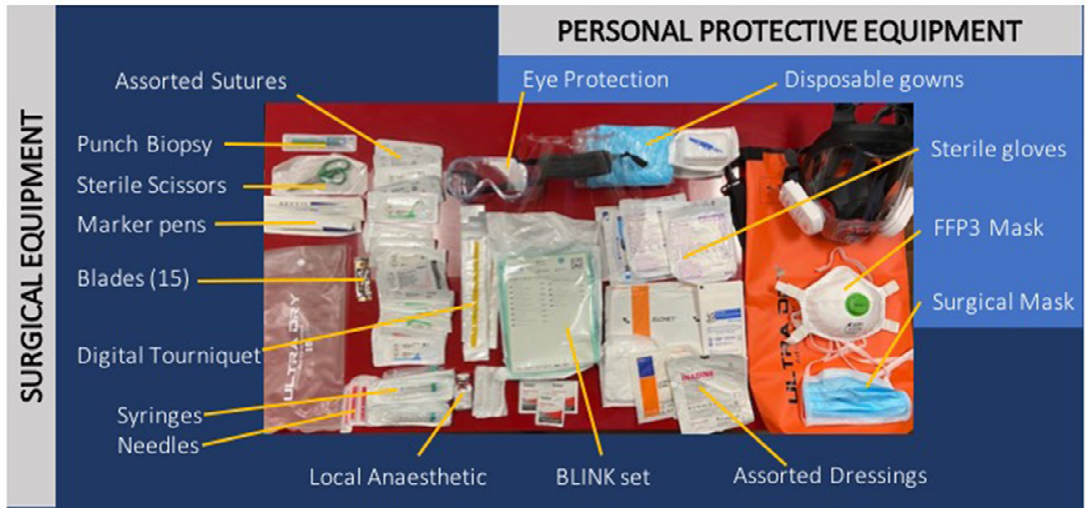

Figure 2 Contents of the Pandemic Pack.

cate implementing such a toolkit to facilitate management of trauma patients and reduce the amount time frontline staff need to be in a potential "dirty" environment during the COVID-19 pandemic.

\section{Declaration of Competing Interest}

None.

\section{Funding}

None.

\section{References}

1. Raphael T. Why surgeons don't want to operate right now. Bloomberg. Available at URL: https://www.bloomberg.com/ opinion/articles/2020-03-24/the-coronavirus-crisis-is- puttingsurgeons-at-risk-too (accessed April 3 2020,).

2. Pearce C. GPs should assume 'most' patients have Covid-19 and use PPE, says NHS England. Pulse. Available at URL: http: / / www. pulsetoday.co.uk/clinical/clinical-specialties/respiratory-/ gps-should-assume-most-patients-have-covid-19-and-use-ppesays-nhs-england/20040541. article (accessed April 3 2020,).

3. Ando W, et al. Handling and packaging of medical bags at acute disaster sites under high-temperature conditions. BMC Res Notes 2020;13:158.

4. Wikipedia. Bag. Available at URL: https://en.wikipedia.org/ wiki/Bag (accessed April 3 2020,).

Stephen R. Ali, Thomas Jovic, John AG Gibson, Harvey Rich, Zita M Jessop, lain S. Whitaker Reconstructive Surgery and Regenerative Medicine Research Group, Institute of Life Sciences 2, Swansea University Medical School, Singleton Park, Sketty, Swansea, SA2 8PP, UK

The Welsh Centre for Burns and Plastic Surgery, Morriston Hospital, Hoel Maes Eglwys, Swansea SA6 6NL, UK

E-mail address: Stephen.ali@wales.nhs.uk (S.R. Ali)

(C) 2020 British Association of Plastic, Reconstructive and Aesthetic Surgeons. Published by Elsevier Ltd. All rights reserved.

https://doi.org/10.1016/j.bjps.2020.05.024

\section{Teleconsultation-mediated nasoalveolar molding therapy for babies with cleft lip/palate during the COVID-19 outbreak: Implementing change at pandemic speed}

Dear Sir,

Cleft lip/palate is among the most common congenital anomalies, requiring multidisciplinary care from birth to adulthood. The nasolaveolar molding (NAM) revolutionized the care provided to babies with a complete cleft, with proving its benefits to patients, parents, clinicians, and society. ${ }^{1}$ This therapeutic modality requires parents' engagement with NAM care at home and continuous clinicianpatient/parent encounters, commencing at the second week of life and finishing just before the lip repair.

The rapidly expanding COVID-19 pandemic $^{2}$ has challenged clinicians who are dealing with NAM therapy to fully stop it, or adjust it to protect, both, the patient/parent and the healthcare team. Based on the current WHO recommendation, to maintain social distancing, and the national regulation for the use of telemedicine, ${ }^{2,3}$ the NAM-related clinician-patient/parent relationship has timely been adjusted by implementing the non-face-to-face care model.

Babies with clefts are consulted individually by clinicians, proactively establishing the initial and subsequent telemedicine consultations, also providing an open communication channel for parents. Based on a shared decisionmaking process, all parents have the option to completely stop NAM therapy or use only lip tapping. Given that each patient is at a particular stage within the continuum of NAM care, numerous patient- and parent-derived issues are being addressed by video-mediated consultations. Overall, this has helped explain the current COVID-19-related public health recommendations and precautions to parents, while addressing patients' needs and parents' feelings, fears, expectations, and answering parents' questions. Moreover, clinical support is provided to patients and parents by 
visual inspection (looking for potential NAM-derived facial irritation), and checking parents' hand-hold maneuvers, such as feeding and placement of the lip tapping and NAM device, with immediate feedback for corrections. Thus, the use of an audiovisual communication tool has considerably reduced the number of in-person consultations.

When a face-to-face consultation could not be resolved using the telemedicine triage, an additional video-based conversation had been implemented, focusing on the key steps, established for patient/parent visits to the facility (i.e., frequent hand-cleaning, mask usage, and keeping $1 \mathrm{~m}$ social distance) and on the COVID-19-focused screening. ${ }^{5}$ Symptom- and exposure-screened negative parents/babies have been consulted in a time-specific scheduling with minimum waiting time to avoid crowded waiting rooms, by a clinician wearing personal protective equipment (cap, face shield, N95 mask, goggles, gloves, and gowns), and working in an environment with constant surface/object decontamination. ${ }^{5}$ Parents, who screened positive for symptoms (e.g., fever, cough, sore throat), were indicated to follow to the appropriate self-care or triage mechanism, stipulated by the WHO guidelines and local authorities. ${ }^{2-5}$

In the COVID-19 era, the care provision should be aligned with the latest clinical evidence. ${ }^{4}$ In response to the constantly changing needs, clinicians across the globe could adapt the telemedicine-based possibilities to their own environment of national/hospital regulatory bodies, technology accessibility, and the parents' level of technological literacy. As most of the issues addressed in the video conversations were recurrent reasons for consultations prior to the COVID-19 outbreak, future investigations could assist in truly defining the key aspects of telemedicinebased clinician-patient/parent relationship in delivering NAM therapy, and its impact on NAM-related proxy-reported and clinician-derived outcome measures.

\section{Financial disclosure}

None

\section{Declaration of Competing Interest}

There are no conflicts of interest to disclose.

\section{References}

1. Esenlik E, Gibson T, Kassam S, et al. NAM therapy-evidencebased results. Cleft Palate Craniofac J 2020;57:529-31.

2. Tanne JH, Hayasaki E, Zastrow M, Pulla P, Smith P, Rada AG. Covid-19: how doctors and healthcare systems are tackling coronavirus worldwide. BMJ 2020;368:m1090.

3. Gostin LO, Wiley LF. Governmental public health powers during the COVID-19 pandemic: stay-at-home orders, business closures, and travel restrictions. JAMA 2020. doi:10.1001/jama. 2020.5460

4. Armstrong A. et al. A plastic surgery service response to COVID19 in one of the largest teaching hospitals in Europe. J Plast Reconstr Aesthet Surg 2020. doi:10.1016/j.bjps.2020.03.027.

5. Peng X, Xu X, Li Y, Cheng L, Zhou X, Ren B. Transmission routes of 2019-nCoV and controls in dental practice. Int J Oral Sci 2020;12:9.
Rafael Denadai*

Institute of Plastic and Craniofacial Surgery, SOBRAPAR Hospital, Av. Adolpho Lutz 100, Campinas, Sao Paulo 13084-880, Brazil

Lun-Jou Lo

Department of Plastic and Reconstructive Surgery and Craniofacial Research Center, Chang Gung Memorial Hospital, Chang Gung University, 5 Fu-Shin Street, Kwei Shan, Taoyuan 333, Taiwan

*Corresponding authors. E-mail address: denadai.rafael@hotmail.com (R. Denadai)

(C) 2020 British Association of Plastic, Reconstructive and Aesthetic Surgeons. Published by Elsevier Ltd. All rights reserved.

https://doi.org/10.1016/j.bjps.2020.05.005

\section{Virtual clinics: Need of the hour, a way forward in the future. Adapting practice during a healthcare crisis}

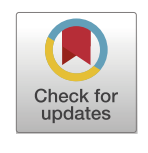

Dear Sir,

The whole world is gripped by the novel coronavirus pandemic, with huge pressures on the health services globally. Within the coming days, this is only going to increase the pressure on the health care services and needs robust planning and preparedness for this unprecedented situation, lest the whole system may cripple and we may see unimaginable mortalities and suffering. ${ }^{1}$

The whole concept of social distancing ${ }^{2}$ and keeping people in self isolation has reduced footfall to the hospitals but this is affecting delivery of routine care to patients for other illnesses in the hospital and telehealth is an upcoming way to reduce the risk of cross contamination as well as reduce close contact without affecting the quality of health care delivered. ${ }^{3}$

At the Bedford hospital NHS trust, for the past one year we have been running a virtual clinic for our skin cancer suspect patients, where in after a particular biopsy if the clinical suspicion of a malignancy was low, these patients were not given a follow up clinic appointment and instead they were informed of the biopsy result through post, sent both to their GP and themselves. Most patients encouraged this model to not have to come back to an appointment and this took significant pressure off our clinics. In the event we needed to see a patient, they were informed via a telephonic conversation to attend a particular clinic appointment. From an administration standpoint, this resulted in less unnecessary follow up appointments in our skin cancer follow up clinics, which could then be offered to our regular skin cancer follow up patients as per the recommended guidelines, without having to struggle with appointments. 
Virtual clinics have previously shown to be safe and cost effective alternatives to the Out patient visits in surgical departments like Urology ${ }^{4}$ and Orthopedics. ${ }^{5}$ They improved performance as well as improved economic output. ${ }^{3,4}$

We have increased the use of these virtual clinics, with the onset of the novel Coronavirus pandemic, in order to reduce the patient footfall to our clinics. Most patients voluntarily chose not to turn up and with the risk being highest amongst the elderly, it was logical to keep them away from hospitals as far as possible. In order to achieve this, we have started virtual clinics for nearly all patients in order to triage patients that can do without having to come to the hospital for now.

The world of telemedicine is the way forward in nearly all aspects of medical practice ${ }^{3}$ and this pandemic situation might just be the right time to establish such methods. We propose setting up of more such clinics in as many subspecialties of plastic surgery, which not only will help in the current crises situation, but will also be useful in the future to take pressure of our health care services.

\section{Declaration of Competing Interest}

None declared

\section{Ethical approval}

Not required

\section{Funding}

None

\section{References}

1. Cucinotta D, Vanelli M. WHO Declares COVID-19 a Pandemic. Acta Biomed 2020;91(1):157-60 Mar 19.

2. Mahase E. Covid-19: UK starts social distancing after new model points to 260000 potential deaths. BMJ 2020;368:m1089 Mar 17.

3. Smith AC, Thomas E, Snoswell CL, Haydon H, Mehrotra A, Clemensen J, Caffery LJ. Telehealth for global emergencies: implications for coronavirus disease 2019(COVID-19). J Telemed Telecare 2020 Mar 20:1357633X20916567.

4. Browne C, Davis NF, Mac Craith ED, Lennon GM, Galvin DJ, Mulvin DW. Prospective evaluation of a virtual urology outpatient clinic. Ir J Med Sci 2018;187(1):251-4 Feb.

5. Holgate J, Kirmani S, Anand B. Virtual fracture clinic delivers British Orthopaedic Association compliance. Ann R Coll Surg Engl 2017;99(1):51-4 Jan.

K. Maheshwari S. Hindocha

A. Yousif

Dept. of Plastic surgery, Bedford Hospital NHS trust, Kempston road MK42 9DJ, United Kingdom

E-mail addresses:

kavish.maheshwari@bedfordhospital.nhs.uk, Sandip.hindocha@bedfordhospital.nhs.uk, Ali.yousif@bedfordhospital.nhs.uk (A. Yousif)

(C) 2020 British Association of Plastic, Reconstructive and Aesthetic Surgeons. Published by Elsevier Ltd. All rights reserved.

https://doi.org/10.1016/j.bjps.2020.05.012

\section{Webinars in plastic and reconstructive surgery training - a review of the current landscape during the COVID-19 pandemic}

Dear Sir,

The COVID-19 pandemic has resulted in cancellation of postgraduate courses and the vast majority of elective surgery. Plastic surgery trainees and their trainers have therefore needed to pursue alternative means of training. In the face of cross-speciality cover and redeployment there is an additional demand for COVID-19 specific education. The Joint Committee on Surgical Training (JCST) Quality Indicators for Higher Surgical Training (HST) in Plastic Surgery state that trainees should have at least $2 \mathrm{~h}$ of facilitated formal teaching each week. ${ }^{1}$ Social distancing requirements have meant that innovative ways of delivering this teaching have needed to be found. A seminar is a form of academic instruction based on the Socratic dialogue of asking and answering questions, with the word originating from the Latin word seminarium meaning "seed plot". ${ }^{2}$ Fast and reliable internet and the ubiquitous nature of webcams has led to the evolution of the seminar into the webinar. Whilst webinars have been common place for a number of years, they represent an innovative and indispensable tool for remote learning during the COVID-19 pandemic, where trainees can interact and ask questions to facilitate deep and meaningful learning.

Speciality and trainee associations have traditionally used their websites and email lists to publicise training opportunities. However, the COVID-19 pandemic has seen a shift to social media; with people seeking constant updates and information from public figures, brands and organisations alike. Surgical education has mirrored this trend, and we have increasingly observed that webinars are being launched through speciality and trainee association social channels to keep up with the fast-paced demand for accessible online content. The aim of this study was to audit cumulative compliance of active publicly accessible postgraduate plastic surgery training webinar frequency and duration against JCST Quality Indicators.

We used the social listening tool Brand24 ${ }^{T M}$ (https:// brand24.com). This tool monitors social media platforms for selected 'keywords' and provides analysis of search results. We used the search terms "Plastic Surgery Webinar", "Reconstructive Surgery Webinar", "Royal College of Surgeons", "BAPRAS", "BSSH", "British Burns Association", "PLASTA" and "BSSH". There were 733 mentions of these terms from 6th May 2019 to 5th May 2020 and 727 of these were after 23rd March 2020, the date that lockdown began in the United Kingdom (UK). This represents an increase of $12,017 \%$ post-lockdown. We supplemented this search strategy by searching Google $e^{T M}$ and YouTube ${ }^{T M}$ with "Plastic and Reconstructive Surgery Webinar". These search engines rank results in order of relevance using a relevancy algorithm, we therefore reviewed the first 100 results only. Additional webinars were identified through a snowballing 
Table 1 Active plastic and reconstructive surgery webinar series in progress during COVID-19.

\begin{tabular}{|c|c|c|c|c|}
\hline Host & Webinar series Theme & Frequency & $\begin{array}{l}\text { Duration } \\
\text { (minutes) }\end{array}$ & Registration and viewing details \\
\hline $\begin{array}{l}\text { Royal college of surgeons } \\
\text { of England }\end{array}$ & COVID-19 & Weekly & 60 & $\begin{array}{l}\text { https://www.rcseng.ac.uk/news-and-events/ } \\
\text { events/covid-19-webinars/?_id= } \\
\text { B3FC6CC4688A4A7E8A52FD0F81E50FDA\&_z=z }\end{array}$ \\
\hline $\begin{array}{l}\text { Royal college of surgeons } \\
\text { of Edinburgh }\end{array}$ & $\begin{array}{l}\text { COVID-19; head and } \\
\text { neck surgery }\end{array}$ & Weekly & 60 & $\begin{array}{l}\text { https://www.rcsed.ac.uk/ } \\
\text { professional-support-development-resources/ } \\
\text { learning-resources/webinars }\end{array}$ \\
\hline $\begin{array}{l}\text { British association of } \\
\text { plastic, reconstructive } \\
\text { and aesthetic surgeons } \\
\text { (BAPRAS) }\end{array}$ & COVID-19 & Weekly & 120 & $\begin{array}{l}\text { http://www.bapras.org.uk/professionals/ } \\
\text { training-and-education/bapras-events/ } \\
\text { COVID-19-webinars }\end{array}$ \\
\hline $\begin{array}{l}\text { Plastic surgery trainee } \\
\text { Association (PLASTA) } \\
\text { UK }\end{array}$ & Pan-plastic surgery & Weekly & 60 & $\begin{array}{l}\text { https://www.plasta.org/education/resources/ } \\
\text { webinars.aspx }\end{array}$ \\
\hline Pulvertaft hand centre & Hand surgery & Weekly & 60 & $\begin{array}{l}\text { https://www.pulvertafthandcentre.org.uk/ } \\
\text { derby-on-line-teaching-programme/ }\end{array}$ \\
\hline $\begin{array}{l}\text { International master } \\
\text { course on aging } \\
\text { science (IMCAS) } \\
\text { academy }\end{array}$ & Aesthetic surgery & Weekly & 90 & https://www.imcas.com/en/academy/webinars \\
\hline $\begin{array}{l}\text { The international society } \\
\text { of plastic surgery } \\
\text { (ISAPS) }\end{array}$ & Aesthetic surgery & Weekly & 60 & https://www.isaps.org/webinars/ \\
\hline
\end{tabular}

Table 2 Historic plastic and reconstructive surgery webinar series available online.

\begin{tabular}{|c|c|c|c|}
\hline Host & Webinar Series Theme & Duration (minutes) & Achieve details \\
\hline $\begin{array}{l}\text { International Confederation } \\
\text { of Plastic Surgery } \\
\text { Societies (ICOPLAST) } \\
\text { Confederation }\end{array}$ & Pan-plastic surgery & Variable & $\begin{array}{l}\text { https://www.youtube.com/channel/ } \\
\text { UCcQQrZp97sAOZT2NLn8jw7w/videos }\end{array}$ \\
\hline The Aesthetic Society & Aesthetic surgery & 60 & $\begin{array}{l}\text { https://www.surgery.org/professionals/ } \\
\text { publications/webinars }\end{array}$ \\
\hline
\end{tabular}

technique where the host webinar webpage was searched for advertised webinars at other institutions. We included any educational webinar series aimed at trainees that was free to access, mirroring weekly plastic surgery HST teaching. Free webinars which required membership registration were also included. We excluded webinars aimed at patient or parent education, webinars with less than one video, any historic webinar that did not have an accessible link and webinars behind a paywall or requiring paid membership. We systematically reviewed the search results from Brand $24^{T M}$, Google ${ }^{T M}$ and YouTube ${ }^{T M}$ and identified webinar series currently in progress (Table 1) and historic webinar series (Table 2). Seven active webinar series and two historic webinar series were identified respectively. All were consultant or equivalent delivered. Of the active webinar series, 3 (43\%) related to COVID-19, 2 (29\%) related to aesthetic surgery, $1(14 \%)$ related to pan-plastic surgery and $1(14 \%)$ related to hand surgery. The weekly total running time for active webinars amounted to $8 \mathrm{~h} 30 \mathrm{~min}$, with $4 \mathrm{~h}$ and 30 min plastic surgery specific. This was a surplus of $2 \mathrm{~h}$ $30 \mathrm{~min}$ to JCST Quality Indicators.

Limitations of this study include us only identifying webinars advertised publicly. We are aware of training pro- grammes in the UK running in-house webinar series to supplement training and therefore the total available for training is likely to be higher than we have identified. We have also not reviewed the quality of educational content. We acknowledge there are good quality webinar series that require paid for membership such as those provided by the British Association of Aesthetic Plastic Surgeons and American Society of Plastic Surgeons but it was not the aim of the study to present them here.

Innovation flourishes during times of crisis. The education of surgical trainees is of paramount importance and should be maintained, even during the difficult times we currently face. While operative skills will be difficult to develop, the use of technology can allow for the remote delivery of expert teaching to a large number of trainees at once. In this study we identify a number of freely available webinar series that provide a greater number of teaching hours than is recommended by the JCST. The training exists, it is up to trainees to make the most of it.

\section{Conflict of Interest}

None. 


\section{Funding}

None.

\section{References}

1. The Joint Committee on Surgical Training (JCST). Quality indicators for plastic surgery training. Available at URL: https://www.jcst.org/- /media/files/jcst/quality-assurance/ quality-indicators/plastic-surgery-qis-final-v10.pdf (accessed May 5 2020,).

2. Wikipedia. Seminar. Available at URL: Available at URL: https: //en.wikipedia.org/wiki/Seminar (accessed May 5 2020).

Stephen R. Ali, Thomas D. Dobbs, lain S. Whitaker Reconstructive Surgery \& Regenerative Medicine Research Group, Institute of Life Sciences 2, Swansea University Medical School, Swansea, SA2 8PP, UK

The Welsh Centre for Burns \& Plastic Surgery, Morriston Hospital, Hoel Maes Eglwys, Swansea, SA6 6NL, UK

Corresponding author. E-mail address: Stephen.ali@wales.nhs.uk (S.R. Ali)

(C) 2020 British Association of Plastic, Reconstructive and Aesthetic Surgeons. Published by Elsevier Ltd. All rights reserved.

https://doi.org/10.1016/j.bjps.2020.05.038

\section{Trauma transformed: A positive review of change during the COVID-19 pandemic}

\section{Dear Sir,}

Salisbury District Hospital (SDH) is based in Southwest England and provides a plastic surgery trauma service across the south coast, serving six local hospitals and the designated major trauma centre (MTC). Prior to the COVID-19 pandemic all patients referred to the trauma service, apart from open lower limb trauma, were reviewed in person within the trauma clinic. If surgery was required, it was usual for patients to return on a separate day for their operation and in most instances this was carried out under general anaesthetic in the main operating theatres. After discharge, patients were referred to the hand therapy and plastics dressing services and returned in person for all follow-up visits including dressing changes and therapy. $\mathrm{Pa}$ tients with lower limb injuries from the MTC were transferred from Southampton General Hospital as inpatients to $\mathrm{SDH}$ for all complex reconstruction including free tissue transfer.

At the start of the COVID-19 crisis, it became quickly apparent that reducing patient footfall within our department was necessary to protect both patients and staff from the disease. This included reducing inpatient stays in hospital. We responded to this challenge in the following ways and hope that our experience will be of assistance to other trauma services over the course of the global pandemic.

Firstly, all patient protocols underwent significant redesign following which changes to the layout of our plastic surgery outpatient facility were made and patient flow through the department was altered and reduced. Now, when patients are referred to our hand trauma service from peripheral hospitals, the initial patient consultations are carried out remotely using the 'attend anywhere' video platform. We are following the BSSH Covid-19 Hand trauma guidelines $^{2}$ for patient management. All patient decisions are discussed with the trauma consultant of the day. We are managing a greater number of patients conservatively and to aid this we have designed comprehensive patient information leaflets that enable our patients to increase understanding of their own management.

Patients who need to be seen in person at our department are screened for symptoms of Covid-19 and their temperature taken at the department entrance. Level 2 PPE is worn by staff at all times.

For hand trauma patients requiring surgery, this is provided on the same day to maximize efficiency and reduce the need for multiple visits. We have transformed our minor operating theatres, located adjacent to our clinic, into fully functional theatres equipped with a mini C-arm and all instruments for trauma operating. This reduces the need for our patients to be taken into the main hospital theatre suite. Operations are carried out either under local anaesthetic, WALANT or regional block depending on complexity. All theatre staff wear level 3 PPE and staffing is kept to a minimum. All wounds are closed with dissolvable sutures. Immediately post operation, our on-site hand therapists review patients. Splints are made on the same day and patients are educated about their post-operative management at this time. All follow-up is subsequently carried out virtually by the hand therapy team using 'attend anywhere'.

With our hub and spoke service set up for lower limb trauma patients, we have ensured that there is an on-site consultant at the MTC every day. Wound coverage is being undertaken for all patients at the MTC. Two plastic surgery consultants in conjunction with the orthopaedic team carry out operating for these patients. All inter-hospital transfers for this group of patients have been stopped. Choice of wound coverage for these patients is being designed to minimise inpatient stay and reduce operative time.

The changes that we have made to our service in a short period of time have already been beneficial for patients, streamlining their care and reducing time spent in hospital. Figure 1 shows the drop in numbers of trauma patients that we have seen during the first four weeks of the UK lockdown $(n=213$ in January 2020 to $n=75$ over the first 4 weeks into lockdown). This is in line with reports from other UK units. This has given us time to refine our protocols for an expected upsurge of patients as the lockdown is lifted. Furthermore, during this period where we have had extra capacity, our registrars have been trained to carry out new techniques. They now undertake insertion of both mid-lines and PICC lines for medical inpatients under ultrasound guidance to support and reduce the burden placed on our anaesthetic and critical care colleagues who previously would have placed these.

It is our expectation that many of the changes we have implemented to our service will be continued in the longterm. We will continue to learn and adapt our protocols as 


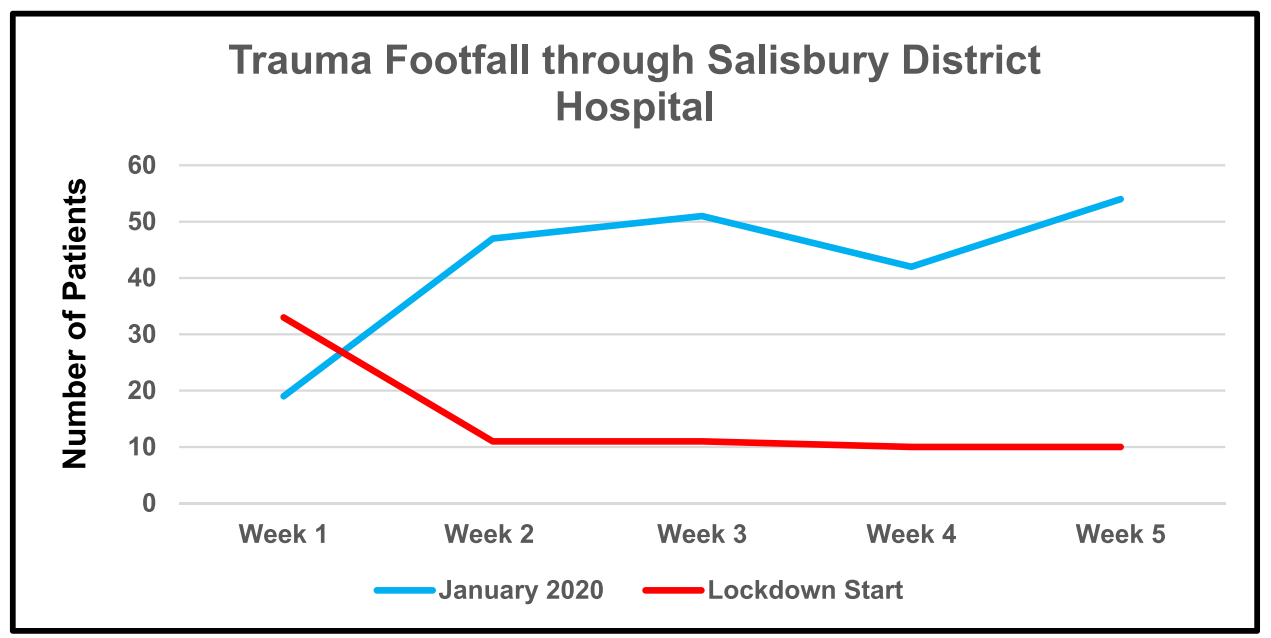

Figure 1 Graph showing the reduction in trauma patients presenting during the COVID lockdown period compared to the month of January 2020 prior to the COVID- 19 Pandemic.

this phase of work continues. Whilst many of the outcomes of the Covid-19 pandemic will be negative, it has also been the catalyst for significant positive change within the UK NHS.

\section{References}

1. Internet resource: The Telegraph. The Inflexibility of our lumbering NHS is why the country has had to shut down. April 2020. https://www.telegraph.co.uk/news/2020/04/03/ inflexibility-lumbering-nhs-country-has-had-shut/ [Accessibility verified April 27, 2020].

2. Internet resource: The British Society for Surgery of the Hand. Covid-19 Resources for Members. March 2020. https://www. bssh.ac.uk/about/news/163/covid19_resources_for_members [Accessibility verified April 27, 2020].

Poonam Valand, Nola Lloyd Plastic Surgery Specialty Training Registrar, Salisbury District Hospital, Odstock Road, Salisbury SP2 8BJ, Wiltshire

Megan Robson

Senior Physiotherapist, Department of Physiotherapy, Salisbury District Hospital, Odstock Road, Salisbury SP2 $8 B J$, Wiltshire

Jessica Steele

Consultant Plastic Surgeon, Department of Plastics and Reconstructive Surgery, Salisbury District Hospital, Odstock Road, Salisbury SP2 8BJ, Wiltshire

Corresponding author. E-mail address: jessief@doctors.org.uk (J. Steele)

(c) 2020 British Association of Plastic, Reconstructive and Aesthetic Surgeons. Published by Elsevier Ltd. All rights reserved.

https://doi.org/10.1016/j.bjps.2020.05.037

\section{Breast reconstruction and the COVID-19 pandemic: A viewpoint}

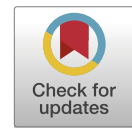

Dear Sir,

The COVID-19 pandemic has caused unprecedented disruptions in patient care globally including management of breast and other cancers. ${ }^{1}$ However, cancer care should not be compromised unnecessarily by constraints caused by the outbreak.

Clinic availability and operating lists have been drastically reduced with many hospital staff members reassigned to the "frontline". Furthermore, all surgical specialties have been advised to undertake emergency surgery or unavoidable procedures only with shortest possible operating times, minimal numbers of staff and leaving ventilators available for Covid-19 patients. ${ }^{2}$ In consequence, much elective surgery including immediate breast reconstruction (IBR) has been deferred in accordance with guidance issued by professional organisations such as the Association of Breast Surgery (UK) and the American Society of Plastic Surgeons. ${ }^{3,4}$ This will inevitably lead to backlogs of women requiring delayed reconstructions and it is therefore imperative that reconstructive surgeons consider ways to mitigate this and adapt local practice in accordance with national guidelines and operative capacity.

In the context of the current "crisis" or the subsequent "recovery period", time consuming and complex autologous tissue reconstruction (free or pedicled flap) should not be performed. Approaches to breast reconstruction might include the following options:

1. A blanket ban on immediate reconstruction, and all forms of risk-reducing, contralateral balancing and revisional/tertiary procedures. 
2. Where reconstructive delay is neither feasible nor desirable, opting for simple and expedient surgery should be considered e.g.:

a) Expanded use of therapeutic mammaplasty: as a unilateral procedure in selected cases instead of mastectomy and IBR.

b) Exploring less technically demanding (albeit "controversial") implant-based forms of IBR:

i. Epipectoral breast reconstruction (fixed volume implants): this adds about 30 minutes to the ablative surgery as the pre-prepared implant-ADM complex is easily secured with minimal sutures.

ii. "Babysitter" tissue expander/implant: this acts as a scaffold to preserve the breast skin envelope for subsequent definitive reconstruction.

3. During the restrictive and early recovery phase, either a solo oncological breast surgeon or a joint ablative and reconstructive team (breast and plastic surgeon) performs surgery without the assistance of trainees or surgical practitioners. For joint procedures, the plastic surgeon acts as assistant during cancer ablation and as primary operator for the reconstruction.

Despite relatively high rates of complications for implant-based IBR (risking re-admission, prolonged hospital stays or repeat clinic visits),${ }^{5}$ avoiding all IBR will lead to long waiting lists and have a negative psychological impact, particularly among younger patients. This will also impair aesthetic outcomes due to more extensive scars and inevitable loss of nipples.

Whilst appreciating the restrictions imposed by COVID19 , there is opportunity to offer some reconstructive options depending on local circumstances, operating capacity and the pandemic phase. We suggest that these proposals involving greater use of therapeutic mammaplasty as well as epipectoral and "babysitter" prostheses be considered in efforts to offset some of the disadvantages of COVID-19 on breast cancer patients whilst ensuring that their safety and that of healthcare providers comes first.

\section{Disclosure}

The authors have no financial interests to declare in relation to the content of this article and have received no external support related to this article. No funding was received for this work.

\section{References}

1. van de Haar J, Hoes LR, Coles CE, Seamon K, Fröhling S, Jäger D, Valenza F, de Braud F, De Petris L, Bergh J, Ernberg I, Besse B, Barlesi F, Garralda E, Piris-Giménez A, Baumann M, Apolone G, Soria JC, Tabernero J, Caldas C, Voest EE. Caring for patients with cancer in the COVID-19 era. Nat Med 2020;26(5):665-71 Epub 2020 Apr 16. doi:10.1038/s41591-020-0874-8.

2. Edwards SP, Kasten S, Nelson C, Elner V, McKean E. Maxillofacial Trauma Management During COVID-19: Multidisciplinary Recommendations. Facial Plast Surg Aesthet Med. 2020;22(3):157-9 Epub 2020 Apr 7. doi:10.1089/fpsam.2020.0158.
3. American Society of Plastic Surgeons. ASPS Statement on Breast Reconstruction in the face of COVID-19 Pandemic. Available at: https://www. plasticsurgery.org/documents/ medicalprofessionals/COVID19-Breast-Reconstruction.

4. Association of Breast Surgery. Statement from the association of breast surgery 15th March 2020: confidential advice for health professionals. Available at: https://associationofbreastsurgery. org.uk/media/252009/abs-statement-150320-v2.pdf.

5. Potter S, Conroy EJ, Cutress RI, Williamson PR, Whisker L, Thrush S, Skillman J, Barnes N, Mylvaganam S, Teasdale E, Jain A, Gardiner MD, Blazeby JMBreast Reconstruction Research Collaborative. Short-term safety outcomes of mastectomy and immediate implant-based breast reconstruction with and without mesh (iBRA): a multicentre, prospective cohort study. Lancet Oncol 2019;20(2):254-66

Bruno Di Pace

Department of Medicine, Surgery and Dentistry "Scuola Medica Salernitana", PhD School of Translational Medicine of Development and Active Aging, University of Salerno, Salerno, Italy

Plastic and Reconstructive Surgery Department, Addenbrooke's Hospital Cambridge University Hospitals NHS Foundation Trust, Cambridge, UK

Anglia Ruskin School of Medicine, Anglia Ruskin University, Cambridge \& Chelmsford, UK

John R. Benson

Anglia Ruskin School of Medicine, Anglia Ruskin University, Cambridge \& Chelmsford, UK

Cambridge Breast Unit, Addenbrooke's Hospital, Cambridge University Hospitals NHS Foundation Trust, Cambridge, UK

Charles M. Malata

Plastic and Reconstructive Surgery Department, Addenbrooke's Hospital Cambridge University Hospitals NHS Foundation Trust, Cambridge, UK

Anglia Ruskin School of Medicine, Anglia Ruskin University, Cambridge \& Chelmsford, UK

Cambridge Breast Unit, Addenbrooke's Hospital, Cambridge University Hospitals NHS Foundation Trust, Cambridge, UK

Corresponding author at: Consultant Plastic and Reconstructive Surgeon, Department of Plastic and

Reconstructive Surgery, Addenbrooke's Hospital, Cambridge University Hospitals NHS Foundation Trust, Hills Road, Cambridge, CB2 2QQ, United Kingdom. E-mail address: cmalata@hotmail.com (C.M. Malata)

(C) 2020 British Association of Plastic, Reconstructive and Aesthetic Surgeons. Published by Elsevier Ltd. All rights reserved.

https://doi.org/10.1016/j.bjps.2020.05.033 


\section{Managing Hand Trauma during the COVID-19 pandemic using a One-Stop Clinic}

\section{Dear Sir,}

The COVID-19 Pandemic has shifted clinical priorities and resources from elective and trauma hand surgery with general anaesthesia (GA) to treat the growing number of COVID patients. At the time of this correspondence, the pandemic has affected over 2 million people resulting in 129045 deaths worldwide, with 12868 UK deaths, with numbers still climbing.

This has particularly affected our Hand Trauma services which serves North London, a population of more than 2 million. We receive referrals from a network of 8 hospitals in addition to 3 Emergency Departments of the Royal Free Group of Hospitals and numerous GP practices and urgent care centres.

In the first week following The British Government lockdown, which commenced March 23rd, we experienced a $75 \%$ drop in referrals, from 25 to 6 a day. Subsequently, numbers have been steadily rising to $12-14$ a day by $6^{\text {th }}$ of April. The British Association of Plastic, Reconstructive and Aesthetic Surgeons, the British Society for Surgery of the Hand and the Royal College of Surgeons of England, have all issued guidance: both encouraging patients to avoid risky pursuits, which could result in accidental injuries and to members how to prioritise and optimise services for trauma and urgent cancer work.

We have adapted our Hand Trauma Service to a 'One Stop Hand Trauma and Therapy' clinic, where patients are assessed, definitive surgery performed and offered immediate post-operative hand therapy where therapists make splint and give specialist advice on wound care and rehabilitation including an illustrated hand therapy guide.

Patients are categorised based on the BSSH Hand Injury Triage App. We already have a specific 'closed fracture' Hand Therapy led clinic, to manage the majority of our closed injuries. We combined this clinic with the plastic surgeons' led hand trauma clinic, and improved its efficiency further by utilising the Mini C-arm fluoroscope within the clinic setting. This enabled us to immediately assess fractures and perform fracture manipulation under simple local anaesthesia.

We have successfully been able to perform 95\% of our operations for Hand trauma under Wide Awake Local Anaesthesia No Tourniquet (WALANT). ${ }^{1}$ Prior to the pandemic, we used WALANT for selected elective and trauma hand surgical cases. In infected cases, where local anaesthesia is known to be less effective, we have used peripheral nerve blocks.

Previous data showed $50 \%$ of our trauma cases were conducted under GA, 33\% under LA, and 17\% under brachial or peripheral nerve blocks. ${ }^{2}$
We have specifically modified our wound care information leaflets to minimise patient hospital attendance. Afterwards patients receive further therapy phone consultations and encouragement to use the Hand Therapy exercise App developed by the Chelsea and Westminster Hand Therapists.

The patient is given details of a designated Plastic Surgery NHS Trust email address, for direct contact with the plastic surgery team: for concerns, questions and transfers of images.

We have to date received 39 emails, of which 21 have been from patients directly, and the remainder from referring healthcare providers. The majority of inquiries are followed up via a telephone consultation and only complex cases or complications, attend face-to-face follow-up.

This model has successfully combined assessment, treatment and post-op therapy into a one-stop session, which has greatly limited patient exposure to other parts of the hospital, such as the radiology and therapy departments. The other benefit of such clinic is an improved outcome through combined decision making. ${ }^{3}$

There is also a cost saving benefit compared to our traditional model of patient care. We have treated 31 patients based on this model so far, who have been suitable for remote monitoring. On average we have saved 2 Plastics Dressing Clinic (PDC) visits for wound checks per patient, as a very minimum. We have previously calculated the cost of PDC at our centre at $£ 155$ per visit ${ }^{4}$ and for our $31 \mathrm{pa}$ tients this translates to an approximately saving of $£ 9000$ per month just on PDC costs. If 30 patients each month could be identified for remote monitoring, this could potentially lead to an annual saving of more than $£ 110,000$. In addition, the estimated cost-saving by converting the mode of anaesthesia from GA to WALANT has been shown to cause a $70 \%$ reduction. $^{5}$

The concept of a one-stop clinic has already been successfully implemented in the treatment of Head \& Neck tumours, following introduction of NICE guidelines in $2004^{3}$ and the COVID-19 Pandemic has made us redesign a busy metropolitan service for Hand Injuries along the same lines.

We believe this model is a good strategy and combining this with more widespread use of the WALANT technique, technology such as apps and telemedicine, as well as encouraging greater patient responsibility in their post-operative care and rehabilitation; is the way forward.

We hope sharing this experience will result in improved patient care at this time of crisis.

\section{References}

1. Lalonde DH, Tang JB. How the Wide Awake Tourniquet-Free Approach Is Changing Hand Surgery in Most Countries of the World. Hand Clin. 2019 Feb;35(1):xiii-xxiv.

2. Choo A, De Leo A, Jemec B. Hand Trauma Service: efficiency and quality improvement at the Royal Free NHS Foundation Trust, London. In: Poster, BSSH Spring meeting; 2017.

3. "One -stop" clinics in the investigation and diagnosis of head and neck lumps. BJOMS Jan 2007:19-22.

4. Sadr AH, Pau A, Griffin MF, Butler P, Mosahebi A. The implications of cosmetic tourism on tertiary plastic surgery services; The need for a national reporting database. J Plast Reconstr Aesthet Surg. 2019 Jul;72(7):1219-43. 
5. Ree PC, et al. Cost Savings and Patient Experiences of a Clinic-Based, Wide-Awake Hand Surgery Program at a Military Medical Center: A Critical Analysis of the First 100 Procedures. JHS 2017 Mar;42(3):e139-e147.

Yours Truly,

Mr A H Sadr*

Miss S Gardiner

Mrs Nikki Burr

Mr D Nikkhah

Miss Barbara Jemec

Department of Plastic and Reconstructive Surgery,

Department of Plastic and Reconstructive Surgery, Royal Free Hospital NHS Trust, 77 Pond street, Hampstead, London, London NW3 2QG, United Kingdom

*Corresponding author.

E-mail address: ahsadr@yahoo.com (M.A.H. Sadr)

Crown Copyright (c) 2020 Published by Elsevier Ltd on behalf of British Association of Plastic, Reconstructive and Aesthetic Surgeons. All rights reserved.

https://doi.org/10.1016/j.bjps.2020.05.026

\section{The effect of the ongoing COVID-19 nationwide lockdown on plastic surgery trauma caseload?}

\section{Dear Sir}

'This is a Saint Patrick's Day like no other' declared the Irish Prime Minster on March 17th 2020, whilst announcing sweeping social restrictions in a response to the worsening COVID-19 pandemic. This nationwide lockdown involved major restrictions on work, travel and public gatherings and signified the government's shift from the suppression to the mitigation phase of the outbreak. The national COVID-19 Task Force produced a policy specifying the redeployment of heath care workers to essential services such as the emergency department and intensive care. ${ }^{1}$ With the introduction of virtual outpatient clinics and the curtailment of elective operating lists, the apparent clinical commitments of a plastic surgeon during this pandemic has lessened. Trauma is a continual and major component of our practice ${ }^{2}$; however, a decline in emergency department presentations has fuelled anecdotal reports of a reduction in the trauma workload. With diminishing resources, the risk of staff redeployment and consequences of poor patient outcomes we aim to assess the effect of the current lockdown due to COVID-19 pandemic on plastic trauma caseload.

We performed a retrospective review of a prospectively maintained trauma database at a tertiary referral hospi-
Table 1 Surgeries performed during the current lockdown (2020) compared to same time in previous years (2019, 2018).

\begin{tabular}{llll}
\hline & 2018 & 2019 & 2020 \\
\hline Wound exploration & & & \\
Primary closure & 9 & 13 & 9 \\
FTSG/local flap/SSG & 4 & 3 & 3 \\
Washout abscess & 0 & 0 & 4 \\
Repair nailbed & 2 & 6 & 3 \\
Removal FB & 3 & 0 & 1 \\
Tendon repair & & & \\
Flexor & 4 & 6 & 4 \\
Extensor & 3 & 6 & 3 \\
Nerve Repair & 6 & 4 & 4 \\
Artery anastomosis & 2 & 0 & 0 \\
Fracture Fixation & 6 & 3 & 2 \\
Termilisation & 5 & 4 & 7 \\
Nerve Repair & 6 & 4 & 4 \\
MUA/ K Wire removal & $\mathbf{1}$ & 0 & 2 \\
Collateral ligament & $\mathbf{1}$ & 0 & 1 \\
Total & 52 & 49 & 47 \\
\hline
\end{tabular}

tal. Patients undergoing plastic trauma surgery during the first 25 days of nation wide lockdown (18th March to April 12th 2020) were evaluated. Referral numbers and surgeries performed were analysed and compared to the same time frame (18th March to April 12th) for the previous two years, 2019 and 2018.

During the first 25 days of the lockdown, 48 patients attended plastic surgery trauma clinic, in which 41 (85.4\%) underwent a surgical procedure. As seen in Figure 1, these numbers are comparable over the same time frame for the two previous years. Upper limb trauma accounted for the near majority of referrals. Frequency and type of surgery performed during the lockdown were similar to the previous two years, as seen in Table 1. The percentage of patients requiring general anaesthesia was $46.3 \%(19 / 41)$ in 2020 , $44.2 \%(19 / 43)$ in 2019 , and slightly higher in 2018 at $58.9 \%$ $(23 / 39)$.

We have refuted any anecdotal evidence proposing a decline in plastic trauma caseload during the COVID19 nationwide lockdown. Comparing the same time in previous years, the lockdown has produced an equivalent trauma volume. Despite, the widespread and necessary restriction of routine elective work, somewhat surprisingly the pattern and volume of trauma remains similar to preceding years. With people confined to their household, it is the 'DIY at home' associated injuries which attributes to this trend. And the exemption from regulations of certain industries such as agriculture and the food preparation chain. Whilst not every trauma risk may be mitigated, the potential for these DIY injuries to overwhelm the healthcare service has resulted in the British Society for Surgery of the Hand (BSSH) cautioning the general public on the safety of domestic machinery. ${ }^{3}$

As healthcare systems are stretched further than ever before we all must recognise the need for adaptation and structural reorganisation to treat those of our patients most in need during this pandemic. Staff redeployment is a necessary tool to maintain frontline services; nonetheless, we 


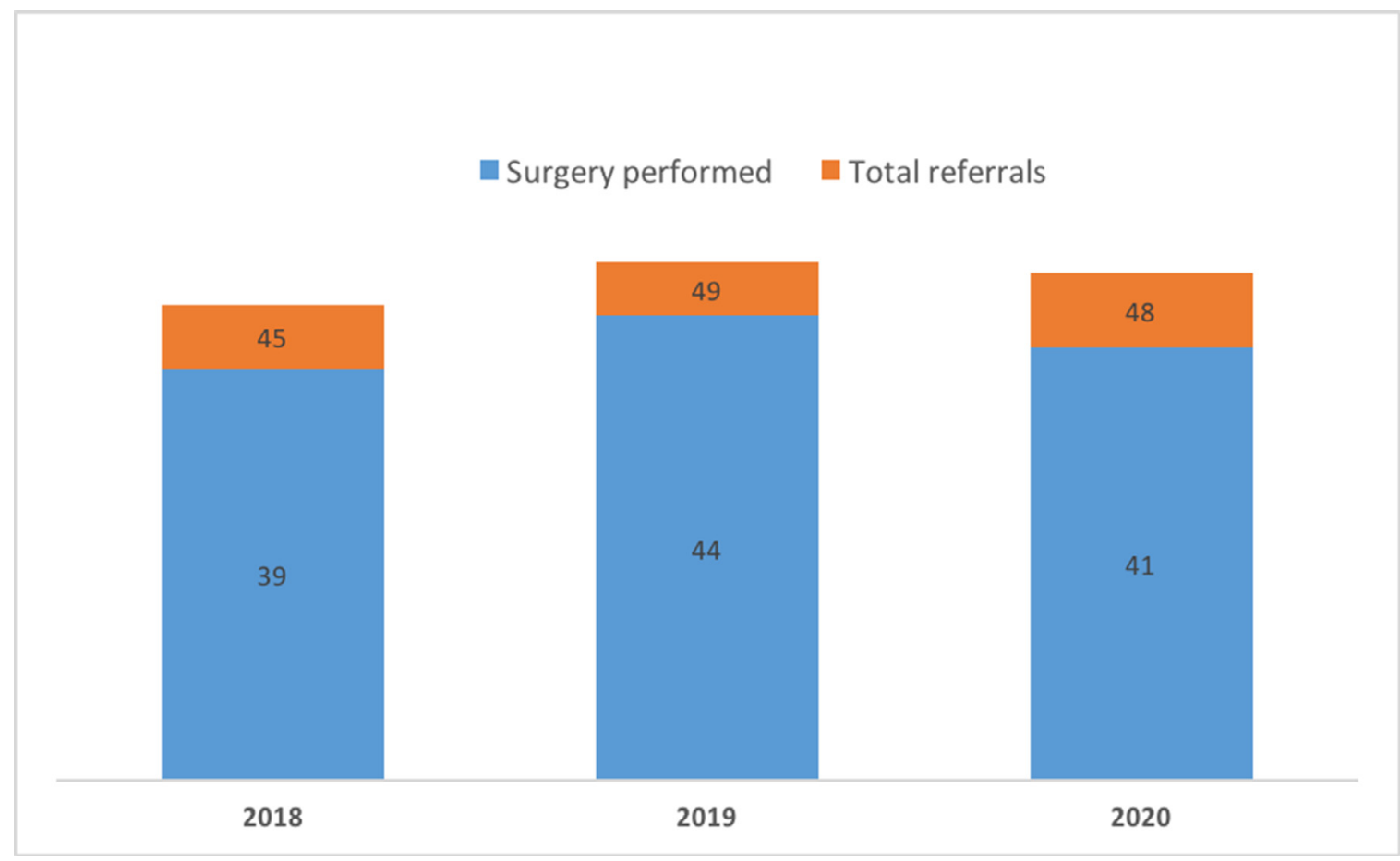

Figure 1 Volume of plastic trauma referrals and surgeries in the current lockdown (2020) compared to same time in previous years $(2019,2018)$.

wish to highlight the outcomes of this study to the clinical directors with the challenging job of allocating resources. Our trauma presentations have not reduced during the first 25 days of this pandemic, resources (staff and theatre) should still be accessible for the plastic surgery trauma team, with observance of all the appropriate risk reduction strategies as documented by British Association of Plastic, Reconstructive and Aesthetic Surgeons. ${ }^{4}$

\section{Declaration of Competing Interest}

None.

\section{Funding}

None.

\section{References}

1. Policy on the redeployment of staff. (2020) https:// healthservice.hse.ie/staff/news/coronavirus/redeployment-ofstaff-during-covid-19-infection-policy-and-procedure.html. Accessed 10/05/2020.

2. Jalali M, Loughnane F, Winterton R. Trauma management within UK plastic surgery units. J Plast Reconstruct Aesthet Surg 2011;64:558-9.

3. Warwick, D. President of the British Society for Surgery of the Hand. (2020) 24th March. Available at https://twitter.com/ BSSHand (Accessed: 12th April 2020).

4. Highlights for Surgeons from PHE COVID-19 IPC guidance. (2020) http://www.bapras.org.uk/docs/default-source/covid19-docs/phe-surgical-highlights-v2.pdf?sfvrsn=2 (Accessed: 15th April 2020).
C.M. Sugrue, P. Sullivan Department of Plastic \& Reconstructive Surgery, Connolly Hospital, Blanchardstown, Dublin 15, Ireland Department of Plastic \& Reconstructive Surgery Beaumont Hospital, Beaumont Road, Dublin 9, Ireland E-mail address: conormsugrue@rcsi.ie (C.M. Sugrue)

(C) 2020 British Association of Plastic, Reconstructive and Aesthetic Surgeons. Published by Elsevier Ltd. All rights reserved.

https://doi.org/10.1016/j.bjps.2020.05.031

\section{Economic implications of the COVID-19 pandemic on the plastic surgery community}

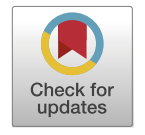

Dear Sir,

In light of the ongoing COVID-19 pandemic, the American Society of Plastic Surgeons (ASPS) has released a statement urging the suspension of elective, non-essential procedures. ${ }^{1}$ This necessary and rational suspension will result in detrimental financial effects on the plastic surgery community.

Given the simultaneous economic downturn inflicted by public health social-distancing protocols, there will be a bear market for elective surgery lasting well past the bans being lifted on elective surgeries. This effect will largely 
be due to the elimination of discretionary spending as individuals attempt to recover from weeks to months of lost earnings.

As demonstrated during the 2008-2009 recession, economic decline was associated with a decrease in both elective and non-elective surgical volume. ${ }^{2}$ Private practice settings performing mostly cosmetic procedures were particularly vulnerable to these fluctuations and demonstrated a significant positive correlation with GDP. ${ }^{3}$

The surgery community must prepare for the economic impact that this pandemic will have on current and future clinical volumes. These effects are likely to be more severe than the previous recession as surgeons are currently indefinitely unable to perform elective surgeries, coupled with the immense strain on hospital resources at this time. Given this burden, elective surgery cases may be some of the last to be added back to the hospital once adequate resources are restored.

While surgeons are temporarily unable to operate, they do have the potential to use telehealth in order to arrange preoperative consults and postoperative follow-up appointments. This could be accomplished in private practice settings with the use of telehealth services such as Teladoc Health, American Well, or Zoom, which allow for live consultation with patients without unnecessary exposure of patients or providers to potential infection. ${ }^{4}$ The main limitation of these types of appointments is the lack of an inperson physical exam, so providers have found that billing based on time spent with the patient is more effective with this tool..$^{5}$ This could generate revenue and facilitate future surgical cases after the suspension of in-person elective patient care has been lifted.

Several strategies should be considered by the elective surgery community to minimize financial losses. Many financial entities have changed their policies in order to support small businesses. Examples include the Small Business Administration offering expanded disaster impact loans and deferment of the federal income tax payments by three months to July $15 .^{5}$ Another option employers may leverage is temporarily laying off of employees so that employees can apply for and collect an expanded unemployment package by federal and state governments thereby reducing the payroll burden on stagnant practices with no cash flows and providing employees with a steady source of income during the pandemic. The employer's incentive to do this may be reduced with the potential suspension of the payroll tax on employers and loan forgiveness to employers who continue to pay employees wages. 5

Once elective procedures are again permitted, plastic surgeons that have retained a reconstructive practice should make a strategic business decision to increase reconstructive surgery and emergent hand surgery bookings as historically these procedures are less fluctuant with the economy. ${ }^{3}$ Other options to maintain aesthetic case volume include price reductions or temporary promotions. However, it is important that these be adopted universally in order to minimize price wars between providers.

As physicians, it is principle that surgeons practice nonmaleficence and minimize non-essential patient contact for the time being. However, this time of financial standstill should be used constructively to prepare for the financial uncertainty in the months to come.

\section{Declaration of Competing Interest}

None

\section{References}

1. American Society of Plastic Surgery website. ASPS guidance regarding elective and non-essential patient care. https: / / www.plasticsurgery.org/for-medical-professionals / covid19-member-resources\#statement. [Accessibility verified March 19, 2020]

2. Fujihara N, Lark ME, Fujihara $\mathrm{Y}$, et al. The effect of economic downturn on the volume of surgical procedures: a systematic review. Int J Surg 2017;44:56-63.

3. Hoppe IC, Pastor CJ, Paik AM. An analysis of leading, lagging, and coincident economic indicators in the United States and its relationship to the volume of plastic surgery procedures performed. Ann Plast Surg 2012;69:471-3.

4. Shokri T, Lighthall JG. Telemedicine in the Era of the COVID19 Pandemic: implications in Facial Plastic Surgery. Facial Plast Surg Aesthet Med 2020.

5. Johnson J., D'Angelo M. United States chamber of commerce website. resources to help your small business survive the coronavirus. https://www.uschamber.com/co/start/ strategy/business-owner-tips-coronavirus-pandemic. [Accessibility verified March 26, 2020]

Dani C. Inglesby Medical University of South Carolina College of Medicine, 96 Jonathan Lucas St, Charleston, Charleston, SC, United

States

Carter J. Boyd School of Medicine, University of Alabama at Birmingham, Birmingham, AL, United States Collat School of Business, University of Alabama at Birmingham, Birmingham, AL, United States

Corresponding author.

E-mail address: inglesbyeras@gmail.com (D.C. Inglesby)

(C) 2020 British Association of Plastic, Reconstructive and Aesthetic Surgeons. Published by Elsevier Ltd. All rights reserved.

https://doi.org/10.1016/j.bjps.2020.05.030

\section{Letter to the Editor: Productively protecting a cohort of vulnerable plastic surgery trainees in the COVID-19 pandemic in a new virtual trauma clinic}

Dear Sir,

UK Government guidelines for protection of those who are at increased risk of severe illness from COVID-19 pan- 
demic advise certain groups to stringently follow social distancing measures. Inevitably some health care workers fall into these categories and working in a hospital places them at high risk of exposure to the virus. Studies have shown human to human transmission from positive COVID-19 patients to health care workers demonstrating that this threat is real ${ }^{1,2}$ and as in other infectious diseases is worse in certain situations such as aerosol generating and airway procedures $^{3,4}$. There is therefore a part of our workforce that has been out of action reducing available workforce at a time of great need.

In our hospital a group of vulnerable surgical trainees ranging from CT2 to ST8, and also Consultants, have been able to keep working while socially isolating within their usual workplace. In light of COVID-19 our hospital, a regional trauma centre for Burns, Plastic Surgery and Oral and Maxillofacial Surgery, was reorganized to increase capacity for both trauma and cancer work. As part of this a virtual hand trauma service has been set up. The primary aim of the new virtual hand trauma clinic was to allow patients to be triaged in a timely manner while adhering to social distancing guidelines by remotely accessing the clinic from home. Further aims were to reduce time spent in hospital and reduced time between referral and treatment.

In brief, patients referred to our virtual hand trauma clinic from across the region receive a video or telephone consultation using Attend Anywhere software, supported by NHS Digital. Following the virtual consultation patients are then triaged to theatre, further clinic, or discharged. Our group of isolating doctors, plus a pharmacist and trauma coordinator, have been redeployed away from their usual face to face roles and are now working solely in the virtual trauma clinic. They are able to work to provide this service in an isolated part of the hospital named the 'Virtual Nest.' The Nest is not accessible in a 'face to face' manner by non-isolating staff or patients. This allows a safe 'clean' environment to be maintained. The virtual team is able to participate in morning handover with other areas of the hospital via video conferencing using Webex software. The Nest workspace is large enough to allow social distancing between clinicians and by being on site they benefit from availability of dedicated workspaces with suitable IT equipment and bandwidth.

It is widely recognised that reconfiguration of hospitals and redeployment of staff has meant that training is effectively 'on hold' for many trainees. We have found that a benefit of the new virtual hand trauma clinic is that trainees can continue to engage with the Intercollegiate Surgical Curriculum Programme with work based assessments in a surgical field. While direct observation of procedural skills and procedure based assessment are not feasible, case based discussions and clinical evaluation exercises have been easily achievable due to trainees managing patients with involvement of supervising senior colleagues in decision making. This plus a varied case mix seen has enhanced development of knowledge, decision making, leadership and communication skills. As trainees are unable to attend theatre practical skills may suffer depending on how long clinicians are non patient facing. This has been acknowledged by the GMC in the skill fade review; skills have been shown to decline over $6-18$ months $^{5}$. Although it can only be postulated at the current time colleagues who are patient facing but redeployed may face a similar skill decline.

The structure of the team is akin to the firm structure of days gone by with the benefits that brings in terms of support and mentorship. Patients benefit from having access to a group of knowledgeable trainees, supported by consultants, and a service accessible from their own home. This minimizes footfall within our hospital, exposure to, and spread of COVID-19. Local assessment of our practice is ongoing but we have found that this model has enabled a cohort of vulnerable plastic surgery trainees to successfully continue to work whilst reducing the risk of exposure to COVID-19 and providing gold standard care for patients.

\section{Declaration of Competing interest}

None.

\section{Financial disclosure statement}

Nothing to disclose.

\section{References}

1. Heinzerling A, Stuckey MJ, Scheuer T, et al. Transmission of COVID-19 to Health Care Personnel During Exposures to a Hospitalized Patient - Solano County, California, February 2020. MMWR Morb Mortal Wkly Rep 2020 Apr 17;69(15):472-6.

2. Li Q, Guan X, Wu P, et al. Early transmission dynamics in Wuhan, China, of novel coronavirus-infected pneumonia. N Engl J Med 2020 Jan 29;382(13):1199-207.

3. Jotz GP, Voegels RL, Bento RF. Otorhinolaryngologists and Coronavirus Disease 2019 (COVID-19). Int Arch Otorhinolaryngol 2020;24(2):e125-8.

4. Macintyre $C R$, Seale $H$, Yang $P$, et al. Quantifying the risk of respiratory infection in healthcare workers performing high-risk procedures. Epidemiol Infect 2014;142(9):1802-8.

5. General Medical Council. Skills fade: a review of the evidence that clinical and professional skills fade during time out of practice, and of how skills fade may be measured or remediated. London: GMC; 2014.

\author{
Suzanne Westley \\ Henrietta Creasy \\ Rupali Shah \\ Shazrinizam Shaharan \\ Rikki Mistry \\ Guirgis Awad \\ Jame Blair \\ Tania Cubison
}

The Department of Plastic Surgery, The Queen Victoria Hospital, Holtye Road, East Grintstead. RH19 3DZ

E-mail address: suzanne.westley@nhs.net (T. Cubison)

Crown Copyright $\odot 2020$ Published by Elsevier Ltd on behalf of British Association of Plastic, Reconstructive and Aesthetic Surgeons. All rights reserved.

https://doi.org/10.1016/j.bjps.2020.05.029 


\section{The first worldwide use and evaluation of augmented reality $(A R)$ in "Patient information leaflets" in plastic surgery}

\section{Dear Sir}

A Scottish Sarcoma Network (Glasgow Centre) special study day on 6th March 2019 at the School of Simulation and Visualisation, Glasgow School of Art, with representatives from Sarcoma UK, Beatson Cancer Charity and the BBC. Traditional patient information leaflets inadequately convey medical information due to poor literacy levels: $16-27 \%$ of UK population have the lowest adult literacy level ${ }^{1}$ and $40 \%$ the lowest "Health literacy" level (ability to obtain, understand, act on, and communicate health information). ${ }^{2}$ It was hypothesised that an entirely visual approach, such as AR, may obviate literacy problems by faciliating comprehension of complex 3 dimensional concepts integral to reconstructive surgery. We report the first Augmented Reality (AR) in Patient Information Leaflets in Plastic Surgery. To our knowledge we are among the first in the world to develop, implement, and evaluate an AR patient information leaflet in any speciality.

Developed for sarcoma surgery, the AR patient leaflet centred around a prototypical leg sarcoma. A storyboard takes patients through tumour resection, reconstruction, and the potential post-operative outcomes. Input from specialist nurses, sarcoma patients, and clinicians during a Scottish Sarcoma Network Special Study day in March 2019 informed the final content (Figure 1). When viewed by smartphone camera (HP Reveal Studio, HP Palo Alto, California USA), photos in the AR leaflet automatically trigger additional content display without need for QR codes or internet connectivity:

(1) Sequential tumour resection (Figure 2).

(2) 3D model animation of ALT flap (supplementary video 1).

(3) Sequential flap reconstruction.

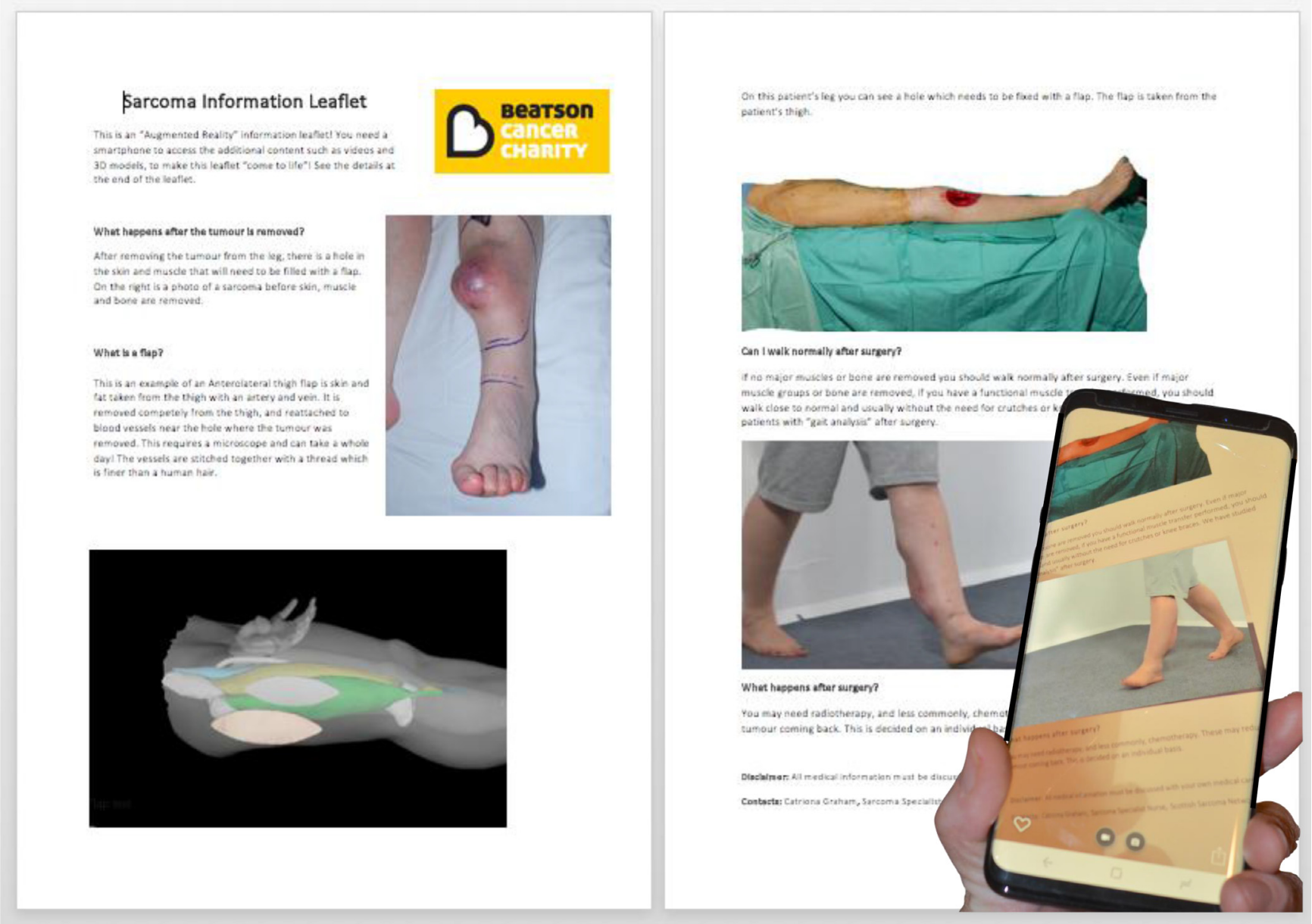

Figure 1 Augmented Reality patient information leaflet.

All the pictures in this leaflet trigger additional content when a smartphone camera is pointed at the 'target' photos. For example, when a smartphone is pointed at the last photo of the patient walking, a video of the patient actually walking appears in real time on the smartphone as if it were playing on the pages of the leaflet. 


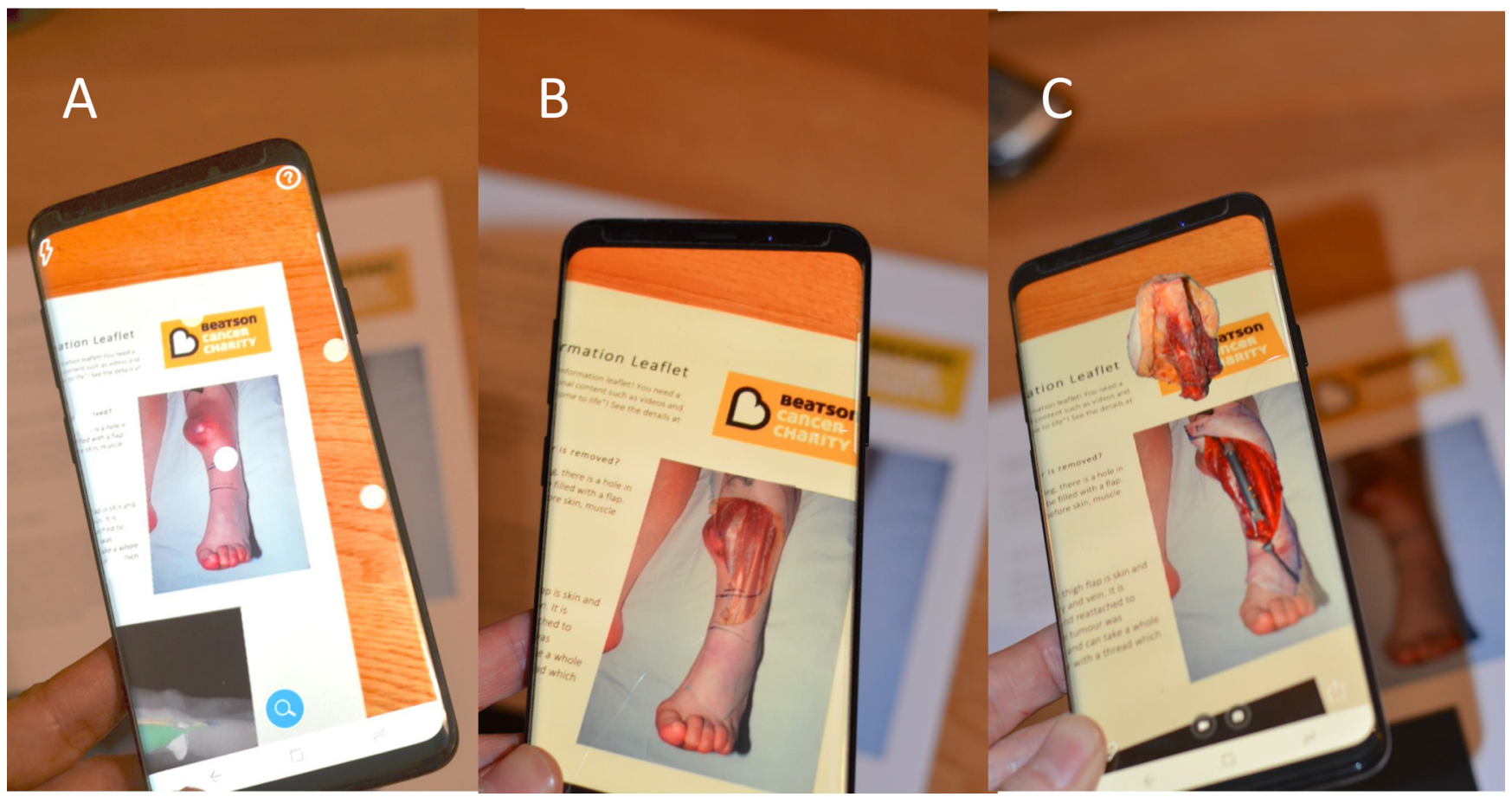

Figure 2 Photo of patient information leaflet in use.

This is the first photo in the patient leaflet from Figure 1. (A) Smartphone camera is pointed at the "target" picture of a leg. (B) This triggers the additional AR content which shows the tumour resection $(C)$ the tumour resection floats above the page, and an endoprosthesis can be seen for bone reconstruction.

(4) Post-operative gait video (supplementary video 2).

(5) Logo of Beatson Cancer Charity - automatically opens the Beatson Cancer Charity homepage (supplementary video 3 ).

A 3D ALT flap model was developed using Bodyparts3D (Research Organization of Information and Systems Database centre for Life Science, Japan) and custom anatomical data. ${ }^{4}$ Leaflet evaluation by 14 consecutive lower limb sarcoma patients was exempted from ethics approval by Greater Glasgow and Clyde NHS Research Office as part of service evaluation. AR leaflets were compared with pooled data from traditional information sources (Sarcoma UK website patient leaflets (6), self-directed internet searches (5), generic sarcoma patient leaflets (5); some patients used $>1$ source). The Mental Effort Rating Scale evaluated perceived difficulty of comprehension (or extrinsic cognitive load), ${ }^{3}$ as a key outcome measure in comparison to traditional information sources. Patient satisfaction was assessed by Likert Scale (1 was very, very satisfied and 9 very, very dissatisfied). Statistical analysis performed with Social Science Statistics, 2019.

AR leaflets were rated as 1.57 (very, very low mental effort), traditional information sources as 6.36 (high mental effort) [Unpaired $t$-test $p<0.0001$ ]. Likert-scale satisfaction was 1.43 , indicating a very, very high satisfaction. When asked "Do you think the AR leaflet would make you less anxious about surgery?", 12/14 (86\%) patients responded 'yes'. When asked "Would you think other patients would like to have a similar AR leaflet before surgery" and "Would you like to see further AR leaflets to be developed in the future?", 100\% responded "yes". No correlation was found between age or educational level and Mental Effort Rating Scale scores for AR patient leaflet (data not shown). Subjective feedback analysis found that self-directed internet searches had too much unfocussed information: “ (I) didn't want to Google as may end up with all sorts" and "(there is) good and bad stuff on the internet, don't know what you're looking at". All patients felt the visual content in AR leaflets helped their understanding: "incredible...that would have made a flap easier to understand", "tremendous... good way of explaining things to my family", "so much better seeing the pictures, gives an idea in your head", and "helpful for others with dyslexia". Traditional patient leaflets were often difficult to comprehend: "(I) didn't fully understand the sarcoma leaflets", “couldn't take information in from leaflets". Feedback recommended adding simple instructions on the leaflet, however the AR leaflet is intended for use by the clinician in clinic, and to be so simple that no instructions are required once software is downloaded to the patient's smartphone (i.e., point and shoot without technical expertise, menus, or website addresses). All patients desired an actual paper leaflet for reassurance, preferring something physical show their family rather than direction to a website or video.

This study demonstrates significant reduction in extraneous cognitive load (mental effort required to understand a topic) with AR patient leaflets compared to traditional information sources $(p<0.0001)$. AR visualisation may make inherently difficult topics (intrinsic cognitive load), such as reconstructive surgery, easier to understand and process. Significant learning advantages exist over tradi- 
tional leaflets or web-based videos, including facilitating patient control, interactivity, and game-based learning. All contribute to increased motivation, comprehension, and enthusiasm in the learning process. ${ }^{5}$ AR leaflets reduced anxiety ( $86 \%$ patients), and scored very highly for patient satisfaction with information, which is notable given increasing evidence of strong independent determination of overall health outcomes.

This study provided impetus for investment in concurrent development of other AR leaflets across the breadth of plastic surgery, and non-plastic surgery specialties. Chief Scientist Office (CSO, Scotland) funding was recruited to aid development of improved, free, fully interactive 3D AR patient information leaflets and a downloadable app. Ethical approval is in place for a randomised controlled trial to quantify the perceived benefits of AR in patient education. Our belief is that AR leaflets will transform and redefine the future Plastic Surgery patient information landscape, empowering patients and bridging the health literacy gap.

\section{Declaration of Competing Interest}

None.

\section{Acknowledgements}

The authors would like to thank Catriona Graham, Sarcoma Specialist Nurse who helped in the evaluation of this study.

\section{Funding}

The authors kindly thank the Beatson Cancer Charity, UK (Grant Application number 19-20-001), the Jean Brown Bequest Fund, UK, and The Canniesburn Research Trust, UK for funding this study. The sponsors had no influence on the design, collection, analysis, write up or submission of the research.

\section{Supplementary materials}

Supplementary material associated with this article can be found, in the online version, at doi:10.1016/j.bjps.2020.03. 011.

\section{References}

1. https://literacytrust.org.uk/parents-and-families/adultliteracy/ (website accessed 14th Feb 2020).

2. Ad hoc committee on health literacy for the council on scientific affairs. JAMA 1999;281:552-7.

3. Paas FGWC. Training strategies for attaining transfer of problemsolving skill in statistics: a cognitive-load approach. J Educ Psychol 1992;84:429-34.

4. Lo S, Abaker ASS, Quondamatteo F, Clancy J, Rea P, Marriott M, Chapman P. Use of a virtual 3D anterolateral thigh model in medical education: augmentation and not replacement of traditional teaching? J Plast Reconstr Aesthet Surg 2019 pii: S17486815(19)30437-1[Epub ahead of print]. doi:10.1016/j.bjps.2019. 09.034 .
5. Pellas N, Fotaris P, Kazanidis I, et al. Augmenting the learning experience in primary and secondary school education: a systematic review of recent trends in augmented reality game-based learning. Virtual Real 2018. doi:10.1007/s10055-018-0347-2.

Steven Lo

Canniesburn Plastic Surgery Unit, Glasgow Royal Infirmary, Glasgow G4 OSF, United Kingdom College of Medical, Veterinary and Life Sciences, University of Glasgow, United Kingdom Translational Research Centre, Kaohsiung Medical University, Kaohsiung, Taiwan

Paul Chapman School of Simulation and Visualisation, The Glasgow School of Art, United Kingdom

E-mail address: Steven.lo@nhs.net (S. Lo)

(C) 2020 British Association of Plastic, Reconstructive and Aesthetic Surgeons. Published by Elsevier Ltd. All rights reserved.

\section{Influence of age on scar tissue: A retrospective study on the differences in scar tissue development between children and adults}

\author{
Dear Sir,
}

We investigated if age has an influence on wound healing. Wound healing can result in hypertrophic scars or keloids. From previous studies we know that age has an influence on the different stages of wound healing. ${ }^{1-4}$ A general assumption seems to be that adults make better scars than children. Knowledge of the influence of age on healing and scarring can give opportunities to intervene in the wound healing process to minimize scarring. It could guide patients in their decision when to revise a scar. It could also lead patients and physicians in their decision of the timing of a surgery, if the kinds of surgery allows this.

This study is a retrospective cohort study at the department of plastic, reconstructive, and hand surgery of the Amsterdam University Medical Center. All patients underwent cardiothoracic surgery through a median sternotomy incision. All patients had to be at least one year after surgery at time of investigation. Hypertrophic scars were defined as raised $1 \mathrm{~mm}$ above skin level while remaining within the borders of the original lesion. Keloid scars were defined as raised $1 \mathrm{~mm}$ above skin level and extending beyond the borders of the original lesion. ${ }^{5}$ The scars were scored with the Patient and Observer Scar Assessment Scale (POSAS) as primary outcome measure. As secondary outcome measures we looked at wound healing problems and scar measurements. 
Table 1 Primary outcome measure: POSAS scores.

\begin{tabular}{|c|c|c|c|}
\hline Outcome measure & Group 1: children & Group 2: adults & $\mathrm{p}$-value* \\
\hline Patients, No. (\%) & $53(50.5)$ & $52(49.5)$ & \\
\hline \multicolumn{4}{|c|}{ POSAS observer part, median (IQR) } \\
\hline Vascularization & $2.0(2.0-3.0)$ & $2.0(1.0-3.0)$ & 0.353 \\
\hline Pigmentation & $2.0(2.0-3.0)$ & $2.0(2.0-3.0)$ & 0.157 \\
\hline Thickness & $2.0(1.0-2.0)$ & $1.0(1.0-2.0)$ & 0.671 \\
\hline Relief & $2.0(1.0-2.0)$ & $2.0(1.0-3.0)$ & 0.659 \\
\hline Pliability & $2.0(2.0-3.0)$ & $2.0(1.0-2.8)$ & 0.022 \\
\hline Surface & $2.0(2.0-3.0)$ & $2.0(2.0-3.0)$ & 0.732 \\
\hline Total score & $13.0(10.0-16.0)$ & $12.0(9.0-16.0)$ & 0.595 \\
\hline Overall opinion & $2.0(2.0-3.0)$ & $3.0(2.0-3.8)$ & 0.162 \\
\hline \multicolumn{4}{|c|}{ POSAS patient part, median (IQR) } \\
\hline Pain & $1.0(1.0-1.0)$ & $1.0(1.0-1.0)$ & 0.025 \\
\hline Itchiness & $1.0(1.0-1.0)$ & $1.0(1.0-2.0)$ & 0.111 \\
\hline Color & $3.0(2.0-5.0)$ & $3.0(2.0-5.0)$ & 0.642 \\
\hline Stiffness & $3.0(2.0-4.0)$ & $3.0(1.0-4.0)$ & 0.247 \\
\hline Thickness & $3.0(1.0-4.0)$ & $2.0(1.0-7.0)$ & 0.760 \\
\hline Irregularity & $2.0(1.0-3.0)$ & $2.0(1.0-5.8)$ & 0.091 \\
\hline Total score & $13.0(10.0-18.5)$ & $13.0(9.0-25.3)$ & 0.531 \\
\hline Overall opinion & $3.0(1.5-4.0)$ & $2.5(1.0-6.0)$ & 0.940 \\
\hline
\end{tabular}

No.: number. IQR: interquartile range.

* Mann-Whitney U test.

Table 2 Scar measurements.

\begin{tabular}{|c|c|c|c|}
\hline Outcome measure & Group 1: children & Group 2: adults & p-value* \\
\hline Patients, No. (\%) & $53(50.5)$ & $52(49.5)$ & \\
\hline \multicolumn{4}{|l|}{ Scar width in $\mathrm{mm}$, median (IQR) } \\
\hline Cranial & $7.0(5.0-10.0)$ & $6.0(1.0-12.8)$ & 0.391 \\
\hline Middle & $5.0(3.0-9.0)$ & $3.0(2.0-10.0)$ & 0.153 \\
\hline Caudal & $5.0(3.0-8.5)$ & $4.0(2.0-10.0)$ & 0.340 \\
\hline Scar height in mm, median (IQR) & $0.0(0.0-0.0)$ & $0.0(0.0-0.0)$ & 0.166 \\
\hline Hypertrophic/keloid scars, No. (\%) & $5(9.4)$ & $10(19.2)$ & 0.153 \\
\hline
\end{tabular}

No.: number. mm: millimeter. IQR: interquartile range.

* Mann-Whitney U test.

In order to ensure that the results of this study are as little as possible influenced by the already known risk and protective factors for hypertrophic scarring, the patients were questioned about co-existing diseases, scar treatment, allergies, medication, length, weight, cup size (females) and smoking. Their skin type was classified with the Fitzpatrick scale I to VI. All calculations were performed using SPSS and the level of significance was set at $p \leq 0.05$.

105 patients were enrolled in this study. Group 1 contained 53 children and group 2 contained 52 adults. There is a significant difference between the two groups for the amount of pain in the scar scored by the patient. This item was given higher scores by adults than children $(p=0.025)$. There is no significant difference between the two groups for the other POSAS items (itchiness, color, stiffness, thickness, and irregularity), the total score of the scar and the overall opinion of the scar scored by the patient (Table 1).

There is a significant difference between the two groups in pliability of the scar scored by the observer. The POSAS item pliability of the scars of the children was assessed higher, thus stiffer, than in adults $(p=0.022)$. There is no significant difference between the two groups for the other POSAS items (vascularization, pigmentation, thickness, relief, and surface), the total score of the scar and the overall opinion of the scar scored by the observer (Table 1).

There is no significant difference between children and adults in the occurrence of wound problems post-surgery.

There is no significant difference in scar measurements between children and adults. In children we found three hypertrophic scars and two keloid scars. In adults we found seven hypertrophic scars and three keloid scars. For both groups together that is a percentage of 14.3 hypertrophic and keloid scars (Table 2 ).

Patients with Fitzpatrick skin type I and IV-VI scored significantly higher, thus worse, in their overall opinion of the scar $(p=0.024)$ than patients with skin type II and III. Observer and patient assessed the overall opinion of the scar significantly higher (worse) in people who had gone through wound problems (respectively $p=0.020$ and $p=0.007$ ) than 
those who had not. We found no significant differences in the primary outcome measure between men and women, cup size $A-C$ and $D-G$, smokers and non-smokers, $B M I<25$ and $\mathrm{BMI}>25$, allergies and no allergies, and scar treatment and no scar treatment.

Age at creation of a sternotomy wound does not seem to influence the scar outcome. This is contrary to what is often the fear of a parent of a child who needs surgery early in life. Comparing scars remains difficult because of the many factors that can influence scar formation. We found that scars have the tendency to change, even years after they are made.

A limitation of the study is the retrospective design. The long follow-up period after surgery is a strength of the study. To our best knowledge this is the first study that compares scars of children and adults to specifically look at the clinical impact of age on scar tissue. In order to detect even more reliable and possibly significant differences between children and adults, more patients should be enrolled in future prospective studies. For now we can conclude that there is no significant difference in the actual scar outcome between children and adults in the sternotomy scar. If we extend these results to other scars, the timing of surgeries should not depend on the age of a patient.

\section{Declaration of Competing Interest}

None.

\section{Funding}

None.

\section{Ethics}

METc. Reference number: W18_050 \# 18.068.

\section{References}

1. Gosain A, DiPietro LA. Aging and wound healing. World J Surg 2004;28(3):321-6.

2. Hu MS, Maan ZN, Wu JC, et al. Tissue engineering and regenerative repair in wound healing. Ann Biomed Eng 2014;42(7):1494507.

3. Pajulo OT, Pulkki KJ, Alanen MS, et al. Duration of surgery and patient age affect wound healing in children. Wound Repair Regen 2000;8(3):174-8.

4. Westra I, Verhaegen $\mathrm{P}$, Ibrahim Korkmaz $\mathrm{H}$, et al. Investigating histological aspects of scars in children. J Wound Care 2017;26(5):256-65.

5. Mahdavian Delavary B, van der Veer WM, Ferreira JA, Niessen FB. Formation of hypertrophic scars: evolution and susceptibility. $J$ Plast Surg Hand Surg 2012;46(2):95-101.

Annekatrien L. van de Kar Department of Plastic, Reconstructive and Hand Surgery, Amsterdam University Medical Center, Location AMC, Meibergdreef 9, 1105 AZ, Amsterdam, The Netherlands
Department of Plastic, Reconstructive and Hand Surgery, Onze Lieve Vrouwe Gasthuis Oost, Amsterdam, The Netherlands

Frederique van Riessen

Department of Plastic, Reconstructive and Hand Surgery, Amsterdam University Medical Center, Location AMC, Meibergdreef 9, 1105 AZ, Amsterdam, The Netherlands

David R. Koolbergen

Department of Cardiothoracic Surgery, Amsterdam University Medical Center, Location AMC, Amsterdam, The Netherlands

Department of Cardiothoracic Surgery, Leiden University Medical Center, Leiden, The Netherlands

Chantal M.A.M. van der Horst Department of Plastic, Reconstructive and Hand Surgery, Amsterdam University Medical Center, Location AMC, Meibergdreef 9, 1105 AZ, Amsterdam, The Netherlands

Correspondence to: Frederique van Riessen, Department of Plastic, Reconstructive and Hand Surgery, Amsterdam University Medical Center, Location AMC, Meibergdreef 9, $1105 \mathrm{AZ}$, Amsterdam, The Netherlands. E-mail address: frederiquevanriessenAMC@gmail.com ( $\mathrm{F}$. van Riessen)

(C) 2020 British Association of Plastic, Reconstructive and Aesthetic Surgeons. Published by Elsevier Ltd. All rights reserved.

https://doi.org/10.1016/j.bjps.2020.02.024

\section{Quality issues identified in systematic reviews on early laser intervention to reduce scar formation in wound healing}

Dear Sir,

We published a systematic review of randomized controlled trials (RCTs) on early laser intervention to reduce scar formation in wound healing by primary intention. ${ }^{1}$ While comparing our results with two other systematic reviews on the same topic, ${ }^{2,3}$ we identified various overt methodological inconsistencies in those other systematic reviews.

Issue 1. Including duplicate data (Table 1): Karmisholt et al. ${ }^{2}$ included two RCTs of which both reported the identical data on five people. The inclusion of duplicate data can bias the results of a systematic review and should be prevented in the quantitative as well as the qualitative synthesis of evidence. 
Table 1 RCTs reported by the identified systematic reviews ${ }^{a)}$.

\begin{tabular}{|c|c|c|c|c|}
\hline Study ID [PMID] & Control & Kent et al. ${ }^{3}$ & Karmisholt et al. ${ }^{2}$ & Behrouz-Pirnia et al. ${ }^{1}$ \\
\hline Search date ${ }^{\text {b) }}$ & & 06 November 2015 & 12 June 2017 & 14 January 2019 \\
\hline Publication date ${ }^{c)}$ & & 21 March 2019 & 09 February 2018 & 24 November 2019 \\
\hline Alam 2006 [16393594] & n.l.t. d) & $\mathrm{RCT}$ & "PCS"e) & $\mathrm{RCT}$ \\
\hline Alberti 2017 [28117496] & n.l.t. & - & - & $\mathrm{RCT}$ \\
\hline Buelens 2017 [28009692] & n.l.t. & - & Missing studys) & $\mathrm{RCT}$ \\
\hline Capon 2009 [18727027] & n.l.t. & - & "PCS" & Excluded $^{\text {h) }}$ : Duplicate data \\
\hline Capon 2010 [20108089] & n.l.t. & $\mathrm{RCT}$ & "PCS" & RCT \\
\hline Carvalho 2010 [19821701] & n.l.t. & $\mathrm{RCT}$ & Missing study & $\mathrm{RCT}$ \\
\hline Casanova 2017 [28233128] & n.l.t. & - & - & $\mathrm{RCT}$ \\
\hline Conologue 2006 [16393593] & n.l.t. & Not analyzed ${ }^{\mathrm{i})}$ & "PCS" & $\mathrm{RCT}$ \\
\hline Davari 2012 [22228413] & n.l.t. & $\mathrm{RCT}$ & "PCS" & $\mathrm{RCT}$ \\
\hline Gladsjo 2014 [24373006] & n.l.t. & $\mathrm{RCT}$ & "PCS" & $\mathrm{RCT}$ \\
\hline Karmisholt 2018 [30101519] & n.l.t. & - & - & $\mathrm{RCT}$ \\
\hline Kim 2012 [22409153] & Other Laser ${ }^{\mathrm{j})}$ & - & "PCS" & $\begin{array}{l}\text { Excluded: Not comparator } \\
\text { of interest }\end{array}$ \\
\hline Kim 2014 [25111438] & Other Laser & - & "PCS" & $\begin{array}{l}\text { Excluded: Not comparator } \\
\text { of interest }\end{array}$ \\
\hline Nouri 2003 [12534515] & n.l.t. & Not analyzed & "PCS" & RCT \\
\hline Nouri 2010 [19662486] & n.l.t. & $\mathrm{RCT}$ & "PCS" & $\mathrm{RCT}$ \\
\hline Ojea 2016 [27841968] & n.l.t. & - & Missing study & $\mathrm{RCT}$ \\
\hline Ozog 2011 [21931055] & n.l.t. & Not analyzed & "PCS" & $\mathrm{RCT}$ \\
\hline Rohrer 2002 [11870788] & n.l.t. & Not analyzed & "PCS" & $\mathrm{RCT}$ \\
\hline Shin 2014 [25367640] & Other Laser & - & "PCS" & $\begin{array}{l}\text { Excluded: Not comparator } \\
\text { of interest }\end{array}$ \\
\hline Sobanko 2015 [25559589] & n.l.t. & $\mathrm{RCT}$ & "PCS" & $\mathrm{RCT}$ \\
\hline Tierney 2009 [19250300] & Other Laser & - & "PCS" & $\begin{array}{l}\text { Excluded: Not comparator } \\
\text { of interest }\end{array}$ \\
\hline Vazquez-Martinez 2015 [26580869] & n.l.t. & $\mathrm{RCT}$ & "PCS" & $\mathrm{RCT}$ \\
\hline Included RCTs & 22 & 8 & 16 & 17 \\
\hline
\end{tabular}

Abbreviations. ID: identity; n.l.t.: no laser treatment; PCS: prospective cohort study; PMID: PubMed identifier; RCT: randomized controlled trial.

a) Listed are RCTs which were included by at least one of the three identified systematic reviews. The systematic reviews are ordered by search date from left to right.

b) "Search date" refers to the searching of bibliographic databases by the authors of the corresponding systematic reviews.

c) "Publication date" refers to the publication history status according to MEDLINE $₫ / P u b M e d \circledast$ Data Element (Field) Descriptions.

d) "n.l.t." means that the authors of the RCTs compared laser treatment with no treatment or a treatment without laser.

e) "PCS" means that the authors used this term to label the corresponding RCT. ${ }^{\mathrm{f}}$ "-" indicates that an RCT could not have been identified because the publication of the corresponding RCT happened after the search date.

g) "Missing study" means that an RCT could have been identified because the publication of a corresponding RCT happened before the search date.

h) "Excluded" that the authors of the present review excluded the corresponding RCT based on the exclusion criteria provided.

i) "Not analyzed" means that an RCT was reported within an article but the corresponding data were not included in the metaanalysis.

j) "Other Laser" means that the authors of the RCTs compared various types of laser treatment.

Issue 2. Missing RCTs (Table 1): Karmisholt et al. ${ }^{2}$ did not report three RCTs, although they were published before the stated search date and thus could have been detected. Kent et al. ${ }^{3}$ based the results on a literature search which was performed in November 2015. If Kent et al. ${ }^{3}$ had undertaken an update search, then it would have been possible to include additional RCTs. The missing of data from relevant but overseen RCTs can bias the results of a systematic review. A systematic review is a snapshot in time. If new studies were published after the search date, then its databased conclusion could be outdated within a short time.

Issue 3. Misclassifying study designs (Table 1): Karmisholt et al. ${ }^{2}$ attached the label "prospective cohort" to almost all considered studies including 16 RCTs and seven nonrandomized studies. In RCTs, subjects are allocated to different interventions by the investigator based on a random allocation mechanism. In cohort studies, subjects are not allocated by the investigator but rather allocated in the course of usual treatment decisions or peoples' choices based on a nonrandom allocation mechanism. ${ }^{4}$ We believe that 'cohort study' is certainly not an appropriate label for RCTs. Furthermore, it is known for a long time that the shorthand labeling of a study using the words 'prospective' and 'retrospective' may create confusion due to the experience that these words carry contradictory and overlapping meanings. ${ }^{5}$ 
Issue 4. Mixing data from various study designs: Karmisholt et al. ${ }^{2}$ did not clearly separate randomized from nonrandomized studies. Combinations of different study design features should be expected to differ systematically, and different design features should be analyzed separately. ${ }^{4}$

Issue 5. Unclear definition of outcomes and measures of treatment effect: Kent et al. ${ }^{3}$ reported, quote: "The primary outcome of the meta-analysis is the summed measure of overall efficacy provided by the pooling of overall treatment outcomes measured within individual studies." We think that the so-called "summed measure" is not defined and not understandable. The meta-analysis reported in that article included mean and standard deviation values from four RCTs. These RCTs applied endpoints and time periods for assessment which differed considerably among the included studies. It appears obscure to us which data were transformed in what way to finally arrive in the meta-analysis. We believe that traceability and reproducibility of data analyses are mainstays of systematic reviews.

Issue 6. Missing an understandable risk of bias assessment: Kent et al. ${ }^{3}$ reported, quote: "The risk of bias assessment tool provided by RevMan indicated that all studies had 2-3 categories of bias assessed as high risk." The term "RevMan" is a short term for the software "Review Manager $5^{\prime \prime}$ provided by Cochrane for preparing their reviews. The Cochrane risk-of-bias tool for randomized trials is structured into a fixed set of domains of bias including those arising from the randomization process, due to deviations from intended interventions, due to missing outcome data, those in measurement of the outcome, and in selection of the reported result. We believe that the risk of bias assessment reported by Kent et al. ${ }^{3}$ is not readily understandable and presumably does not match standard requirements.

Systematic reviews of healthcare interventions aim to evaluate the quality of clinical studies, but they might have quality issues in their own right. The identification of various inconsistencies in two systematic reviews on plateletrich plasma therapy for pattern hair loss should prompt future authors to consult the Cochrane Handbook (https: //training.cochrane.org/handbook) and the EQUATOR Network (http: //www.equator-network.org/). The latter provides information to various reporting standards such as PRISMA for systematic reviews, CONSORT for RCTs, and STROBE for observational studies.

\section{Declaration of Competing Interest}

The authors declare no conflict of interest.

\section{Acknowledgement}

None.

\section{Funding}

The authors declare no funding.

\section{References}

1. Behrouz-Pirnia A, Liu H, Peternel S, Dervishi G, Labeit A, Peinemann F. Early laser intervention to reduce scar formation in wound healing by primary intention: a systematic review. J Plast Reconstruct Aesthet Surg 2020;73(3):528-36.

2. Karmisholt KE, Haerskjold A, Karlsmark T, Waibel J, Paasch U, Haedersdal M. Early laser intervention to reduce scar formation - a systematic review. J Eur Acad Dermatol Venereol 2018;32(7):1099-110.

3. Kent RA, Shupp J, Fernandez S, Prindeze N, DeKlotz CMC. Effectiveness of early laser treatment in surgical scar minimization: a systematic review and meta-analysis. Dermatol Surg 2020;46(3):402-10.

4. Higgins JPT, Thomas J, Chandler J, et al. Cochrane handbook for systematic reviews of interventions version 6.0 (updated July 2019). London: Cochrane; 2019 https: / training.cochrane.org/ handbook [Accessibility verified January 19, 2020].

5. Vandenbroucke JP. Prospective or retrospective: what's in a name? BMJ 1991;302(6771):249-50.

Frank Peinemann Children's Hospital, University of Cologne, Kerpener Str. 62, 50937 Cologne, Germany FOM University of Applied Science for Economics \& Management, Essen, Germany

Armin Behrouz-Pirnia Children's Hospital, University of Cologne, Kerpener Str. 62, 50937 Cologne, Germany

E-mail addresses: pubmedprjournal@gmail.com (F. Peinemann), arminpirnia@icloud.com (A. Behrouz-Pirnia)

(C) 2020 British Association of Plastic, Reconstructive and Aesthetic Surgeons. Published by Elsevier Ltd. All rights reserved.

https://doi.org/10.1016/j.bjps.2020.03.003

\section{Tactics for effective contemporary hand surgery journal clubs}

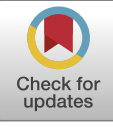

Dear Sir,

Journal clubs have contributed to medical education since the 19 th century. ${ }^{1}$ Along the way, different models and refinements have been proposed. Recently, there has been a shift towards "virtual" journal clubs, often using social media platforms. ${ }^{2}$ Our team has refined the face-to-face journal club model and successfully deployed it at two independent UK National Health Service (NHS) Trusts in 2019. We believe there are reproducible advantages to this model.

Over 6 months at one NHS Trust, 8 journal club events were held, with iterative changes made to increase engagement and buy-in of the surgical team. Overall, tangible outputs included 3 submissions of letters to editors, of which 2 have been accepted. 
Following this, the refined model was deployed at a second NHS Trust, which had expanded academic support increasing its impact. Over 4 months, 6 journal club events were held, with 4 submissions of letters to editors, 3 of which have been accepted. Thus, in 10 months of 2019, the two sequential journal clubs generated 7 submissions for publication, with 16 different authors.

These tangible outputs are matched by other intangible benefits, such as improving critical appraisal skills. This is assessed in UK surgical training entry selection and is also a key skill for evidence-based professional practice. Therefore, we feel this helps our team members' career progression and clinical effectiveness.

Key aspects of the model include:

1. Face-to-face meetings continue to have multiple intangible benefits

There is a trend towards social media and online journal clubs. While such initiatives have considerable benefits, maintaining face-to-face contact in a department allows for an efficient discussion, and enhances teambuilding.

2. Social media and messaging platforms can support a journal club and its output

Instead of replacing face-to-face meetings with virtual ones, we use social media platforms, such as WhatsApp, to support our events. This includes communications to arrange the event in advance, and for maintaining momentum on post-event activities, such as authoring letters to journals from the discussion.

\section{Article selection needs consideration in advance}

While some articles describing journal club models highlight the benefit of expert input in article selection, ${ }^{1}$ we also view it as a learning opportunity. A surgical trainee is allocated to present each journal club, with one of our three academically appointed consultant surgeons chairing and overseeing. Trainees are encouraged to screen the literature and identify articles beforehand and make a shared decision with the consultant. The article must be topical and have potential to impact clinical practice. Doing this prior to the session allows the article to be circulated to attendees with adequate time to read it.

4. Use of reporting and methodological quality guidance, structures presentation

We routinely use both reporting guidelines (e.g., PRISMA for systematic reviews), and also methodological quality guidance (e.g., AMSTAR-2 for systematic reviews) to guide trainees and structure the journal club presentation.

\section{Academic support enhances the depth of learning}

In addition to three consultants with university appointments guiding critical appraisal, a locally based information scientist also joins our meetings.

\section{Clinical expertise synergises with academic input}

During journal club discussion, emphasis is placed on relating the article to the clinical experience of team members. This provides context and aids clinical learning for trainees.
7. Considering the tangible benefits for all stakeholders increases buy-in

While undertaking critical appraisal may be a noble endeavour, in busy schedules, it is important that it adds value for everyone involved. Reviewing contemporary topics can inform clinical practice for all levels of surgeon in the team, presenting the article improves trainees' presentation skills, and publishing the appraisal generates outputs that help trainees to progress.

8. Publishing summaries of journal club appraisals can impact on multiple levels

Journal club does not only contribute to our trainees' development and departmental clinical practice. It benefits our own research strategy and quality, and open discussion of literature in plastic surgery contributes to a global culture of improving evidence.

\section{Frequent meetings keep momentum}

Scheduling events on a regular basis increases familiarity with reporting and quality guidance and allows for the study of complementary article types (e.g., systematic review, randomised trial, cohort study).

\section{Follow a set structure}

Our iterations suggest that the following structure is most effective: joint article selection one week before event, dissemination to audience, set time and location during departmental teaching, chairing by an academic consultant with information scientist and senior surgeons present, presentation led by a surgical trainee, open-floor discussion of article and its implications for our own practice, summary, drafting of letter to the editor if appropriate.

As we have used variations of this model successfully at two independent NHS Trusts, we believe that these tactics can be readily adapted and deployed by others as well.

\section{Declaration of Competing Interest}

Nil.

\section{Acknowledgements}

Jeremy Rodrigues provided data from the two NHS Trust journal clubs and invaluable advice.

\section{Funding}

Nil.

\section{References}

1. Deenadayalan $Y$, Grimmer-Somers K, Prior M. How to run an effective journal club: a systematic review. Evid Based Med 2008;14(5):898-911.

2. Topf JM, Sparks MA, Phelan PJ, et al. The evolution of the journal club: from Osler to Twitter. Am J Kidney Dis 2017;69(6):827-36. 
Emily Duggan, Murray Forsyth, Daisy Ryan Department of Plastic Surgery, Stoke Mandeville Hospital, Buckinghamshire Healthcare NHS Trust, Aylesbury, United Kingdom

E-mail address: duggan.eah@gmail.com (E. Duggan)

Crown Copyright (c) 2020 Published by Elsevier Ltd on behalf of British Association of Plastic, Reconstructive and Aesthetic Surgeons. All rights reserved.

https://doi.org/10.1016/j.bjps.2020.02.04

\section{Synchronous scalp tumour resection and latissimus dorsi flap raise: A time efficient approach to scalp and craniotomy reconstruction}

\section{Dear Sir,}

Surgical ablation of advanced scalp malignancies requires wide local excision of the lesion, including segmental craniectomies. The free latissimus dorsi (LD) flap is a popular choice for scalp reconstruction due to its potential for mass surface area resurfacing, ability to conform to the natural convexity of the scalp, reliable vascularity and reasonable pedicle length. ${ }^{1}$ One of the disadvantages of LD free flap use is the perceived need for harvest in in a lateral position. This necessitates a change in position of the patient intraoperatively for flap raise and can add to the overall operative time. Current literature in microvascular procedures on the elderly demonstrates that a longer operative time is the only predictive factor associated with an increased frequency of post-operative medical and surgical morbidity. As most patients undergoing scalp malignancy resection are elderly it is important to reduce this surgical time in this cohort of patients. ${ }^{2,3}$

We present our experience of reconstruction of composite cranial defects with LD flaps using a synchronous tumour resection and flap harvest with supine approach to reduce operative times and potential morbidity.

All patients undergoing segmental craniectomies with prosthetic replacement and LD reconstruction under the care of the senior surgeons were included in the study.

Patients were positioned supine with a head ring to support the neck; a sandbag is placed between the scapulae and the arm on the chosen side of flap raise is free draped. A curvilinear incision is made posterior to the midaxillary line (Figure 1). The lateral border of the LD muscle is identified, and dissection continued in a subcutaneous plane inferiorly, superiorly and medially until the midline is approached. The muscle is divided at the inferior and medial borders, and the flap lifted towards the pedicle. Once the pedicle is

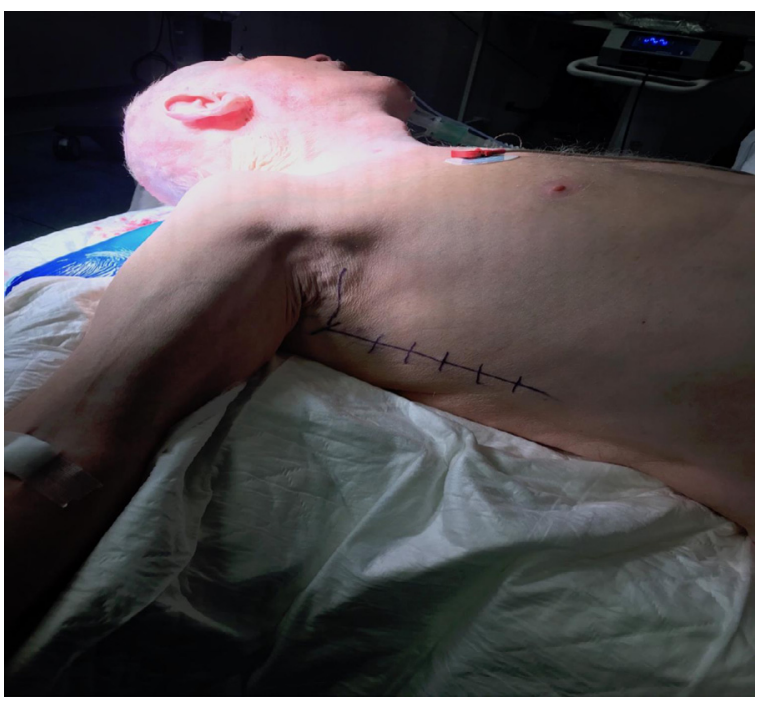

Figure 1 Curvilinear incision in mid-axillary line.

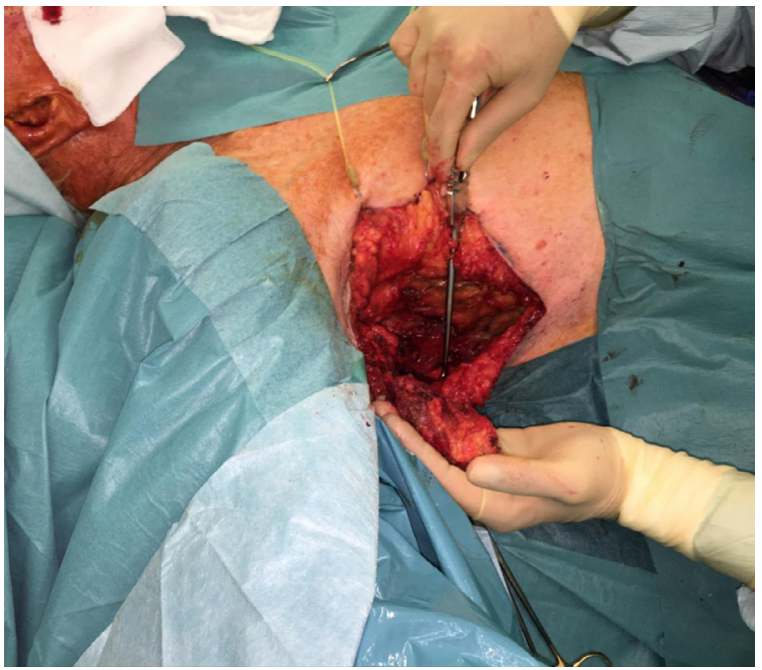

Figure 2 Flap delivered through the wound.

identified, the assistant can manipulate the position of the free draped arm to aid access into the axilla; the pedicle is clipped once adequate length has been obtained. The flap is delivered through the wound and detached (Figure 2). Donor site closure is carried out conventionally. The flap inset is performed using a "vest over pants" technique utilising scalp over muscle by undermining the remaining scalp edges. ${ }^{5}$ A non-meshed skin graft is used to enhance aesthetic outcome.

A total of 11 patients underwent 12 free LD muscle flaps. All were muscle flaps combined with split-thickness skin grafts.

The study population included ten male patients and one female. The age range was 47-74 years with a mean age of 69.5 years.

The defect area ranged from $99 \mathrm{~cm}^{2}-360 \mathrm{~cm}^{2}$. A titanium mesh was utilised for dural cover in all patients fixed with self-drilling $5 \times 1.5 \mathrm{~mm}$ cortical screws. 
The primary recipient vessel used was the superficial temporal artery and vein. However, in cases where a simultaneous neck dissection and parotidectomy are necessary for regional disease, the facial artery and vein are used ( $n=1$ in this series) or contralateral superficial temporal vessels. The ischaemia time ranged from 48-71 $\mathrm{min}$, with a mean of $61.3 \mathrm{~min}$.

There were no take backs for flap re-exploration. The overall flap success rate was $100 \%$. Marginal flap necrosis with secondary infection occurred in one patient with a massive defect (at one week post-op). The area was debrided and a second LD flap was used to cover the resultant defect (30\%). A further posterior transposition flap was used to cover a minor area of exposed mesh. The scalp healed completely.

The total operating time ranged between 210-410 min, with a mean of $289 \mathrm{~min}$. All patients were followed up at 2 and then four weeks for wound checks.

The LD flap remains a popular choice due to its superior size and ability to conform to the natural convexity of the scalp compared with other flap choices. ${ }^{4}$ Also, unlike composite flaps which often require postoperative debulking procedures, the LD muscle flap atrophy's and contours favourably to the skull. ${ }^{5}$ However, the traditional means of access to this flap requires lateral decubitus positioning of the patient, which can hinder simultaneous oncological resection. The supine position facilitates access for neck dissection, especially if bilateral access is required.

Our approach ensures that the tumour ablation and reconstruction is carried out in a time efficient manner in an attempt to reduce postoperative medical and surgical complications.

Synchronous ablation and reconstruction are key in reducing overall operative time and complication risk and is practised preferentially at our institute. It is important to maintain a degree of flexibility to achieve this - there may be situation where supine positioning overall is more favourable. Likewise, there are situations relating to flap topography where a lateral approach to tumour removal and reconstruction is preferred. The resecting surgeon or reconstructive surgeon may have to compromise to achieve synchronous operating but is worthwhile to reduce overall total operative time.

\section{Declaration of Competing Interest}

None.

\section{Funding}

N/A

\section{Ethical Approval}

Not required.

\section{References}

1. Chang KP, Lai CH, Chang $\mathrm{CH}$, Lin CL, Lai CS, Lin SD. Free flap options for reconstruction of complicated scalp and calvarial defects: report of a series of cases and literature review. Microsurgery 2010;30(1):13-18.

2. Jubbal KT, Zavlin D, Suliman A. The effect of age on microsurgical free flap outcomes: an analysis of 5,951 cases. Microsurgery 2017;37(8):858-64.

3. Serletti JM, Higgins JP, Moran S, Orlando GS. Factors affecting outcome in free-tissue transfer in the elderly. Plast Reconstr Surg 2000;106(1):66-70.

4. Kim SW, Hwang KT, Kim JD, Kim YH. Reconstruction of postinfected scalp defects using latissimus dorsi perforator and myocutaneous free flaps. J Craniofac Surg 2012;23(6):1615 - .

5. Hallock GG. Long-term superiority of composite versus muscle-only free flaps for skull coverage. Ann Plast Surg 2004;52(5):507-10 discussion 10-1.

Maleeha Mughal

Guy's \& St. Thomas Hospital, London, UK Division of Plastic Surgery, Department of Surgery and Surgical Oncology, University Health Network, University of Toronto, Toronto, Canada

Natiya Gabuniya, Paul Roblin, Jean-Pierre Jeannon, William Townley Guy's \& St. Thomas Hospital, London, UK

Corresponding author: 200 Elizabeth St 8N-867, Toronto, Ontario, Canada.

E-mail addresses: leeha_h82@hotmail.com, missmplast@gmail.com (M. Mughal)

Crown Copyright (C) 2020 Published by Elsevier Ltd on behalf of British Association of Plastic, Reconstructive and Aesthetic Surgeons. All rights reserved.

https://doi.org/10.1016/j.bjps.2020.02.028

\section{Role of lymphatico venular anastomosis for treatment of lymphorrhea in lower limbs}

Dear Sir,

\section{Introduction}

Once established, lymphorrhea typically persists and can present as an external lymphatic fistula. Lymphorrhea occurs in limbs with severe lymphedema, as a complication after lymphatic damage, and in obese patients. Some cases are refractory to conservative treatment and require surgical intervention. Reconstruction of a lymphatic drainage 
Table 1 Three patients had primary lymphedema, 4 had age-related lymphedema, 3 had obesity-related lymphedema, and 2 had iatrogenic lymphorrhea. In the 2 cases of iatrogenic lymphorrhea, the lesions were located in the groin and the others in the lower leg. Abbreviations: BMI, body mass index; F, female; $M$, male.

\begin{tabular}{|c|c|c|c|c|c|c|c|c|c|c|}
\hline Case & Sex & $\begin{array}{l}\text { Age } \\
\text { (years) }\end{array}$ & Type of edema & $\begin{array}{l}\text { Pre- operative } \\
\text { compresson }\end{array}$ & $\begin{array}{l}\text { Localization of } \\
\text { complaints }\end{array}$ & $\begin{array}{l}\text { Post- operative } \\
\text { compression }\end{array}$ & $\begin{array}{l}\text { Duration of } \\
\text { complaints } \\
\text { (months) }\end{array}$ & $\begin{array}{l}\text { Clinical evidence } \\
\text { of lymphedema- } \\
\text { campisi } \\
\text { staging }\end{array}$ & $\begin{array}{l}\text { Localization } \\
\text { (number) } \\
\text { of LVA }\end{array}$ & $\begin{array}{l}\text { Duration of } \\
\text { follow-up } \\
\text { (months) and } \\
\text { outcome }\end{array}$ \\
\hline 1 & $\mathrm{~F}$ & 86 & $\begin{array}{l}\text { primary, edema } \\
\text { occurrence after } \\
\text { senile }\end{array}$ & bandage & $\begin{array}{l}\text { both lower legs, } \\
\text { persistent } \\
\text { lymphorrhea }\end{array}$ & nothing & 3 months & stage 3 & $\begin{array}{l}3 \text { anastomosis } \\
\text { distal } 1 \\
\text { anastomosis } \\
\text { proximal in } \\
\text { each legs }\end{array}$ & $\begin{array}{l}12 \text { months, no } \\
\text { reccurence }\end{array}$ \\
\hline 2 & $\mathrm{~F}$ & 76 & Primary & nothing & $\begin{array}{l}\text { right foot, persistent } \\
\text { lymphorrhea }\end{array}$ & nothing & 2 months & stage 4 & $\begin{array}{l}2 \text { anastomosis } \\
\text { distal } 4 \\
\text { anastomosis } \\
\text { proximal in } \\
\text { affected leg }\end{array}$ & $\begin{array}{l}36 \text { months, no } \\
\text { reccurennce }\end{array}$ \\
\hline 3 & $\mathrm{~F}$ & 45 & Primary & bandage & $\begin{array}{l}\text { Left lower leg, } \\
\text { persistent } \\
\text { lymphorrhea and } \\
\text { cellulitis }\end{array}$ & bandaging & 192 months & staage 3 & $\begin{array}{l}3 \text { anastomis } \\
\text { distalal } 3 \\
\text { anastomisis } \\
\text { proximal in } \\
\text { affected leg }\end{array}$ & $\begin{array}{l}36 \text { months, no } \\
\text { reccurennce }\end{array}$ \\
\hline 4 & $\mathrm{~F}$ & 77 & $\begin{array}{l}\text { primary, edema } \\
\text { occurrence after } \\
\text { senile }\end{array}$ & nothing & $\begin{array}{l}\text { both lower legs, } \\
\text { persistent } \\
\text { lymphorrhea and } \\
\text { cellulitis }\end{array}$ & nothing & 12 months & stage 3 & $\begin{array}{l}4 \text { anastomosis } \\
\text { distal } 1 \\
\text { anastomosis } \\
\text { proximal in } \\
\text { each legs }\end{array}$ & $\begin{array}{l}12 \text { months, no } \\
\text { reccurence }\end{array}$ \\
\hline 5 & $\mathrm{~F}$ & 78 & Primary & bandage & $\begin{array}{l}\text { Left lower leg, } \\
\text { persistent } \\
\text { lymphorrhea and } \\
\text { cellulitis }\end{array}$ & bandage & 12 months & stage 3 & $\begin{array}{l}2 \text { anastomosis } \\
\text { distal, } 2 \\
\text { anastomosis } \\
\text { proximal in } \\
\text { affected leg }\end{array}$ & $\begin{array}{l}12 \text { months, no } \\
\text { reccurence }\end{array}$ \\
\hline 6 & $\mathrm{~F}$ & 68 & $\begin{array}{l}\text { Primary, edema } \\
\text { occurrence after } \\
\text { senile }\end{array}$ & bandage & $\begin{array}{l}\text { right lower leg, } \\
\text { persistent } \\
\text { lymphorrhea }\end{array}$ & bandage & 6 months & stage 3 & $\begin{array}{l}2 \text { anastomiss } \\
\text { distal } 1 \\
\text { anastomosis } \\
\text { proximal in } \\
\text { affected leg }\end{array}$ & $\begin{array}{l}6 \text { months, no } \\
\text { reccuurence }\end{array}$ \\
\hline
\end{tabular}


Table 1 (continued)

\begin{tabular}{|c|c|c|c|c|c|c|c|c|c|c|}
\hline Case & Sex & $\begin{array}{l}\text { Age } \\
\text { (years) }\end{array}$ & Type of edema & $\begin{array}{l}\text { Pre- operative } \\
\text { compresson }\end{array}$ & $\begin{array}{l}\text { Localization of } \\
\text { complaints }\end{array}$ & $\begin{array}{l}\text { Post- operative } \\
\text { compression }\end{array}$ & $\begin{array}{l}\text { Duration of } \\
\text { complaints } \\
\text { (months) }\end{array}$ & $\begin{array}{l}\text { Clinical evidence } \\
\text { of lymphedema- } \\
\text { campisi } \\
\text { staging }\end{array}$ & $\begin{array}{l}\text { Localization } \\
\text { (number) } \\
\text { of LVA }\end{array}$ & $\begin{array}{l}\text { Duration of } \\
\text { follow-up } \\
\text { (months) and } \\
\text { outcome }\end{array}$ \\
\hline 7 & $\mathrm{~F}$ & 75 & $\begin{array}{l}\text { Primary, edema } \\
\text { occurrence after } \\
\text { senile }\end{array}$ & $\begin{array}{l}\text { JOBST }^{\circledR} \\
\text { UltraSheer } \\
\text { Stockings }\end{array}$ & $\begin{array}{l}\text { Left lower leg, } \\
\text { persistent } \\
\text { lymphorrhea and } \\
\text { cellulitis }\end{array}$ & $\begin{array}{l}\text { JOBST }^{\circledR} \\
\text { UltraSheer } \\
\text { Stockings }\end{array}$ & 1 month & stage 2 & $\begin{array}{l}3 \text { anastomosis } \\
\text { distal } 2 \\
\text { anastomosis } \\
\text { proximal in } \\
\text { affected leg }\end{array}$ & $\begin{array}{c}12 \text { months, no } \\
\text { reccurence }\end{array}$ \\
\hline 8 & $\mathrm{~F}$ & 43 & Obese, BMI 45 & FarrowWrap ${ }^{\circledR}$ & $\begin{array}{l}\text { both lower legs, } \\
\text { persistent } \\
\text { lymphorrhea }\end{array}$ & FarrowWrap ${ }^{\circledR}$ & 2 months & Stage 2 & $\begin{array}{l}3 \text { anastomosis } \\
\text { distal } 1 \\
\text { anastomosis } \\
\text { proximal in } \\
\text { each legs }\end{array}$ & $\begin{array}{l}6 \text { months, no } \\
\text { reccuurence }\end{array}$ \\
\hline 9 & $\mathrm{~F}$ & 41 & Obese, BMI 58 & Bandage & $\begin{array}{l}\text { right lower leg, } \\
\text { persistent } \\
\text { lymphorrhea and } \\
\text { cellulitis }\end{array}$ & bandage & 1 month & stage 2 & $\begin{array}{l}3 \text { anastomosis } \\
\text { distal } 3 \\
\text { anastomosis } \\
\text { proximal in } \\
\text { affected leg }\end{array}$ & $\begin{array}{l}6 \text { months, no } \\
\text { reccuurence }\end{array}$ \\
\hline 10 & M & 57 & Obese, BMI 47 & Bandage & $\begin{array}{l}\text { both lowelegs, } \\
\text { persistent } \\
\text { lymphorrhea and } \\
\text { cellulitis }\end{array}$ & bandage & 3 months & stage 3 & $\begin{array}{l}3 \text { anastomosis } \\
\text { distal } 3 \\
\text { anastomosis } \\
\text { proximal in } \\
\text { each legs }\end{array}$ & $\begin{array}{l}6 \text { months, no } \\
\text { reccuurence }\end{array}$ \\
\hline 11 & $M$ & 70 & $\begin{array}{l}\text { Secondary, soft } \\
\text { tissue sarcoma } \\
\text { knee, lymph node } \\
\text { biopsy in ingunal } \\
\text { region }\end{array}$ & $\begin{array}{l}\text { JOBST }^{\circledR} \\
\text { Opaque } \\
\text { Stockings }\end{array}$ & $\begin{array}{l}\text { right inguinal region, } \\
\text { persistent } \\
\text { lymphorrhea and } \\
\text { cellulitis }\end{array}$ & $\begin{array}{l}\text { JOBST }{ }^{\circledR} \\
\text { Opaque } \\
\text { Stockings }\end{array}$ & 2 months & stage 3 & $\begin{array}{l}6 \text { anastomosis } \\
\text { distal in } \\
\text { affected limb }\end{array}$ & $\begin{array}{l}1 \text { year 6months } \\
\text { no } \\
\text { reccurences }\end{array}$ \\
\hline 12 & $\mathrm{~F}$ & 23 & $\begin{array}{l}\text { revascularization } \\
\text { after malignant } \\
\text { soft tissue sarcoma } \\
\text { resection }\end{array}$ & $\begin{array}{l}\text { JOBST }{ }^{\circledR} \\
\text { Opaque } \\
\text { Stockings }\end{array}$ & $\begin{array}{l}\text { right inguinal region, } \\
\text { persistent } \\
\text { lymphorrhea }\end{array}$ & $\begin{array}{l}\text { JOBST }^{\circledR} \\
\text { Opaque } \\
\text { Stockings }\end{array}$ & 3 months & stage 3 & $\begin{array}{l}6 \text { anastomisis } \\
\text { distal in } \\
\text { affected limb }\end{array}$ & $\begin{array}{l}\text { 1year no } \\
\text { reccurrences }\end{array}$ \\
\hline
\end{tabular}


route is considered ideal treatment for lymphorrhea. In this study, we reviewed the efficacy of lymphaticovenous anastomoses as a treatment for lymphorrhea of any etiology.

\section{Materials and methods}

Three patients had primary lymphedema, four had agerelated lymphedema (aging of the lymphatic system and function is thought to be the cause of age-related lymphedema ${ }^{1}$. ), three had obesity-related lymphedema, and two had iatrogenic lymphorrhea (Table 1). One of 2 cases of lymphorrhea in the inguinal region was caused by lymph node biopsy and the other by revascularization after resection of malignant soft tissue sarcoma. Compression therapy had been performed preoperatively in 10 cases (using cotton elastic bandages in 6 cases). Four patients wore a JOBST ${ }^{\circledR}$ compression garment. Compression therapy was difficult to apply in 2 patients. The duration of lymphorrhea ranged from 1 to 192 months. The severity of lymphedema ${ }^{2}$ ranged from Campisi stage 2 to 4 (Table 1). The clinical diagnosis of lymphorrhea was confirmed by observation of fluorescent discharge from the wound on lymphography. No signs of venous insufficiency or hypertension were observed in the subcutaneous vein intraoperatively. All anastomoses were performed between distal lymphatics and proximal veins. Postoperatively, lymph was observed to be flowing from the lymphatic vessels to the veins.

Two to 4 LVAs were performed in the region distal to the lymphorrhea and 1-4 in the region proximal to the lymphorrhea in patients with lower limb involvement. Six LVAs were performed in patients with lymphorrhea in the inguinal region (Table 1).

\section{Results}

All patients were successfully treated with LVAs without perioperative complications. The volume of lymphorrhea decreased within 5 days following the LVA surgery in all cases and had resolved by 2 weeks postoperatively. The compression therapy used preoperatively was continued postoperatively. There has been no recurrence of lymphorrhea or cellulitis since the LVAs were performed.

\section{Case reports}

\section{Case 1}

An 86-year-old woman had gradually developed edema in her lower limbs over a period of 2-3 years. She had also developed erosions on both lower legs (Figure 1). Compression with cotton bandages failed to terminate the percutaneous discharge; about $400 \mathrm{~mL}$ of lymphatic discharge through the erosion was noted each day. Ultrasonography did not suggest a venous ulcer resulting from venous thrombosis, varix, or reflux. Four LVAs were performed in each leg (3 distal and 1 proximal to the leak). The lymphorrhea had mostly resolved by 5 days postoperatively. The erosions healed within 3 weeks of the surgery. No recurrence of lymphorrhea was noted during 12 months of follow-up.

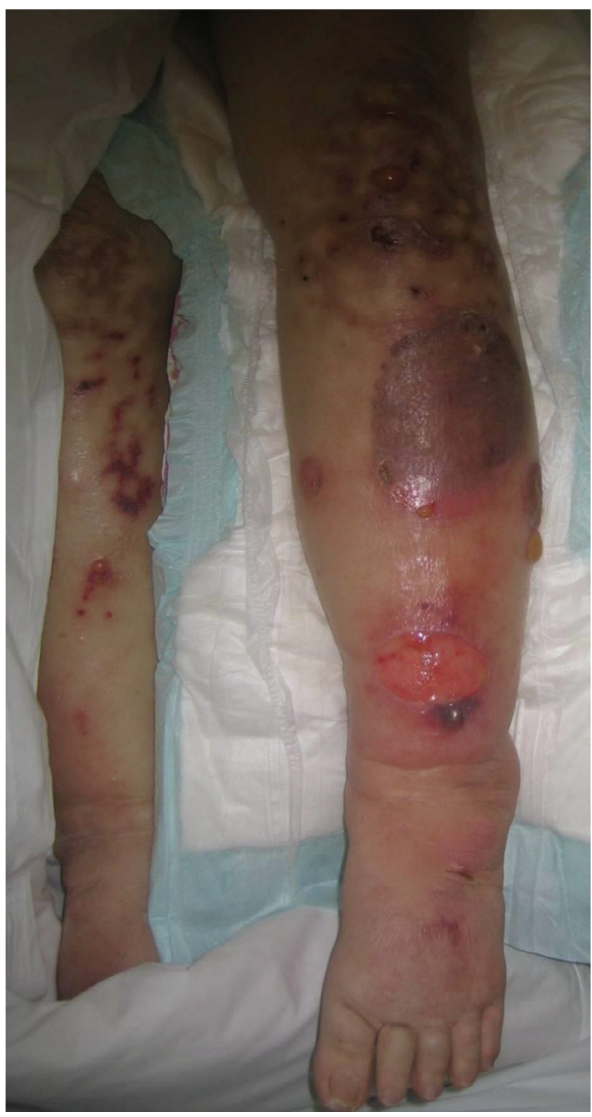

Figure 1 Case 1. An 86-year-old woman gradually developed lymphedema and erosions in her lower limbs over a period of 2-3 years.

\section{Discussion}

latrogenic lymphorrhea occurs after surgical intervention involving the lymphatic system. It is also known to occur in patients with severe lymphedema. Obesity ${ }^{3}$ and advancing age $^{1}$ are also risk factors for lymphedema. Most patients with lymphorrhea respond to conservative measures but some require surgical treatment. Patients with lymphorrhea are at increased risk of lymphedema. Lymphorrhea that occurs after surgery or trauma is caused by damage to lymphatic vessels that are large enough to cause lymphorrhea. Lymphorrhea that occurs in association with lipedema or age-related lymphedema indicates accumulation of lymph that has progressed to lymphorrhea. It is possible to treat lymphorrhea by other methods, including macroscopic ligation, compression, or negative pressure wound therapy ${ }^{4}$. However, it is impossible to reconstruct a lymphatic drainage route using these procedures. We hypothesized that lymphorrhea can be managed by using LVA to treat the lymphedema. LVA is a microsurgical technique whereby an operating microscope is used to perform microscopic anastomoses between lymphatic vessels and veins to re-establish a lymph drainage route. The primary benefits of LVA are that it is minimally invasive, can be performed under local anesthesia, and through incisions measuring 2$3 \mathrm{~cm}$. One anastomosis is adequate to treat lymphorrhea and serves to divert the flow of the lymphorrhea-causing lymph 
to the venous circulation. If operative circumstances allow, 5 or more anastomoses are recommended for the treatment of lymphorrhea complicated by lymphedema. Lymphedema is a cause of delayed wound healing, and LVA procedures are considered to improve wound healing in lymphedema via pathophysiologic and immunologic mechanisms ${ }^{5}$.

\section{Conclusion}

LVA is a promising treatment for lymphorrhea because it can treat both lymphorrhea and lymphedema simultaneously. The focus when treating lymphedema has now shifted to risk reduction and prevention, so it is important to consider the risk of lymphedema when treating lymphorrhea.

\section{Declaration of Competing Interest}

None

\section{Acknowledgments}

All authors declare that there were no funding sources for this study and they approved the final article.

\section{Funding}

None

\section{Supplementary material}

Supplementary material associated with this article can be found, in the online version, at doi:10.1016/j.bjps.2020.02. 029.

\section{References}

1. Yoshida S, Koshima I, Imai H, Sasaki A, Fujioka Y, Nagamatsu S, Yokota K, Harima M, Yamashita S, MD, Tashiro K. Indocyanine green lymphography findings in older patients with lower limb lymphedema. J Vasc Surg Venous Lymphat Disord 2019 Jun 20 pii: S2213-333X(19)30327-0.

2. Campisi C, Boccardo F. Microsurgical technique for lymphedema treatment: derivative lymphatic-venous microsurgery. World $\mathrm{J}$ Surg 2004;28:609-13.

3. Greene AK, Grant FD, Slavin SA. Lower-extremity lymphedema and elevated body-mass index. N Engl J Med 2012;366:2136-7.

4. Abai B, Zickler RW, Pappas PJ, Lal BK, Padberg FT Jr. Lymphorrhea responds to negative pressure wound therapy. $J$ Vasc Surg Mar 2007;45(3):610-13.

5. Yoshida S, Koshima I, Hamada Y, Sasaki A, Fujioka Y, Nagamatsu S, Yokota K, Harima M, Yamashita S. Lymphovenous anastomosis aids wound healing in lymphedema: relationship between lymphedema and delayed wound healing from a view of immune mechanisms. Adv Wound Care (New Rochelle) 2019;8(6):263-9.

Shuhei Yoshida The International Center for Lymphedema, Hiroshima University Hospital, Hiroshima, Japan
Yuichi Hamada

Plastic and Reconstructive Surgery, Japanese Red Cross Fukuoka Hospital, Japan

Isao Koshima, Hirofumi Imai

The International Center for Lymphedema, Hiroshima University Hospital, Hiroshima, Japan

\section{Toshio Uchiki \\ Plastic and Reconstructive Surgery, Japanese Red Cross Fukuoka Hospital, Japan}

Ayano Sasaki, Yumio Fujioka, Shogo Nagamatsu, Kazunori Yokota Department of Plastic Surgery, Hiroshima University Hospital, Hiroshima, Japan

Mitsunobu Harima, Shuji Yamashita Department of Plastic and Reconstructive Surgery, Graduate School of Medicine, The University of Tokyo, Tokyo, Japan

E-mail address: yoshidas@hiroshima-u.ac.jp (S. Yoshida)

(C) 2020 British Association of Plastic, Reconstructive and Aesthetic Surgeons. Published by Elsevier Ltd. All rights reserved.

https://doi.org/10.1016/j.bjps.2020.02.029

\section{Over-meshing 1:1 meshed skin graft}

Dear Sir,

We were curious to learn if it's feasible to mesh already meshed skin grafts. We run our Skin Bank at the Department of Plastic surgery ${ }^{1}$ and used allograft skin that was tested microbiologically positive and thus not suitable for patient use.

Grafts were cut into $4 \mathrm{~cm} \times 4.5 \mathrm{~cm}$ pieces and meshed using mesh carriers to $1: 1$ and over-meshed with 1:1.5. We used two kind of mesh carriers for 1:1.5 meshes. The meshed grafts were maximally expanded and measured again. The results were expressed as ratios, Figure 1. We found that, over-meshing results in 1.25-fold increase in graft area regardless of the mesh carrier used. Figure 2 illustrates close-up picture of the over-meshed graft. In the close-up picture the small 1:1 incisions are still visible.

In those undesirable "oh no the graft is too small" or "the graft is too large" - situations this technique has its advantages. We have used over-meshed graft in a skin graft harvest site, Supplemental Figure, with acceptable outcome. It seems that the tiny extra incisions in the overmeshed skin graft do not deteriorate the aesthetic outcome from the $1: 1.5$ mesh. What is the clinical value of the tiny incisions, we don't know, but we approximate it to be minimal if even that. 


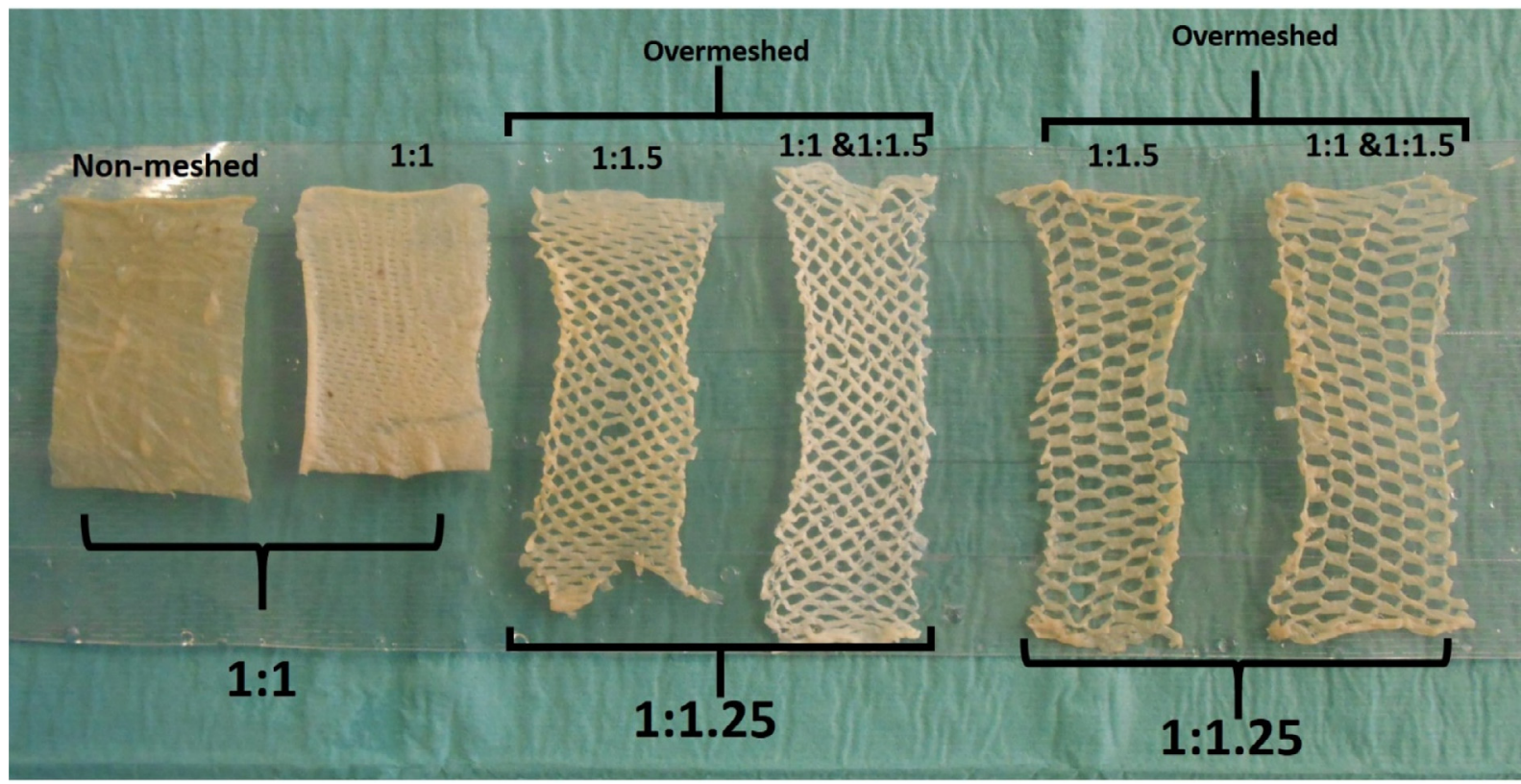

Figure 1 Examples of the $4 \times 4.5$ cut allograft samples meshed, increase of the over-meshed grafts is presented as ratios.

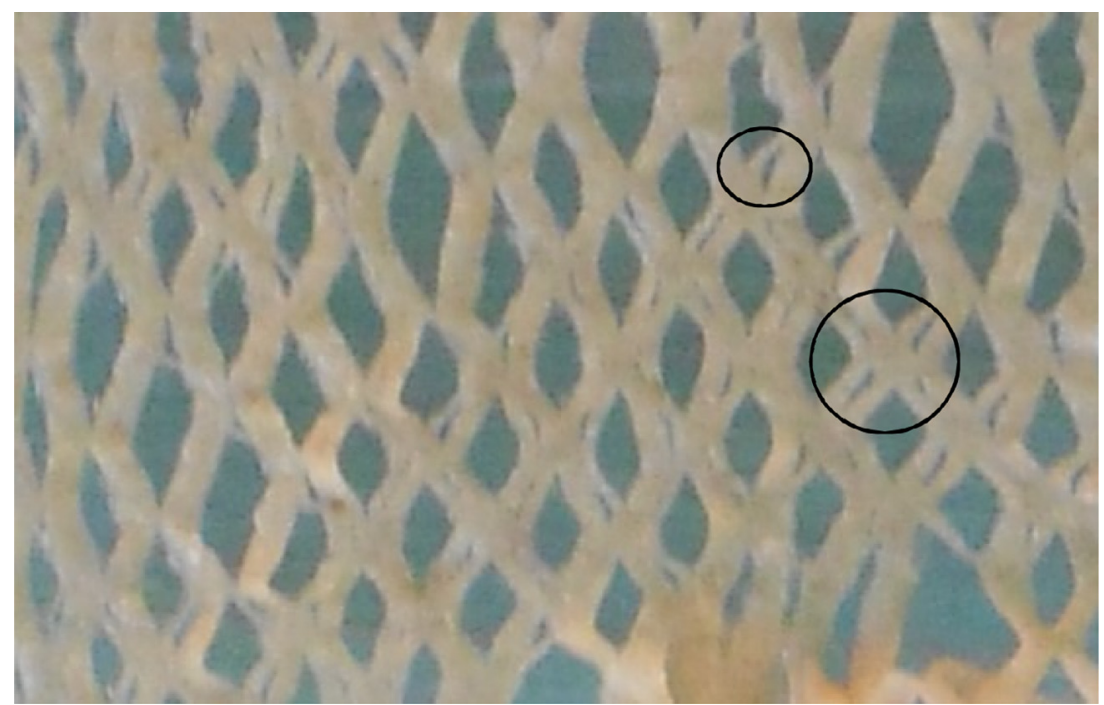

Figure 2 Close-up image of the over-meshed - 1:1 and 1:1.5 - skin graft. Black circles pinpoint to the 1:1 mesh incisions.

To best of our knowledge, only one previous publication has addressed the over-meshing of skin grafts ${ }^{2}$. Henderson et al. showed in porcine split thickness skin grafts that overmeshing resulted in increase of 1.5 ratio, a bit larger compared to our results. Taken together, the results point to the direction that meshing of already meshed graft is feasible and does not destroy the architecture of the original or succeeding mesh.

\section{Declaration of Competing Interest}

Each author declares no financial conflicts of interest with regard to the data presented in this manuscript.

\section{Supplementary materials}

Supplementary material associated with this article can be found, in the online version, at doi:10.1016/j.bjps.2020.02. 048.

\section{References}

1. Lindford AJ, Frey I, Vuola J, Koljonen V. Evolving practice of the Helsinki Skin Bank. Int Wound J 2010;7:277-81.

2. Henderson J, Arya R, Gillespie P. Skin graft meshing, overmeshing and cross-meshing. Int J Surg 2012;10:547-50. 
Tuukka Veija

Department of Surgery, Hyvinkää Hospital, Helsinki and Uusimaa Hospital District, Hyvinkää, Finland

Virve Koljonen

Department of Plastic Surgery, University of Helsinki and Helsinki University Hospital, P.O. Box 266, Fl-00029

Helsinki, Finland

E-mail address: virve.koljonen@hus.fi (V. Koljonen)

(C) 2020 British Association of Plastic, Reconstructive and Aesthetic Surgeons. Published by Elsevier Ltd. All rights reserved.

https://doi.org/10.1016/j.bjps.2020.02.048

\section{The gluteal butterfly flap: Use of a para-sacral artery perforator propeller flap in gluteal augmentation}

Dear Sir,

\section{Introduction}

Numerous autologous techniques for gluteal augmentation flaps have been described. In the well-known currently employed technique for gluteal augmentation, it is noticeable that added volume is unevenly distributed in the buttock. In fact, after a morphological analysis, it becomes clear that the volume is added to the upper buttock to the expense of the lower buttock. ${ }^{1}$ According to Wong's ideal buttock criteria, the most prominent posterior portion is fixed at the midpoint on the side view. ${ }^{2}$ Additionally, Mendieta et al. suggest that the ideal buttock needs equal volume in the four quadrants and its point of maximum projection should be at the level of the pubic bone. ${ }^{3}$ We describe a technique of autologous gluteal augmentation using a para-sacral artery perforator propeller flap (PSAP). This new technique can fill up all the quadrants vertically with a voluminous flap shaped like a gluteal anatomic implant.

\section{Patient selection and evaluation}

Gluteal examination is done in a standing and prone position. Patients must have a body mass index less than $30 \mathrm{~kg} / \mathrm{m} 2$, an indication for a body lift contouring surgery, gluteal ptosis with platypygia and substantial steatomery on the lower back. When the pinch test is greater than $5 \mathrm{~cm}$ this is defined as substantial steatomery.

\section{Preoperative markings: the ten steps}

a. Standing position
1. Limits of the trunk. The median limit (MLT) and the vertical lateral limit (LLT) of the trunk are marked.

2. Limits of the buttock. The inferior gluteal fold (IGF) is drawn. The vertical lateral limit of the buttock (LLB) is defined at the outer third between the MLT and the LLT.

3. Lateral key points. Points C and C' are located on the vertical lateral limits: Point $C$ is 2 to $3 \mathrm{~cm}$ below the iliac crest, depending on the type of underwear. Point C' is determined by an inferior strong tension pinch test performed from point $C$.

4. Median key points. On the MLT axis, point A' is marked at the top/upper part of the inter gluteal fold.

b. Prone position

Point $A$ is determinate by a superior gentle tension pinch test performed from point $A^{\prime}$.

5. Upper resection line. This line is an upward convexity curve, connecting point $\mathrm{A}$ to point $\mathrm{C}$, in a median to lateral direction.

6. Medial key points. Point B is defined by the crossing point of the upper resection line and the LLB. Point $B^{\prime}$ is defined by an inferior moderate tension pinch test performed from point $B$.

7. Lower resection line. This line joins points A', B' and C'.

8. Identifying the perforators. The search area is located next to the lateral limits of the sacrum, on both sides of the median line, between the two resection lines. First, a sound Doppler $(8 \mathrm{MHz}, \mathrm{HADECO}$ ES-100VX, Lemoine Medical, Entraigues, France) is used to locate the perforators. This is then confirmed by color Doppler ultrasound (Voluson LOGIQ E, GE Healthcare, Little Chan Thelfont, UK) with a linear probe of $12 \mathrm{MHz}$. This diagnostic tool is easy to access, non-invasive, and above all, reliable in the identification of perforating arteries, with sensitivity and a positive predictive value of almost $100 \% .{ }^{4}$ Usually, one to three perforators are identified on each side and marked.

9. Design of the gluteal pocket. The shape is oval, with the dimensions similar to those of the flaps. The base is truncated and suspended from the lower resection line. The width of the pocket is one to two centimeters from the LMT laterally and two centimetres from LLT medially. The inferior border of the pocket is not more than two fingers'-breadth above the IFG. Therefore, the pocket lies medial in the gluteal region.

10. Design of the flap. The flap is shaped like a "butterfly wing" with the long axis following a horizontal line. After a $90^{\circ}$ medial rotation, the flap has a shape similar to an anatomical gluteal prosthesis. The medial boundary is two fingers'-breadth from the median limit of the buttock, and the width is defined by the two resection limits.

\section{Surgical technique}

The patient is placed in a prone position, arm in abduction. The flap is harvested from lateral to medial direction, first in a supra-fascial plane then sub-fascial when approaching the LLB. 


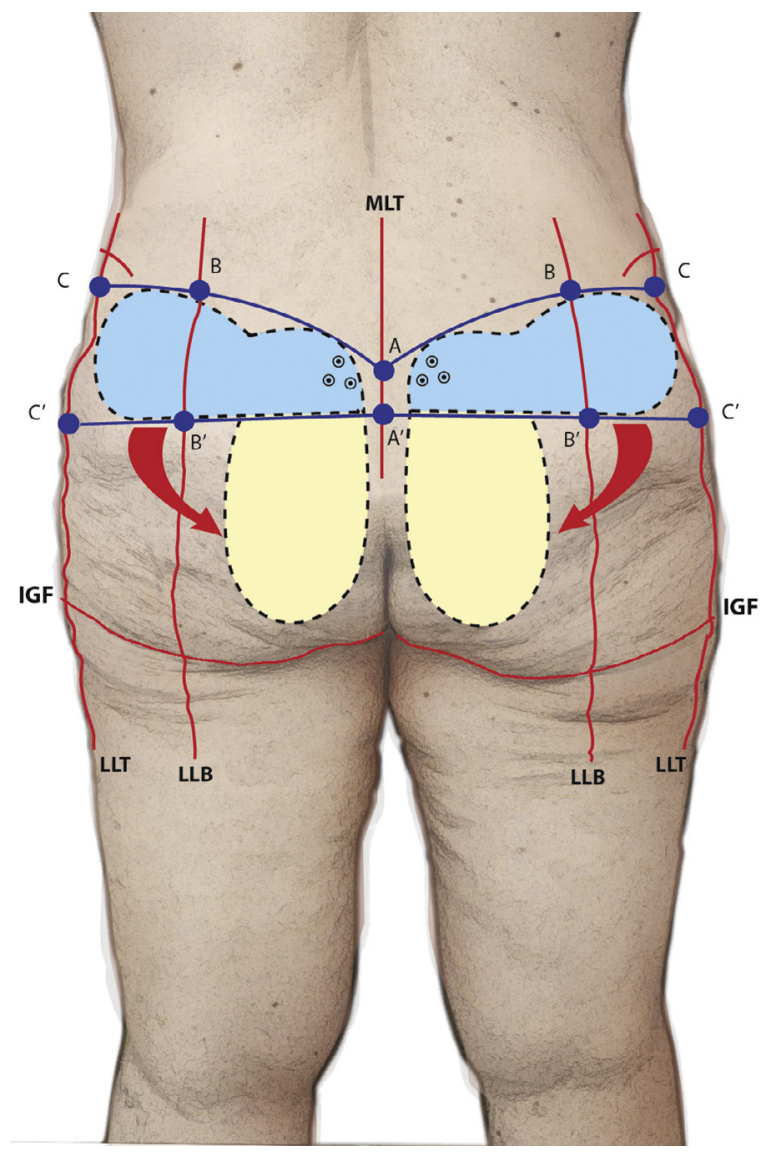

Figure 1 Posterior view of preoperative markings: MLT- Median Limit of the Trunk; LLT - Lateral Limit of the trunk; LLB Lateral Limit of the Buttock; IGF- Inferior Gluteal Fold.

The dissection is completed when the rotation arc of the flap is free of restriction $\left(90^{\circ}-100^{\circ}\right)$, and viewing or dissection of the perforators is usually not required. To create the pocket, custom undermining is done in the sub-fascial plane according to the markings.

The flap is then rotated and positioned into the pocket.

The superficial fascial system is closed with 0 Vicryl (Ethicon) and the deep and superficial dermis are closed with a buried intradermal suture and running subcutaneous suture with 3.0 Monocryl (Ethicon).

A compressive garment (Medical Z lipo-panty elegance coolmax $\mathrm{H}$ model, EC/002-H) was worn postoperatively for one month (Figure 1).

\section{Declaration of Competing Interest}

All authors disclose any commercial associations or financial disclosures.

\section{References}

1. Levan P. and Habre S.B. Gluteal implants versus autologous flaps in patientswith postbariatric surgery weight loss: a prospec- tive comparative of 3-dimensional gluteal projection after lower body lift. 2017; 37: 1012-21.

2. Wendy W. and Wong. Redefining the ideal buttocks: a population analysis. 2016; 137: 1739-47.

3. Constantino G, Mendieta. Classification system for gluteal evaluation. Clin Plast Surg 2018;45:159-77.

4. Phillip N. Blondeel and others. Doppler flowmetry in the planning of perforator flaps. Plast Reconstr Surg 1998;51:202-9.

Farid Bekara

Department of Plastic and Reconstructive Surgery, Wound Healing and Burns Units, Lapeyronie University Hospital, 371 avenue du Doyen Gaston GIRAUD, 34295 Montpellier,

France

Department of Plastic and Reconstructive Surgery, Rangueil University Hospital, Toulouse, France

Benoit Chaput

Department of Plastic and Reconstructive Surgery, Rangueil University Hospital, Toulouse, France

Elena Ciucur

Department of Plastic and Reconstructive Surgery, Wound Healing and Burns Units, Lapeyronie University Hospital, 371 avenue du Doyen Gaston GIRAUD, 34295 Montpellier, France

Department of Plastic and Reconstructive Surgery, Rangueil University Hospital, Toulouse, France

Nicolas Bertheuil Department of Plastic and Reconstructive Surgery, South Hospital, University of Rennes, Rennes, France

David Boccara

Department of Plastic and Reconstructive Surgery and Burns Units, Saint Louis University Hospital, Paris, France

Christian Herlin

Department of Plastic and Reconstructive Surgery, Wound Healing and Burns Units, Lapeyronie University Hospital, 371 avenue du Doyen Gaston GIRAUD, 34295 Montpellier,

France

Gilles Claro

Department of Plastic and Reconstructive Surgery, Rangueil University Hospital, Toulouse, France

Correspondence to: Farid Bekara, Department of Plastic and Reconstructive Surgery, Wound Healing and Burns Units, Lapeyronie University Hospital, 371 avenue du Doyen Gaston GIRAUD, 34295 Montpellier, France. E-mail address: farid.bekara@gmail.com (F. Bekara)

(c) 2020 British Association of Plastic, Reconstructive and Aesthetic Surgeons. Published by Elsevier Ltd. All rights reserved.

https://doi.org/10.1016/j.bjps.2020.02.026 


\section{Minimally invasive cortical bone collector: A new tool in rhinoplasty}

Dear Sir,

\section{Introduction}

Rhinoplasty is one of the most common procedures in plastic surgery and $5-15 \%$ of the patients undergo revision. Dorsal asymmetry is the leading (65\%) nasal flaw in secondary patients. ${ }^{1}$ Careful management of the dorsum to achieve a smooth transition from radix to tip is necessary. Camouflage techniques are well known maneuvers for correcting dorsal irregularities. Cartilage, fascia, cranial bone, and acellular dermal matrix were previously used for this aim. ${ }^{2,3}$ Bone dust is an orthotopic option, which is easily moldable into a paste. It is especially useful in closed rhinoplasty, where our visual acuity on the dorsum is reduced. We introduce a new tool, a minimally invasive bone collector, as an effective and safe device for harvesting bone dust from the nasal bony pyramid to obtain camouflage on the dorsum and for performing ostectomy simultaneously.

\section{Material and method}

Patients were operated for nasal deformity by the senior author (O.B.) with closed rhinoplasty between February 2018 and November 2018. In all cases, a minimally invasive bone collector was used for ostectomy and the harvest of bone dust. Included patients were primary cases with standardized photos, complete medical records, and 1-year follow-up. Written informed consent for operation and publishing their photographs was obtained and the study was performed in accordance with standards of Declaration of Helsinki. The authors have no financial disclosure or conflict of interest to declare. Patient data were obtained from rhinoplasty data sheets and photographs were used for the analysis of nasal dorsum height, symmetry, and contour. Physical examinations were carried out for detecting irregularities.

\section{Description of the device}

Micross (Geitslich Pharma North America Inc., Princeton, New Jersey) is a bone collector, which allows easy harvest, especially in narrow areas. Micross comes with a package containing 1 sterile disposable scraper. It is externally $5 \mathrm{~mm}$ in diameter and has a cutting blade tip. A collection chamber allows harvesting maximum of $0.25 \mathrm{cc}$ graft at once. A sharp technique improves graft viability.

\footnotetext{
is This paper was presented at: The Rhinoplasty Society Annual Meeting 16 May 2019, New Orleans, Louisiana.
}

\section{Surgical technique}

Incisions for lateral osteotomies were used to introduce $\mathrm{Mi}$ cross when the planned ostectomy site was nasomaxillary buttress. Infracartilaginous incision was used when the desired ostectomy site was dorsal cap or radix. Bone dust was collected into a chamber with a rasping movement. The graft is mixed with blood during the harvest, this obtains an easily moldable bone paste (Surgical technique is described in the Video). After the completion of osteotomies and cartilaginous vault closure, the bone paste was placed on the site of bony dorsum, which is likely to show irregularities postoperatively. A nasal splint was used to maintain contour. The bone graft was not wrapped into any other graft.

\section{Results}

Eighteen patients underwent primary closed rhinoplasty with 1-year follow-up. Seventeen of 18 patients were female and one was male. Harvesting sites were nasomaxillary buttress in 18 patients, radix in 7 patients and dorsal cap in 5 patients. The total graft volume was between 0.25 and $0.5 \mathrm{cc} /$ per patient. The nasal dorsum height, symmetry, contour, and dorsal esthetic lines were evaluated using standardized preoperative and postoperative photographs. Dorsal asymmetry, overcorrection of the dorsal height or residual hump were not observed in 17 of the patients (Figures 1-4). Only 1 patient had a visible irregularity of the dorsum. Physical examination revealed palpable irregularities in 3 patients. None of the patients required surgical revision for residual or iatrogenic dorsum deformity.

\section{Discussion}

Asymmetries and irregularities of the upper one-third of the nose, lead to poor esthetic outcomes, and secondary revision surgeries. To treat open roof after hump resection; lateral osteotomies, spreader grafts, flaps and camouflage grafts are commonly used. Warping, resorbtion and migration, visibility, limited volume, donor site morbidity, and the risk of infection are the main disadvantages of grafts. Öreroğlu et al. have presented their technique of using diced cartilage combined with bone dust and blood. ${ }^{4}$ Tas have reported results with harvesting bone dust with a rasp and using this for dorsal camouflage. ${ }^{5}$ The disadvantages of harvesting with a rasp were difficulty with collecting dust from the teeth of the rasp and losing a certain amount of graft material during the harvest. With using Micross, a harvested graft is collected in the chamber, thereby the risk of losing the graft material is resolved. Replacing "like with like" tissue concept is important, therefore the reconstruction of a bone gap can be achieved successfully with bone grafts. To limit the donor site morbidity, we prefer to harvest bone from the dorsal cap, which was preoperatively planned to be resected. The preference of lateral osteotomy lines as the donor site facilitates osteotomies by thinning the bone. The device allows us to effectively harvest the bone under reduced surgical exposure. Simultaneous harvest and ostectomy contributes to a reduced operative time. Operative cost is relatively low in 


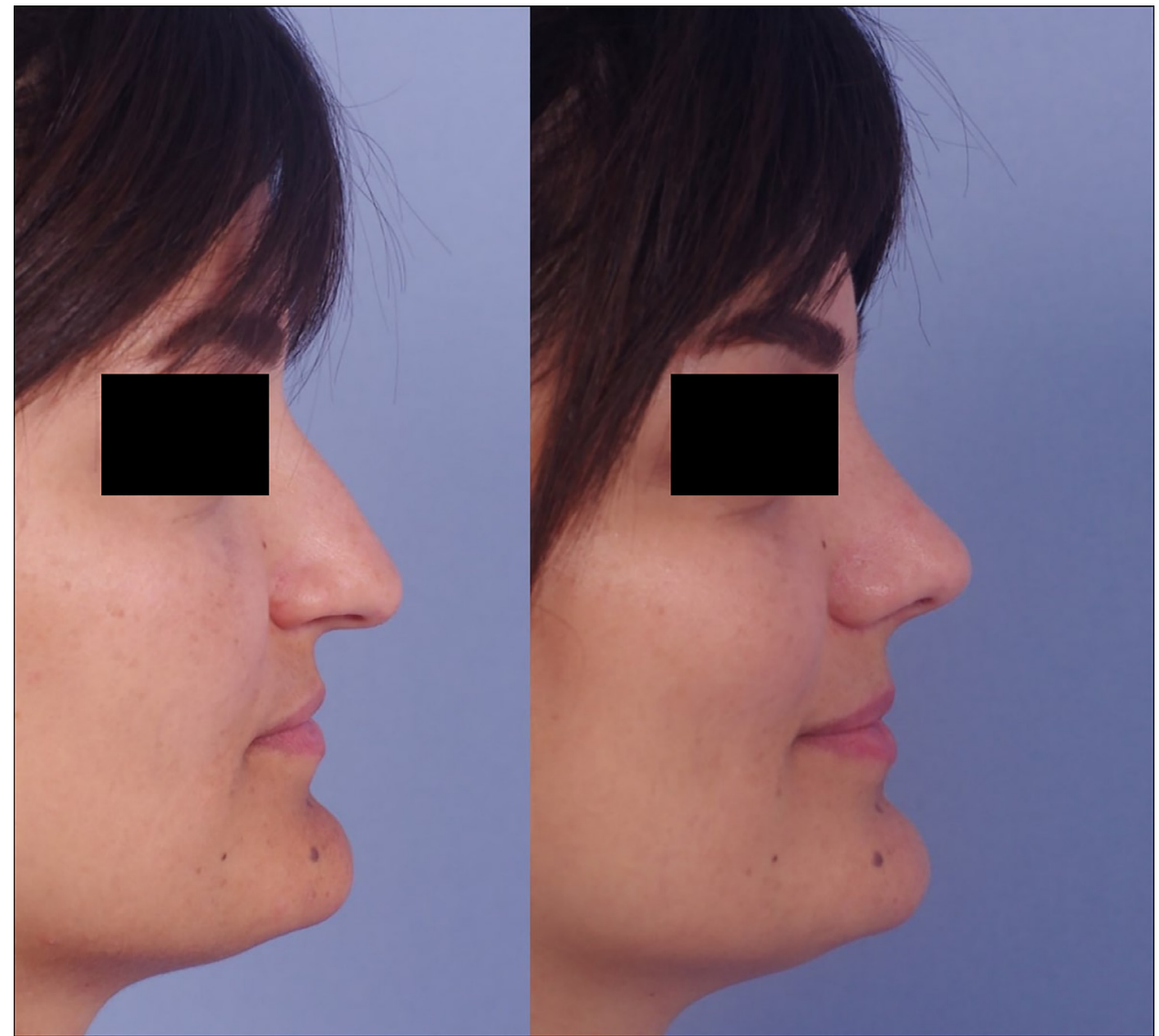

Figure 1 Preoperative lateral photograph (left) of the 27-year-old patient who underwent closed rhinoplasty with bone dust graft material for dorsal camouflage. Postoperative photograph (right) at 1 year shows no visible irregularity.

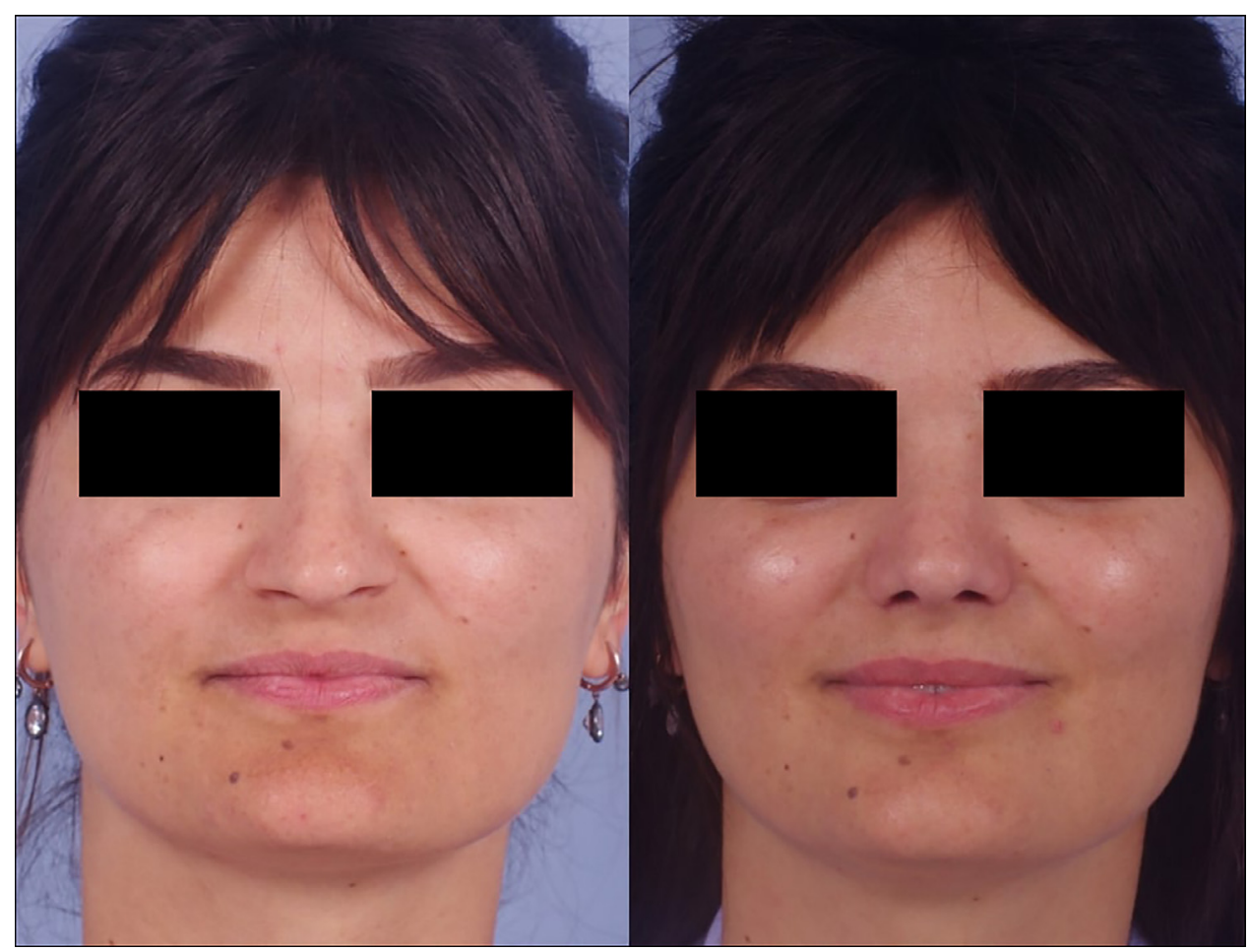

Figure 2 Preoperative (left) and 1 year postoperative anteroposterior photographs (right) of the patient shown in Figure 1. 


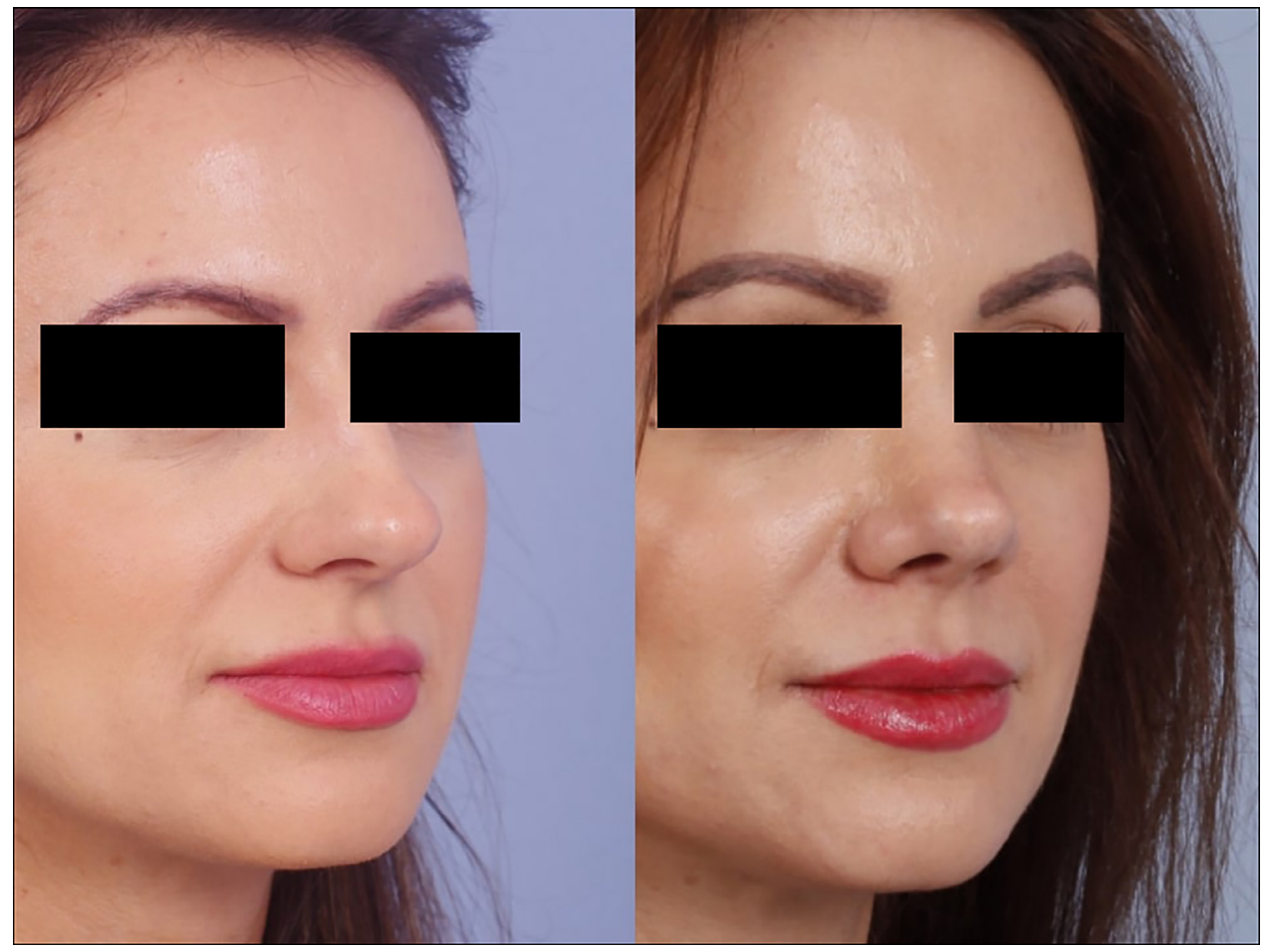

Figure 3 Preoperative oblique photograph (left) of the 30-year-old patient who underwent closed rhinoplasty with bone dust graft material for dorsal camouflage. 1 year postoperative photograph (right) of the patient without evidence of visible irregularities.

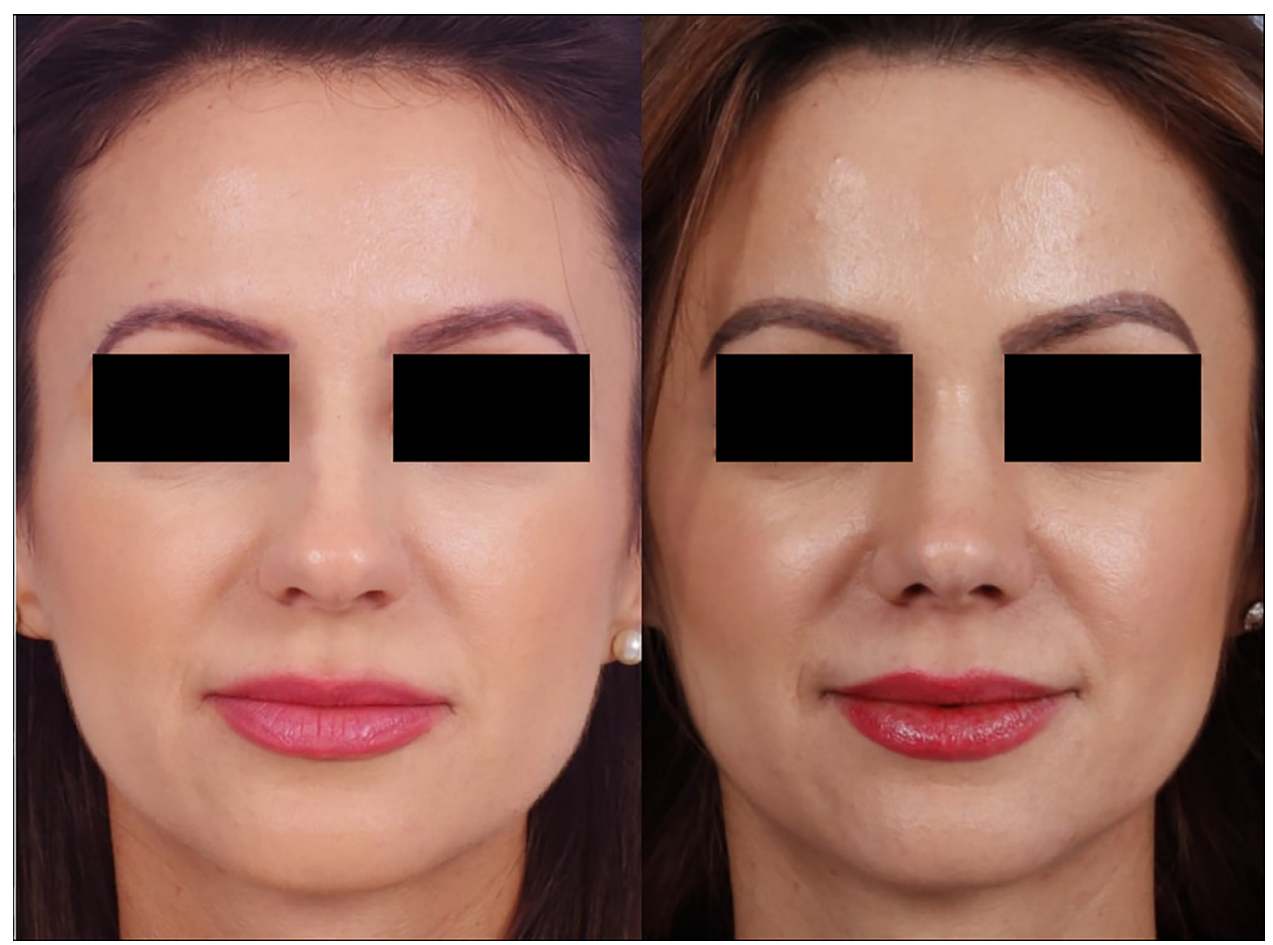

Figure 4 Preoperative (left) and 1 year postoperative (right) anteroposterior photographs of the patient shown in Figure 3. 
comparison with alloplastic materials. In this series, we did not experience resorbtion, migration, visibility problems, or infection with bone grafts.

\section{Conclusion}

A new practical, safe, and efficient tool for rhinoplasty was introduced. Graft material was successfully used for smoothing the bony dorsum without any significant complications.

\section{Funding}

None.

\section{Ethical approval}

Not required.

\section{Financial disclosure statement}

The authors have no financial disclosure or conflict of interest to declare in relation to the content of this article. No funding was received for this article.

The work is attributed to Ozan Bitik, M.D. (Private Practice of Plastic, Reconstructive and Aesthetic Surgery in Ankara, Turkey)

\section{Declaration Competing of Interest}

The authors have no financial or personal relationships with other people or organizations, which could inappropriately influence the work in this study. The authors have no financial disclosure or conflict of interest to declare in relation to the content of this article. No funding was received for this article.

\section{Supplementary materials}

Supplementary material associated with this article can be found, in the online version, at doi:10.1016/j.bjps.2020.02. 034.

\section{References}

1. Lee $M$, Zwiebel S, Guyuron B. Frequency of the preoperative flaws and commonly required maneuvers to correct them: a guide to reducing the revision rhinoplasty rate. Plast Reconstr Surg 2013;132(4):769-76.

2. Baker TM, Courtiss EH. Temporalis fascia grafts in open secondary rhinoplasty. Plast Reconstr Surg 1994;93(4):802-10.

3. Erol 00. The Turkish delight: a pliable graft for rhinoplasty. Plast Reconstr Surg 2000;105(6):2229-41 discussion 42-3.

4. Öreroğlu AR, Çakır B, Akan M. Bone dust and diced cartilage combined with blood glue: a practical technique for dorsum en hancement. Aesthetic Plast Surg 2014;38(1):90-4.
5. Tas $\mathrm{S}$. The use of bone dust to correct the open roof deformity in rhinoplasty. Plast Reconstr Surg 2018;142(3):629-38.

Gokhan Sert

Department of Plastic Surgery, China Medical University Hospital, Taichung City, Taiwan

Ozan Bitik Private Practice in Plastic Surgery, Ankara, Turkey Ibrahim Vargel Department of Plastic Reconstructive and Aesthetic Surgery, Hacettepe University Faculty of Medicine, Ankara, Turkey

E-mail address: drgokhansert@gmail.com (G. Sert)

(c) 2020 British Association of Plastic, Reconstructive and Aesthetic Surgeons. Published by Elsevier Ltd. All rights reserved.

https://doi.org/10.1016/j.bjps.2020.02.034

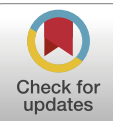

Dear Sir,

Early diagnosis of wound infections is crucial as they have been shown to increase patient morbidity and mortality. Hence, it is important that such infections are detected early to guide decision-making and management 1 . Currently, the most common methods of identifying wound infection is by clinical assessment and semi-quantitative analysis using wound swabs. Bedside assessment is subjective, and it is shown that bacterial infection can often occur without any clinical features. On the other hand, swabs have the disadvantages of missing relevant bacterial infection at the periphery of the wound due to the sampling technique as well as delaying diagnostic confirmation which may lead to a change in the bioburden of the wound. Although tissue biopsy is the gold standard diagnostic tool, it is seldom used as it is invasive, has a higher technical requirement and is also more expensive. A hand-held and portable point-of-care fluorescence imaging device (MolecuLight $\mathrm{i}: \mathrm{X}$ imaging device, MolecuLight, Toronto, Canada) was introduced to address the limitations of the other diagnostic methods 2. This device takes advantage of the fluorescent properties of certain by-products of bacterial metabolism such as porphyrin and pyoverdine. When excited by violet light (wavelength $405 \mathrm{~nm}$ ), porphyrins will emit a red fluorescence whereas pyoverdine has a cyan/blue fluorescence. The types of bacteria that produce porphyrins include S. aureus, E. coli, coagulase-negative staphylococci, beta-hemolytic streptococci and others whereas pyoverdine

Meetings presented: The findings of this study were presented at the BAPRAS Winter Scientific Meeting 2019 as a poster presentation. 
Autofluorescence imaging results for patients with wound infection diagnosed using wound swabs

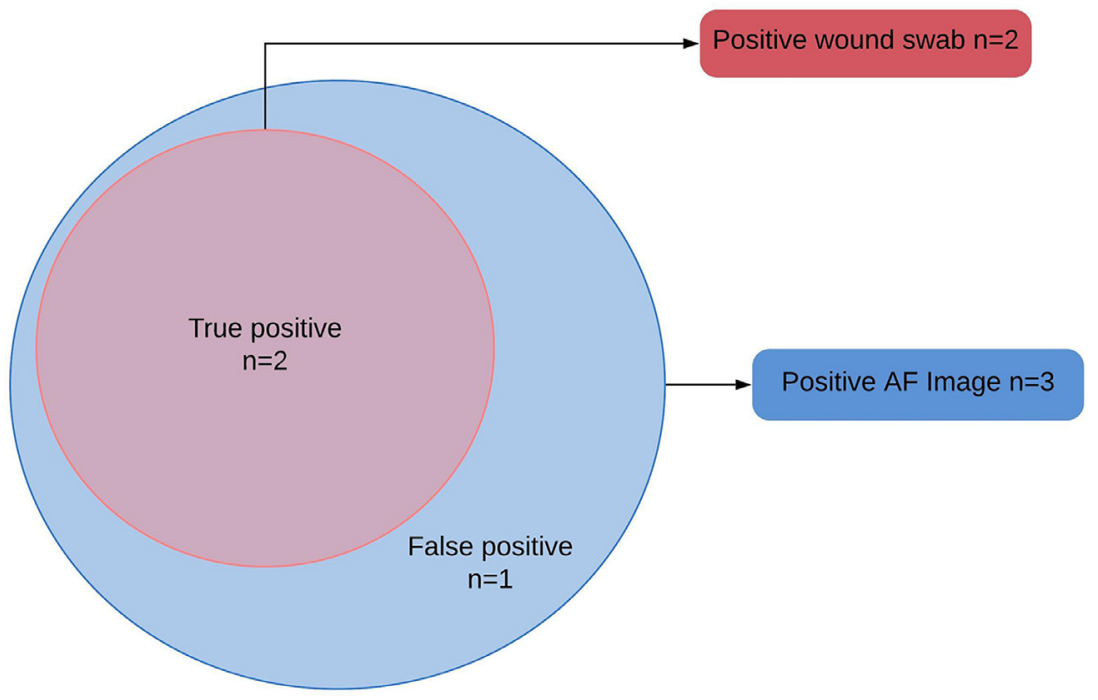

Fig. 1 Venn Diagram illustrating the autofluorescence imaging results for patients with wound infection diagnosed with semiquantitative analysis using wound swabs.

which emits cyan fluorescence is specific to Pseudomonas aeruginosa. This allows users to localise areas of bacterial colonisation at loads $\geq 10^{4}$ amongst healthy tissue which instead emits green fluorescence 3 . The benefits of this device are that it is portable, non-contact which means minimising cross-contamination, non-invasive and it provides real-time localization of bacterial infection. All these features allow it to be a useful tool to aid diagnosis and guide further investigation and management.

Many previous studies that have examined the efficacy of auto fluorescent imaging in diagnosing infections in chronic wounds $3-5$. However, equally important is identifying infections in acute wounds which will help guide antimicrobial management as well as surgical debridement. Often, broad-spectrum antibiotics are given where clinical assessment remains inconclusive. This, however, may lead to an increase in antimicrobial resistance. Therefore, the use of Moleculight $\mathrm{i}: \mathrm{X}$ to identify infections in acute open wounds in hand trauma was evaluated.

We collected data from patients who attended the hand trauma unit over a 4-week period prior to irrigation and/or debridement. Wounds were inspected for clinical signs of infection and autofluorescence images were taken using the Moleculight i:X device. Wound swabs were taken, and the results of these interpreted according to the report by the microbiologist. Autofluorescence images were interpreted by a clinician blinded to the microbiology results.

31 patients were included, and data collected from 35 wounds. 3 wounds $(8.6 \%)$ showed positive clinical signs of infection, $3(8.6 \%)$ were positive on autofluorescence imaging and $2(5.7 \%)$ of wound swab samples were positive for significant infection. Autofluorescence imaging correlated with clinical signs and wound swab results for 34 wounds (97.1\%). In one case, the clinical assessment and autofluorescence imaging showed positive signs of infection but the wound swabs were negative.
To the best of our knowledge, this is the first time the use of autofluorescence imaging in an acute scenario was investigated. In this study, out of 2 of the wound swab samples that were positive, autofluorescence imaging correctly identified both (100\%) (Fig. 1). One of the autofluorescence images which showed red fluorescence on the wound and which was clinically identified as infected showed growth of usual regional flora on microbiological studies. The reason behind this could be due to the method of sampling from the centre of the wound. On autofluorescence image, the areas of significant bacterial growth were on the edges of the wound (Fig. 2). This example illustrates the potential of using autofluorescence imaging to guide more accurate wound sampling. This has also been shown in a non-randomised clinical trial performed by Ottolino-Perry et al. 4. From a surgeon's perspective, autofluorescence imaging can guide surgical debridement by providing real-time information of the infected areas of the wound. Furthermore, because of its portability, this device can also be used in intra-operative scenarios to provide evidence of sufficient debridement.

Although easy to use, the requirement for a dark environment causes a logistical problem. The manufacturers have realised that this is a limitation of the device and have created a single-use black polyethene drape called "DarkDrape" which connects to the Moleculight $\mathrm{i}: \mathrm{X}$ using an adapter to provide optimal conditions for fluorescence imaging. While autofluorescence imaging can help clinicians to decide whether to start antibiotics or not, it does not provide any information on the sensitivities of the bacteria. Another limitation with autofluorescence imaging we encountered in our study is the difficulty with imaging acute bleeding wounds where blood shows up as black on fluorescence and therefore may mask any underlying infection.

In conclusion, autofluorescence imaging in acute open wounds may be useful to provide real-time confirmation of wound infection and therefore guide management. 


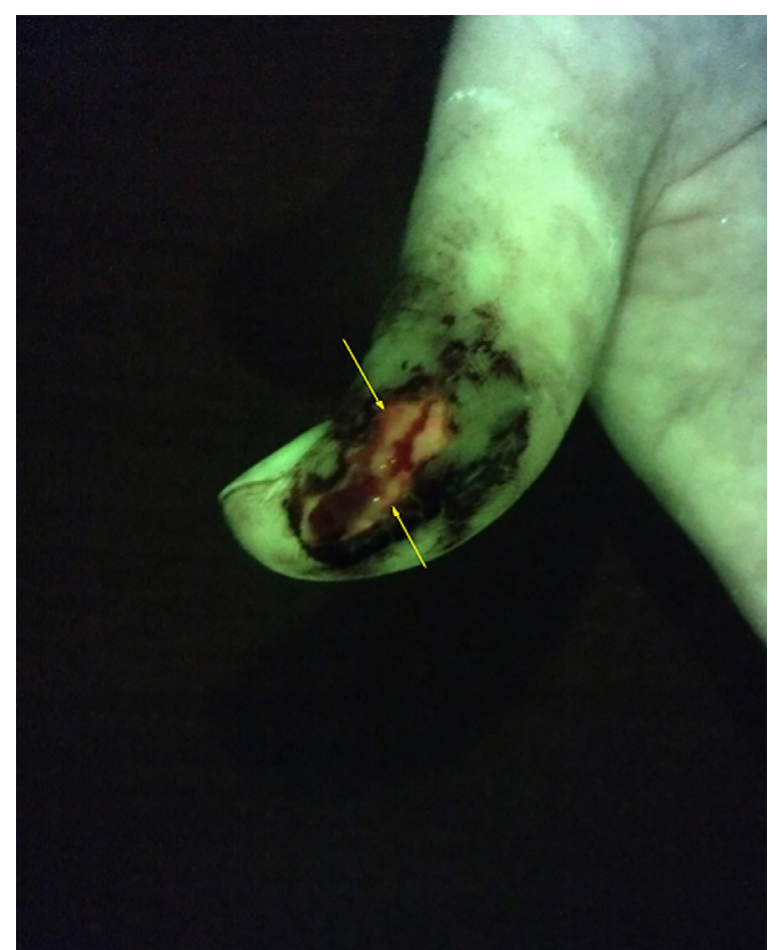

Fig. 2 Autofluorescence image of the wound from a patient showing red fluorescence on the edges of the wound (arrow) indicative of significant levels of infection.

\section{Declaration of Competing Interest}

None declared.

\section{Funding received}

None received.

\section{Supplementary materials}

Supplementary material associated with this article can be found, in the online version, at doi:10.1016/j.bjps.2020.03. 004.

\section{References}

1. Bowler PG, Duerden BI, Armstrong DG. Wound microbiology and associated approaches to wound management. Clin Microbiol Rev 2001;14(2):244-69. doi:10.1128/CMR.14.2.244-269.2001.

2. MolecuLight Inc. MolecuLight i:x user manual. Moleculight Web site. https://moleculight.com/wp-content/uploads/2018/05/ PN_1294_MolecuLight_iX_User_Manual_Rev_1.0_English.pdf. Accessed 26 February 2019.

3. Blumenthal $E$, Jeffery SLA. The use of the MolecuLight $i: X$ in managing burns: a pilot study. J Burn Care Res 2018;39(1):154 61 [doi]. doi:10.1097/BCR.0000000000000565.

4. Ottolino-Perry K, Chamma E, Blackmore KM, et al. Improved detection of clinically relevant wound bacteria using autofluorescence image-guided sampling in diabetic foot ulcers. Int Wound J 2017;14(5):833-41 [doi]. doi:10.1111/iwj.12717.
5. Blackshaw EL, Jeffery SLA. Efficacy of an imaging device at identifying the presence of bacteria in wounds at a plastic surgery outpatients clinic. J Wound Care 2018;27(1):20-6 [doi]. doi:10.12968/jowc.2018.27.1.20.

Bryan J.W. Chew*, Michelle Griffin, Peter E Butler, Ash Mosahebi

Division of Surgery and Interventional Science, University College London, United Kingdom

Department of Plastic Surgery, Royal Free Hospital, London, United Kingdom

*Corresponding author at: Division of Surgery and Interventional Science, University College London, Royal Free Hospital, 9th Floor (East), 2QG, 10 Pond St, London NW3 2PS, United Kingdom.

E-mail address: bryanjwchew@gmail.com (B.J.W. Chew)

(C) 2020 British Association of Plastic, Reconstructive and Aesthetic Surgeons. Published by Elsevier Ltd. All rights reserved.

https://doi.org/10.1016/j.bjps.2020.03.004

\section{Publication rates from BAPRAS meetings: where are we now?}

Dear Sir,

Long has the term 'publish or perish' been considered medical doctrine and this has historically been a prerequisite for progression in research-driven specialties such as plastic surgery. National, or indeed international, presentation is pivotal to disseminating information, but also provides a stepping-stone to future publications. In the UK, BAPRAS meetings have always represented the ideal platform for this. Of significant interest is the conversion of accepted abstracts into peer-reviewed publications.

Previous studies ${ }^{1,2}$ have assessed abstract publication for BAPRAS meetings and have shown a declining conversion rate. We re-assessed this in order to establish whether this reported downtrend is continuing and how plastic surgery compares to other specialties.

All abstracts from BAPRAS meetings between Winter 2014 and Summer 2016 were analysed. Later meetings were excluded to allow adequate lag time for publication. Abstracts were identified retrospectively from conference programmes accessible via the BAPRAS website (www.bapras. org.uk). PubMed (https://www.ncbi.nlm.nih.gov/pubmed/) and Google Scholar (https://scholar.google.com/) databases were used to search for full publications. Cross-referencing of published papers with abstracts for content was completed to ensure matched studies.

Abstracts published prior to the conference date were excluded. Two-tailed $t$-testing was used to assess for statistical significance between variables. 


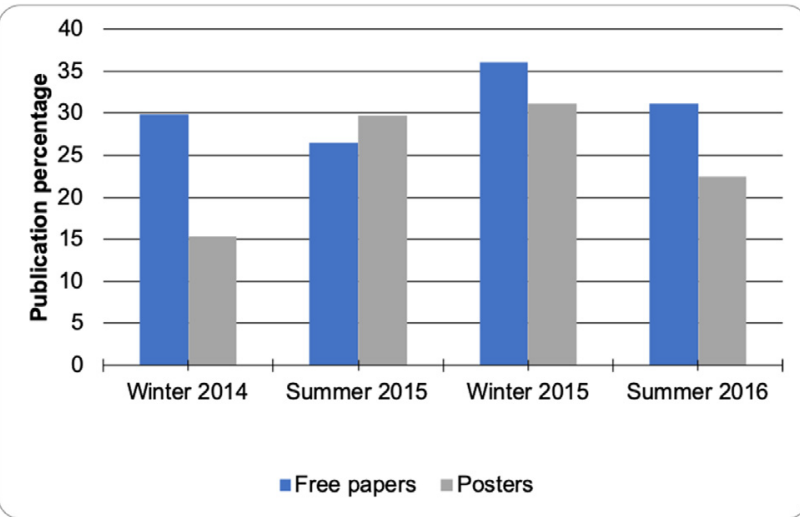

Figure 1 Breakdown by meeting for publications rates of free papers and posters.

A total of 500 abstracts were presented at four meetings between Winter 2014 and Summer 2016. This consisted of 250 free papers and 250 posters. Of note, the Summer 2015 meeting included 7 (of 123) Belgian Society abstracts. The average publication rate across all meetings was $28.4 \%$, with the breakdown for each meeting shown in Figure 1.

Average time to publication was 16.8 months. Comparing free papers versus posters, we noted no significant difference in time to publication $(17.5 \mathrm{~m} \vee 15.1 \mathrm{~m}, p=0.12)$, however the publication rate was $30.9 \%$ vs $24.7 \%$ respectively. The most common publication journal was the Journal of Plastic, Aesthetic and Reconstructive Surgery (JPRAS) (34\%). Other journals included Plastic and Reconstructive Surgery (8.5\%), Burns (4.9\%), Annals of Plastic Surgery (3.5\%), European Journal of Hand Surgery (2.8\%) and multiple others (all <2.5\%).

When compared with the two previously published studies, publication rates have improved from 2007 and have not continued to decline.

Interestingly, the number of publications in JPRAS has fallen. This may be explained by a rise in the impact factor of the journal, increasing competitiveness for publications as well as an expansion in the number of surgical journals.

We observed that journal impact factor for free paper publications was significantly greater and likely reflects the stringency of the BAPRAS abstract vetting process. Comparison with other specialties is inherently difficult, primarily due to differences in study design and inclusion criteria. Exclusion of posters, inclusion of abstracts published prior to presentation and studies not referenced in PubMed affect the reported publication rates. A large meta-analysis, assessing publication of abstracts, reported rates of $44 \%{ }^{3}$ Rates from other specialties are shown in Figure 2. Although our figures of close to $30 \%$ may seemingly rank low versus other specialties, including abstracts published prior to presentation would increase the publication rate to $39 \%$, therefore making it more comparable. However, this would not be a direct comparison to the two previous BAPRAS studies.

One may debate that the academic value of a meeting should be judged upon its abstract publication ratio. However, the definition of a publication is itself clouded, with an increasing number of journals not referenced in the previous 'gold standard' of PubMed, including a number of open

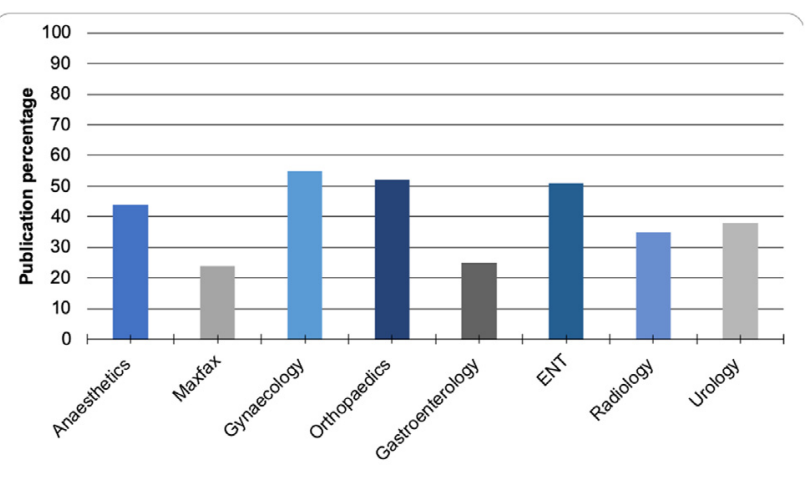

Figure 2 Comparison with other specialities.

access journals. ${ }^{4}$ Most would still argue the importance of stringent peer review as the hallmark of a valuable publication $^{5}$ and perhaps this along with citability should remain the benchmark.

In an age where publications are key components of national selection and indeed lifelong progression in many specialties, we must ensure that some element of quality control remains so as not to dilute production of meaningful data.

We have been able to reassess the publication rates for the primary meeting of UK plastic surgery. The BAPRAS meeting remains a high-quality conference providing a platform to access the latest advances in the field. Significant differences in the methodology of available literature make other speciality comparisons challenging. However, when these are accounted for publication rates are similar.

Within a wider context, with the increase in open access journals, it has become ever more difficult to define a 'publication'. If publication rate is to be used as a surrogate for meeting quality, then only abstracts published after the date of meeting should be included. In order to continually assess the quality of papers presented at BAPRAS meetings, the conversion to publication should be regularly re-audited.

\section{Declaration of Competing Interest}

None.

\section{Acknowledgments}

None.

\section{Funding}

None.

\section{References}

1. Oliver DW, Whitaker IS, Chohan DPK. Publication rates for abstracts presented at the British Association of Plastic Surgeons 
meetings: how do we compare with other specialties? Br J Plast Surg 2003;56(2):158-60.

2. Kain N, Mishra A, McArthur P. Are we still publishing our presented abstracts from the British Association of Plastic and Reconstructive Surgery (BAPRAS)? J Plast Reconstr Aesthet Surg 2010;63(9):1572-3

3. Scherer RW, Langenberg P, von Elm E. Full publication of results initially presented in abstracts. Cochrane Database Methodol Rev 2005;2.

4. Van Noorden R. The true cost of science publishing. Nature 2013;495:426-9.

5. Bartholomew RE. Science for sale: the rise of predatory journals. $J$ R Soc Med 2014;107(Oct (10)):384-5.

Z. Vinnicombe

K.S. Johal

P. Roblin

P-N. Mohanna

Department of Plastic and Reconstructive Surgery, St. Thomas' Hospital, Westminster Bridge Road, London, SE1 7EH, United Kingdom E-mail address: zak.vinnicombe@nhs.net (Z. Vinnicombe)

(C) 2020 British Association of Plastic, Reconstructive and Aesthetic Surgeons. Published by Elsevier Ltd. All rights reserved.

https://doi.org/10.1016/j.bjps.2020.02.046

\section{Healthcare sustainability - The bigger picture}

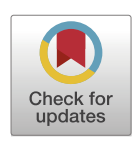

\section{Dear Sir,}

Global environmental impact and sustainability has been a heated topic in the recent years. Plastics and singleuse items are widely, and perhaps unnecessary, used in the healthcare sector. Various recent articles ${ }^{1,2}$ discuss the negative impacts of this in the surgical world, but can we look at the NHS sustainability as a bigger picture?

Whilst it is a positive step to be considering how we can reduce the environmental impact of modern operating practice, it risks falling into the trap of being overly focused and not taking an holistic view of how the health service as a whole can become more environmentally focused and reduce costs.

In fact, the operating theatre is one of the more difficult places to make change. Single use medical devices seem like an obvious item to replace with a more environmentally friendly re-usable alterative, but what about patient safety? Such a change would require the implementation of new workflows and supervision structures to make sure patient safety is maintained. These take time to create, will meet resistance in their design and implementation, and may not ultimately be adopted.

In order to overcome these challenges, we must take a holistic view of the hospital environment - doing this reveals numerous opportunities for improvement with minimal impact on patient safety.

The NHS incurs significant waste through using energy unnecessarily. Some examples are readily visibly working in a hospital for a just few weeks: computers are left on standby through the night and at weekend; lights are left on throughout the night; and empty rooms are heated or cooled when left unoccupied. Other sources of energy waste are less visible, but it is likely that some machinery (particularly air conditioning units) would show rapid return on investment through energy savings if they were replaced on a more regular basis.

In the past, saving energy would have required a sustained campaign to educate staff and still be subject to the vagaries of human management (forgetting to switch the heating off on a Friday night could lead to more than two days of wasted energy if not revisited until Monday). Today, solutions based on Internet of Things (IOT) technology can use sensors to monitor the environment and take action to reduce consumption. With the use of Al and machine learning, these systems are becoming advanced such that they can even monitor and anticipate energy usage allowing rooms to be heated or cooled at times which mean that when staff arrive in the relevant room it is the ideal temperature. The NHS is starting to use such technology, with Wigan Hospital as the first example to install intelligent lighting. ${ }^{3}$

Adoption should not be limited to lighting, however, and the NHS needs to adopt best practice from the commercial sector. For example, SensorFlow based in Singapore, provide an intelligent system that optimises cooling/heating costs for hotels around South East Asia, saving the operators up to $40 \%$ in energy costs. ${ }^{3,4}$ Without doubt, these systems can also apply to hospital infrastructures and can help the NHS further reduce energy consumption.

In addition to reducing energy consumption, the reduction of single use plastics has become a key focus in recent years and the NHS has started to address this issue. At least 196 million single use plastic items were purchased by the NHS last year. ${ }^{5}$ The target to phase out plastic items used by retailers in the next 12 months is laudable, however there is also a significant amount of disposable plastic items used in staff coffee rooms and hospital canteen. Getting rid of such items completely and encourage staff to use reusable coffee cups and metal cutlery can potentially compound the cost-saving and environmental benefits.

The NHS has established an early leadership position tackling environmental challenges - the first European intelligent lighting installation and ambitious targets to cut disposable plastic items - but more needs to be done. To maximise impact, the NHS needs to be seen as a whole (not by department) with the most senior executives in the health service driving national level change.

\section{References}

1. Rizan C, Mortimer F, Stancliffe R, Bhutta MF. Plastics in healthcare: time for a re-evaluation. $J$ R Soc Med 2020;113(2):49-53. doi:10.1177/0141076819890554.

2. Winter G. Green theatre [Internet]. 2019 [cited 23 December 2019]. Available from: https: / / publishing.rcseng.ac.uk/doi/ full/10.1308/rcsbull.2019.272. 
3. Graham C. Wigan's hospital organisation is first health trust in Europe to install intelligent lighting [Internet]. Wigantoday.net. 2019 [cited 23 December 2019]. Available from: https:// www.wigantoday. net/health/wigan-s-hospital-organisation-isfirst-health-trust-in-europe- to-install-intelligent-lighting-110092220.

4. Tan J. SensorFlow provides smart energy management for hotels in Malaysia [Internet]. Digital News Asia 2019. [cited 23 December 2019]. Available from https://www.digitalnewsasia. com/startups/sensorflow-provides-smart-energy-managementhotels-malaysia.

5. NHS bids to cut up to 100 million plastic straws, cups and cutlery from hospitals [Internet]. 2019 [cited 23 December 2019]. Available from: https://www.england.nhs.uk/2019/10/ nhs-bids- to-cut-up-to-100-million-plastic-straws-cups-andcutlery-from-hospitals/.

M. Ip

Department of Plastic Surgery, Wexham Park Hospital, Frimley Health NHS Foundation Trust, United Kingdom E-mail address: minaip@doctors.org.uk (M. Ip)

Crown Copyright $\odot 2020$ Published by Elsevier Ltd on behalf of British Association of Plastic, Reconstructive and Aesthetic Surgeons. All rights reserved.

https: / / doi.org/10.1016/j.bjps.2020.02.035

\section{Letter to the editor: Healthcare sustainability: The bigger picture}

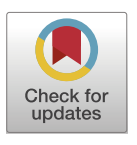

Dear Sir,

We read with interest the recent article 'Healthcare sustainability - the bigger picture'. ${ }^{1}$ The wider picture of the NHS environmental impact and sustainability clearly needs to be addressed. However, large-scale improvement projects to hospital buildings, such as intelligent lighting and heating systems, are likely to require huge investment in infrastructure and modernisation that the NHS in its current form is unfortunately unlikely to be able to make. We believe that the field of medical academia should similarly be contributing to environmental sustainability.

Firstly, the shelves of hospital libraries and offices internationally are lined with print copies of journals. We reviewed the 20 surgical journals with the highest impact factors and found that all were still offering the option of a subscription of print copies, with 19 of these printing monthly issues. ${ }^{2}$ Consumers are able to access all journals electronically through institutional subscriptions or via the NHS OpenAthens platform, which in our view is a more time-efficient way to search for articles, read them and to reference them. As such, we commend JPRAS for their recent move to online-only publication. Additionally, with the increasing use of social media to discuss research and the creation of visual abstracts for articles to encourage readership, this will be likely to encourage this shift further.

Secondly, the environmental impact of the current academic conferencing culture must be addressed. By the end of training, a UK surgical trainee spends an average of £5411 attending academic conferences, but beyond this personal expenditure, what is the environmental cost? ${ }^{3}$ For each conference we attend, the printing of poster presentations, conference programmes and certificates all detrimentally impact our environment. Furthermore, consider the conference sponsor bags we receive, filled with further printed material, plastic keyrings, stress-balls and disposable pens, all contributing to the build-up of plastic in our oceans. ${ }^{4}$ Conferences, such as the British Association of Plastic and Reconstructive Surgeons Scientific Meeting, have now started using electronic poster submissions, with presentations being held consecutively on large television screens - but further measures are possible. A well-designed conference smartphone app forgoes the need for printed programmes and leaflet advertising from sponsors and could include measures to reduce the carbon footprint, such as promotion of ride-share options for venue travel.

The concept of virtual conferences has also been explored. Organisers of an international biology meeting recently asked psychologists to assess the success of a parallel virtual meeting, with satellite groups organising local social events afterwards. More than $80 \%$ of the delegates joined online and there was an overall $10 \%$ increase those attending the conference; a full analysis of the success of this approach to conferences is awaited. ${ }^{5}$ Virtual conferences may enable delegates to sign in from multiple time zones and minimise travel, disruption of clinical commitments and time away from family. This option is being pursued by the Reconstructive Surgery Trials Network (RSTN) in the UK, whereby the annual scientific meeting will be delivered using teleconferencing technology at four research active hubs across the UK, reducing delegate travel substantially and the conference's carbon footprint in turn.

There is a clear but unmeasurable benefit of networking face-to-face for formation of personal connections, exchange of knowledge and opportunities for collaboration. The use of social media, instant messaging applications and modern teleconferencing technology are vital to retain this valuable aspect of academic conferencing. Equally, perhaps there is a balance to be found, with societies currently holding biannual meetings moving to include one virtual, or running a parallel virtual event for those travelling long distances. The academic community must play a role in environmental sustainability by reducing the carbon footprint of our journals and conferences.

\section{Funding statement}

JCRW is funded by the National Institute for Health and Research (NIHR) as an Academic Clinical Fellow. None for completion of submission.

\section{Declaration of Competing Interest}

None. 


\section{References}

1. Ip M. Healthcare sustainability - the bigger picture. J Plast Reconstruct Aesthet Surg 2020 [In Press].

2. Surgical journal impact factors 2020. https://impactfactor. weebly.com/surgery.html [Accessibility verified 20 March 2020]

3. O'Callaghan J, Mohan HM, Sharrock A, et al., on behalf of the Council of the Association of Surgeons in Training Cross-sectional study of the financial cost of training to the surgical trainee in the UK and Ireland. BMJ Open 2017;7:e018086.

4. Jambeck JR, Geyer R, Wilcox C, Siegler T, Perryman M, Narayan R, Law KL. Plastic waste inputs from land into the ocean. Science 2015;347(6228):768-71.

5. Abbott A. Low-carbon, virtual science conference tries to recreate social buzz. Nature 2020;577(7788):13

Abigail V. Shaw*

Department of Plastic and Reconstructive Surgery, John Radcliffe Hospital, Oxford University Hospitals NHS

Foundation Trust, Headley Way, Oxford, United Kingdom

Justin CR. Wormald

Department of Plastic and Reconstructive Surgery, Stoke Mandeville Hospital, Buckinghamshire Healthcare NHS Trust, Mandeville Road, Aylesbury, United Kingdom Nuffield Department of Orthopaedics, Rheumatology and Musculoskeletal Sciences (NDORMS), University of Oxford, Oxford, United Kingdom

${ }^{*}$ Corresponding author. E-mail address: abigail.shaw@nhs.net (A.V. Shaw)

(c) 2020 British Association of Plastic, Reconstructive and Aesthetic Surgeons. Published by Elsevier Ltd. All rights reserved.

https://doi.org/10.1016/j.bjps.2020.03.028
Despite this, satisfaction with autologous reconstruction appears similar across BMI categories. ${ }^{4}$ As the authors discuss, perfusion, as a function of perforator diameter, is of key relevance to the safety of performing autologous breast reconstruction in patients with higher BMI. Larger perforator sizes relative to total flap weight have been suggested to reduce the risk of post-operative flap skin or fat necrosis. ${ }^{5}$ While this is likely an oversimplification, as flap survival will also depend on multiple factors including perforator row compared to abdominal zones harvested, it does suggest that if the high BMI patient group has reliably larger perforators then their risk profile may be reduced.

However, we suggest caution regarding reliance on the correlation they found between BMI or AWT and perforator size when planning free tissue transfer. While they demonstrate $p$ values suggesting correlation between BMI or AWT and perforator diameter, the $r$ (correlation coefficient) values that they determined through Pearson correlation analysis are low, ranging from 0.219 to 0.456 . The resulting $r^{2}$ (coefficient of determination) values are therefore in the range $0.048-0.21$, suggesting that only $4.8-21 \%$ of the variation in perforator diameter can be related to BMI or AWT. It is therefore likely that other variables, such as height and historical abdominal wall thickness, that were not accounted for in the correlation analysis also play roles in determining perforator size, in addition to anatomical variation. In addition, their analysis and results depend on a linear relationship between the variables, which may not be the case.

Therefore although the authors demonstrate a correlation between abdominal wall thickness and perforator size, there is substantial variation between individual patients and so this relationship cannot be relied upon when planning autologous reconstruction.

\section{Funding}

None.

\section{Ethical approval}

None.

\section{Declaration of Competing Interest}

None.

\section{References}

1. Sacher MKR, Wallner C, Wagner JM, et al. Body mass index and abdominal wall thickness correlate with perforator caliber in free abdominal tissue transfer for breast reconstruction. J Plast Reconstr Aesthet Surg 2019;0(0)

2. Scott JR, Sullivan SR, Liu D, et al. Patient body mass index and perforator quality in abdomen-based free-tissue transfer for breast reconstruction. J Reconstr Microsurg 2009;25(4):237-41.

3. O'Neill AC, Sebastiampillai S, Zhong T, Hofer SOP. Increasing body mass index increases complications but not failure rates in microvascular breast reconstruction: a retrospective cohort study. J Plast Reconstr Aesthet Surg 2019;72(9):1518-24.

4. Sinha S, Ruskin O, D’Angelo A, McCombe D, Morrison WA, Webb A. Are overweight and obese patients who receive autologous
Reconstruction in the high BMI patient group can be challenging, and is associated with higher complication rates. ${ }^{3}$ 
free-flap breast reconstruction satisfied with their postoperative outcome? A single-centre study. J Plast Reconstr Aesthet Surg 2016;69(1):30-6.

5. Pennington DG, Rome P, Kitchener P. Predicting results of DIEP flap reconstruction: the flap viability index. J Plast Reconstr Aesthet Surg 2012;65(11):1490-5.

Helen Capitelli-McMahon, John Kiely, Andrew M. Williams Department of Plastic and Reconstructive Surgery, Bradford Teaching Hospitals Foundation Trust, Bradford BD9 6RJ, UK

E-mail address: Helen.Capitelli-McMahon@bthft.nhs.uk (H. Capitelli-McMahon)

(C) 2020 British Association of Plastic, Reconstructive and Aesthetic Surgeons. Published by Elsevier Ltd. All rights reserved.

https://doi.org/10.1016/j.bjps.2020.01.003

\section{Re: The diagnostic effectiveness of dermoscopy performed by plastic surgery registrars trained in melanoma diagnosis}

\section{Dear Sir,}

We read with interest Pescarini's et al. article entitled 'The diagnostic effectiveness of dermoscopy performed by Plastic Surgery Registrars trained in melanoma diagnosis'. ${ }^{1}$ The article is of great interest in highlighting the potential of plastic surgery registrar training in domains such as dermoscopy, especially for those trainees looking to specialise in skin cancer. Training in these experiential skill domains is essential to building a diagnostic framework, and the comparable accuracy in diagnosis to Dermatologists reflects this.

It would be of great benefit to understand further how diagnostic accuracy evolves along the inevitable learning curve experienced using the dermoscope. Pescarini et al. comment briefly on method of training but we believe the timeline is key, as is mentorship and regular appraisal. Terushkin et al. found that for the first year of dermoscopy training benign to malignant ratios in fact increased in trainee dermatologists before going on to decrease ${ }^{2}$ potentially secondary to picking up more anomalies but not yet having the skill set to determine if these are benign or not. There is no reason to suggest that plastic surgery trainees' learning curves should differ significantly. This of course would skew the data presented in terms of accuracy at the end of the three year study period. More helpful would be a demonstration of how accuracy changes with time and experience, as one would expect, and of course how these rates are comparable to those of Dermatologists. This would have implications for training programmes where specific numbers of skin lesions or defined timeframes for skin exposure during training are set as benchmarks for qualification. This is particularly pertinent for UK trainees; the NICE guidelines for Melanoma state that dermoscopy should be undertaken for pigmented lesions by 'healthcare professionals trained in this technique'. ${ }^{3}$ To understand the number of lesions that trainee plastic surgeons have to assess with a dermatosope before their diagnostic accuracy improves - or the time needed to achieve that accuracy might be a key factor for placement duration and numbers required for trainees to become consciously competent dermoscopic practitioners. Reproducible training programmes in this regard are therefore vital.

It must be pointed out that the role of the dermascope for plastic surgeons is likely to be narrower than for our dermatological colleagues. Within the UK, the role of the plastic surgeon is primarily reconstructive, with some subspeciality involvement in diagnosis of melanomas and a range of non-melanomatous skin cancers and skin lesions. The dermoscope is primarily a weapon in the diagnosis of insitu or early melanoma for plastic surgeons where diagnostic certainty is unclear following a referral for consideration for surgical removal. Where doubt remains over a naevus, surgical excision is still the normal safe default. Dermatologists use dermoscopes for a broad range of diagnostic purposes on a wide variety of skin conditions. The familiarity and expertise with this instrument that they garner is therefore not surprising. We must be clear in resource-limited healthcare systems about what our specific roles are as plastic surgeons and how the burden of patient assessment is shared to appropriately deploy our skills within the context of a broader multidisciplinary framework. Accuracy with the dermoscope is essential to safely treating patients in a binary fashion - should the lesion be removed or monitored? Comparison with dermatological expertise is helpful as a guide and dermoscopy has an important diagnostic role for plastic surgeons, but we should not strive to be equivalent in skills to dermatologists with dermascopes at the expense of the development of vital surgical reconstructive skills and excellence throughout plastic surgery training.

\section{Declaration of Competing Interest}

All authors agree to the fact there are no conflicts of interest to declare. No funding was provided for this letter.

\section{References}

1. Pescarini E, De Antoni E, Azzena GP, Vindigni V, Brambullo T. The diagnostic effectiveness of dermoscopy performed by pastic surgery registrars trained in melanoma diagnosis. J Plast Reconst Aesthetic Surg 2019. doi:10.1016/j.bjps.2019.09.032.

2. Terushkin V, Warycha M, Levy M, Kopf AW, Cohen DE, Polsky D. Analysis of the benign to malignant ratio of lesions biopsied by a general dermatologist before and after the adoption of dermoscopy. Arch Dermatol 2010;146(3):343-4. doi:10.1001/ archdermatol.2010.12.

3. NICE Guidelines. Assessing suspected or diagnosed melanoma. https: / / pathways.nice.org.uk/pathways/melanoma\#path=view $\% 3 \mathrm{~A} /$ pathways/melanoma/assessing-suspected-or-diagnosedmelanoma.xml\&content=view-node\%3Anodes-visualisationphotography-and-imaging. [Accessibility verified December 2019]. 
Anna R. Hurley, Kathryn E. Harborough, lan C.C. King Department of Plastic \& Reconstructive Surgery, The Royal Marsden Hospital, Downs Road, Sutton, England

E-mail address: anna.hurley1@nhs.uk (A.R. Hurley)

(c) 2020 British Association of Plastic, Reconstructive and Aesthetic Surgeons. Published by Elsevier Ltd. All rights reserved.

https://doi.org/10.1016/j.bjps.2019.12.012

\section{Response to the comment made on the article "The diagnostic effectiveness of dermoscopy performed by plastic surgery registrars trained in melanoma diagnosis"}

Dear Sir,

We strongly agree with the benefit correlated to understand the learning curve experienced by plastic surgery registrars using the dermoscope. As stated in our article, the limit of our study is its retrospective nature. Moreover, the training and the level of competence differed between the three registrars. At the beginning of the data collection, two of them were at their third year of specialist training and were using dermoscope since at least one year while the other one was at his first year. All the registrars attended specific but different dermoscopy courses and all of them completed a $10 \mathrm{~h}$ on site training with a competent consultant. For this reason, the expertise partially differed among the three registrars. Nevertheless, we believe a 3 years' period should be long enough to truly homogeneously estimate the accuracy in diagnosis of melanoma by them. In fact, Townley et al. ${ }^{1}$ demonstrate the attendance of the First International Dermoscopy for Plastic Surgeons, Oxford, improved the accuracy of diagnosing malignant skin lesions by dermoscopy rather than using naked eye examination. We believe a well-planned prospective study should be of great benefit in term of planning a reproducible dermoscopy plastic surgery-oriented training program. This could help to estimate when a clinician can be considered as competent dermoscopic practitioner. It should be underlined as learning how to use dermoscope is something is not possible to do from time to time but it need effort and self-study. We believed is important to properly plan a formal training in dermoscopy for all the plastic surgery registrars who will use this tool in their practice. Vahedi et al. ${ }^{2}$ stated, as per their survey, only one of $53 \%$ of the plastic surgery trainees that used dermoscope in their practice had formal training. As all trainees perform outpatient appointments dealing with skin lesions, especially for trainees looking to specialize in skin cancer, we believed the expertise gained through specific course and training is not at expense of the development of surgical reconstructive skills, but instead it can lead improvement in performing outpatient appointment. Proper use of dermoscope will make the skin cancer specialized plastic surgeon more confident and truthful if not in detecting melanoma at least in leaving evident benign lesions. Keeping always in mind a multidisciplinary approach and a close cooperation between dermatologists and plastic surgeon is of paramount importance in skin cancer treatment.

\section{Declaration of Competing Interest}

There is no conflict of interest for all of the authors.

\section{References}

1. Townley WA, Cassell OC, Bowling J. Dermoscopy-time for plastic surgeons to embrace a new diagnostic tool? J Plast Reconstr Aesthet Surg 2011;64(10):1386-7 Epub 2011 Jun 29. doi:10.1016/j. bjps.2011.06.007.

2. Vahedi A, Javed MU, Gorse SH. The use of dermatoscopy amongst plastic surgery trainees in the United Kingdom. J Plast Reconstr Aesthet Surg 2015 May;68(5):e111-e112 Epub 2015 Feb 3. doi:10.1016/j.bjps.2015.01.016.

Elena Pescarini

Eleonora De Antoni

Gian Paolo Azzena

Vincenzo Vindigni

Franco Bassetto

Tito Brambullo

Clinic of Plastic and Reconstructive Surgery, Neuroscience Department, University of Padua, Via Giustiniani 2,

Padova 35128, Italy

E-mail address: elena.pescarini@gmail.com (E. Pescarini)

(c) 2020 British Association of Plastic, Reconstructive and Aesthetic Surgeons. Published by Elsevier Ltd. All rights reserved.

https://doi.org/10.1016/j.bjps.2020.02.052

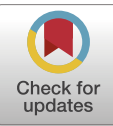
injection after lower blepharoplasty"

Dear Sir,

As the author mentioned in this publication, the correction of infra-orbital groove by microfat injection did increase the postoperative satisfaction of lower 
blepharoplasty surgery ${ }^{1}$. In this study, we want to explore whether this procedure can replace the previous fat pad transposition. Months after the microfat injection, we have observed that fat continues to be present but its volume gradually disappears, and, with some, it totally vanishes. With fat pad transposition, the fat volume does not decrease, it seems that both have their advantages and disadvantages because the volume of transplanted fat after lower blepharoplasty might disappear gradually by time. Survival of transposed fat through fat pad transposition is the best, creating a more natural look at the tear trough. However, the volume of augmentation might not be enough.

It would be exceptional if we could combine both advantages; that is, to administer microfat injection after fat transposition. But prior to that, we would like to share the experience of the author. The fat pad is usually transposed to periosteum by two limits: one is the transposition of the medial fat pad to the inner groove and the other one is the transposition of the central fat pad to the center of the infra-orbital groove. As mentioned by the author, we fill the superficial layer (under the skin) and the periosteum layer (deep layer). Injection into the deeper layer is not performed after lower blepharoplasty but before the musculocutaneous flap was closed. After fat pad transposition is completed, we would first cover up the musculocutaneous flap before asking the patient to sit up. Then, the surgeon assesses whether a further filling of the groove with the fat is needed or not. If necessary, the musculocutaneous flap is opened and more fat is injected in-between the fat pads into the groove, but, definitely, not into the fat pads.

The reason why we do the injection before the flap is closed is to accurately perform the insertion and to avoid entering into the intra-orbital fat pad, which may worsen the presence of eye bags. We inject the superficial fat only after the flap wound is closed. This procedure modifies the groove under the eye more accurately.

We share with you our surgical methods with the hope that fat utilization and fat pad transposition will greatly improve surgical satisfaction.

\section{Declaration of Competing Interest}

None.

\section{Funding}

None.

\section{Reference}

1. Lee W, Cho JK, Koh IS, et al. Infraorbital groove correction by microfat injection after lower blepharoplasty. J Plast Reconstr Aesthet Surg 2019 Nov 29. pii: S1748-6815(19)30504-2.

Wen-Tsao Ho

Department of Dermatology, Dr Sweet Cosmetic Clinic, 3F., No. 38-6, Wenhua 2nd Rd., Guishan Dist., Taoyuan City 33380, Taiwan ROC E-mail address: derm.administration@gmail.com (W.-T. Ho)
(C) 2020 British Association of Plastic, Reconstructive and Aesthetic Surgeons. Published by Elsevier Ltd. All rights reserved.

https://doi.org/10.1016/j.bjps.2020.02.044

\section{Letter comments on published article "Modification of jumping man flap"}

Dear Sir,

Diver and Lewis described a modification of the "Jumping Man Flap". ${ }^{1}$ In fact, what they have described is a modification of the 5-flap Z-plasty. This was described by Hirschowitz et al. ${ }^{2}$ It is not a jumping man as it has no body.

The true Jumping Man Flap was described by Mustarde ${ }^{3}$ for the correction of epicanthal folds and telecanthus.

We have used the 5-flap z-plasty particularly for the release of 1 st web space contractures following burns, the modification of raised curved scars of the trunk and limbs following burns, and for the correction of epicanthal folds in small children.

Using the Diver and Lewis modification in burn cases results in thin and less vascular flaps. When correcting epicanthal folds in children the flaps are so small that reducing their size in any way would make it near impossible to suture the flaps correctly.

\section{Declaration of Competing Interest}

No conflicts of interest.

\section{References}

1. Diver AJ, Lewis AG. Modification of jumping man flap. JPRAS 2019;72:1862-3.

2. Hirschowitz B, Karev A, Rousso M. Combined double Z-plasty and v-y advancement for thumb web contracture. Hand 1975;7:2923.

3. Mustarde JC. (1971) (Ed.) Plastic Surgery in Infancy and Childhood Edinburgh and London, B\&S Livingstone p. 209

Inez I. Eiben

Philip Martin Gilbert

Queen Victoria Hospital, East Grinstead, United Kingdom E-mail address: phlglbrt@aol.com (P.M. Gilbert)

(c) 2020 British Association of Plastic, Reconstructive and Aesthetic Surgeons. Published by Elsevier Ltd. All rights reserved.

https://doi.org/10.1016/j.bjps.2020.02.053 


\section{Letter of response to the comment in "Modification of jumping man flap"}

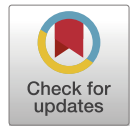

Dear Sir,

Eiben and Gilbert are thanked for their comments. They may be correct in the original description of the respective flaps, but the five-flap z-plasty in our experience has always been known colloquially as the jumping man flap. Indeed, extra caution is required in burns secondary reconstruction. The skin of these patients is typically thin, often scarred and unforgiving. Flaps should never be undermined unless in an area of completely virgin tissue. The modification we presented does result in an apparently thinner base for the 'arm limb' flaps, but traditionally wider based flaps would have been transferred and then trimmed with the same outcome. The tiny sizes involved in paediatric eyelid surgery would not be the best forum to experiment, and certainly Mustardé's original design would seem safest in that setting. We had uniquely sought to also measure precisely the geometric gain in length, and felt that the result was impressive.

\section{Declaration of Competing Interest}

None

\section{Letter to the editor: Evaluating the effectiveness of plastic surgery simulation training for undergraduate medical students ${ }^{1}$}

\section{Dear Sir,}

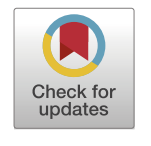

We read with interest the recent correspondence regarding the effectiveness of plastic surgery simulation for training undergraduate medical students. We are in wholehearted agreement with the statement regarding medical school curricula lacking exposure to plastic surgery and commend the authors for their efforts to pique the interest of medical students in our specialty. We wish however to point out some vagueness that, unless clarified, could be misleading to your readership.

The correspondence states: "The decrease in competition ratios for plastic surgery". We believe that current data supports the opposite view. Taking into account published data from Health Education England over the last 4 years ${ }^{2}$, there has in fact been a $41 \%$ rise in the competition ratios from 2016 to 2019 (Fig. 1.) suggesting an increasing interest in the specialty.
Competition Ratios For Plastic Surgery ST3 2016-19

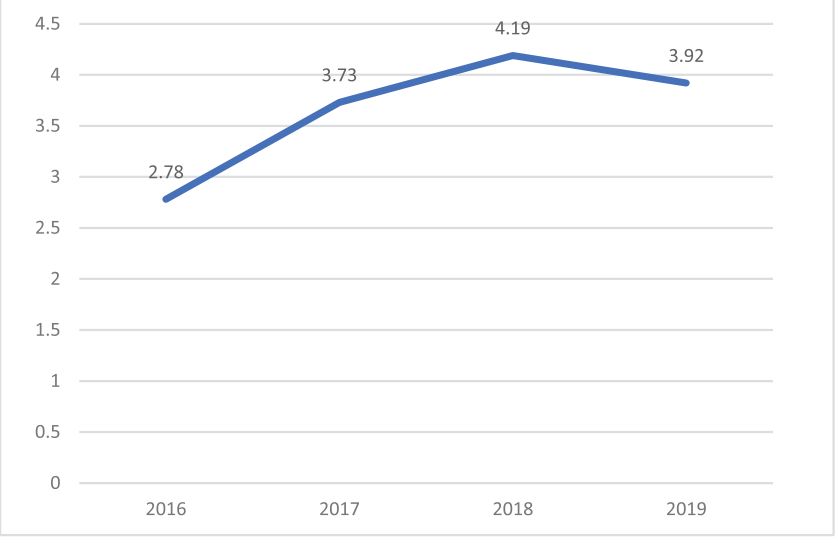

Figure 1

Highlighting this increase in demand supports the authors' desire for more undergraduate exposure to plastic surgery. This increased input in the UK curriculum would also help all medical students become aware of the support plastic surgeons can provide to other specialties as this is a particular feature of the specialty. In an increasingly specialised medical world, we feel it is important that all doctors are equipped with the knowledge to best serve their patients.

\section{Declaration of competing interest}

No funding has been received for this work and the authors have no competing interest.

\section{References}

1. Zargaran D, Turki M, Farzaneh B, et al. Evaluating the effectiveness of plastic surgery simulation training for undergraduate medical students. J Plast Reconstr Aesthet Surg 2019. doi:10.1016/j.bjps.2019.10.005.

2. Health Education England [Online] Available at: https:// specialtytraining.hee.nhs.uk/Competition-Ratios (Accessed 28 February 2020)

Miss K.J. Taylor*

Queen Victoria Hospital, East Grinstead, United Kingdom

Mr. B.S. Dheansa

Queen Victoria Hospital, East Grinstead, United Kingdom

*Corresponding author Queen Victoria Hospital, Holtye Road, East Grinstead, RH19 3DZ, United Kingdom

E-mail address: Kirsten.taylor5@nhs.net (M.K.J. Taylor)

(C) 2020 British Association of Plastic, Reconstructive and Aesthetic Surgeons. Published by Elsevier Ltd. All rights reserved.

https://doi.org/10.1016/j.bjps.2020.03.021 


\section{FFP 3 reusable respirators for COVID-19; adequate and suitable in the healthcare setting}

\section{Dear Sir/Madam,}

In response to critical Personal Protective Equipment (PPE) shortages during the COVID-19 pandemic, MedsupplydriveUK was established by ENT trainee Ms. Jasmine Ho, and MedsupplydriveUK Scotland by two Plastic Surgery trainees (Ms. Gillian Higgins and Mrs. Eleanor Robertson). We applied the principles of creative problem solving and multidisciplinary collaboration instilled by our specialty. Since March 2020, we have recruited over 400 volunteers to mobilise over 200,000 pieces of high quality PPE donated from industry to the NHS and social care. We have partnered with academics and leaders of industry to manufacture: surgical gowns, scrubs and visors using techniques including laser cutting, injection molding, and 3D printing. We have engaged with NHS Boards and Trusts and politicians at local, regional and national level to advocate for healthcare worker protection in accordance with Health and Safety Executive and COSHH legislation including: engineering controls and PPE that is adequate for the hazard and suitable for task, user and environment.

Public Health England (PHE) currently advise FFP3 level of protection only in the context of a list of aerosol gener- ating procedures ${ }^{1}$. A surgical mask confers $6 \times(63 \%)$ protection, FFP2/N95 100x (92-98\%) and FFP3 100-10,000x (>99\%) protection (Figure 1). As SARS-CoV-2 is a novel pathogen, evidence is naïve and evolving, and since transmission occurs via aerosol, droplets and fomites from the aerodigestive tract, all 10 UK Surgical Associations have issued guidance to use higher levels of PPE for procedures that are not included in the PHE list(2). CBS, ENTUK and BAOMS have issued statements supporting the use of reusable respirators and power air-purifying respirators, and their use is approved by PHE, Health Protection Scotland, Public Health Agency, Public Health Wales, NHS and the Academy of Medical Royal Collages ${ }^{1}$. The first author has experienced the need to quote BAPRAS guidance ${ }^{2}$ in defense of their use of $\mathrm{PPE}^{2}$.

MedSupplyDrive (UK and Scotland) hope to empower all healthcare workers to demand provision of adequate (i.e. will protect from SARS-CoV-2) and suitable (for the task, user and environment) PPE by engaging with their employers directly or through Unions, Royal Colleges and Associations. As a nation we must learn from other countries who successfully protected their workforce. Data suggests that staff death is avoidable with the use of occupational health measures and FFP3 grade $\mathrm{PPE}^{3}$, despite which at least 245 UK health care workers have died of COVID-19 ${ }^{4}$.

The strain placed on systems by SARS-CoV-2, with reduced access to operating theatres, beds, equipment and staff has the potential for serious detrimental consequences for surgical training ${ }^{5}$. PPE shortages and the subsequent necessity for rationing is causing additional harm. Due to global demand and supply chain failures, FFP3 disposable masks for people with small faces are in particularly short supply. The majority of these individuals are female, and they are currently provided with no solution apart from

The authors have no competing interests.

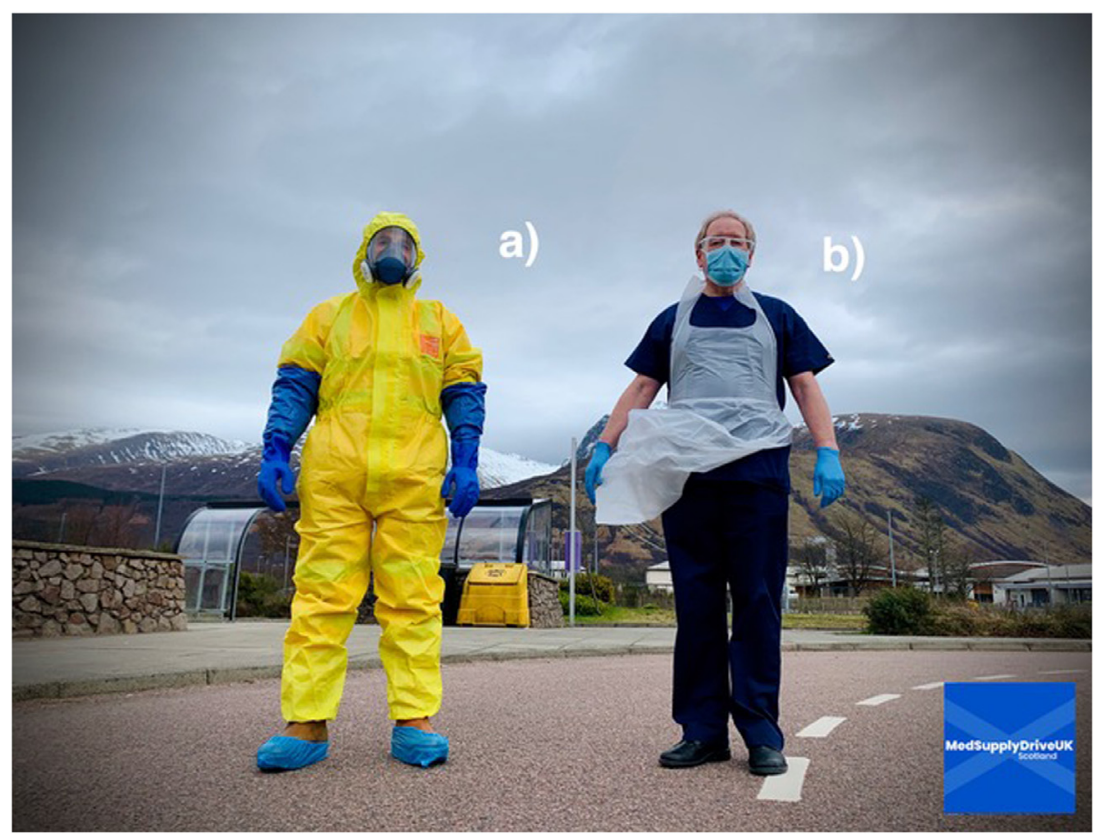

Figure 1 (a) Full face FFP3 reusable respirator conferring $\sim 10,000 x$ (>99\%) protection. (b) Surgical mask conferring $6 x(63 \%)$ protection. 
avoiding "high risk" operating if/when this resource runs out; further depriving them of training opportunities.

Reusable respirators provide superior respiratory protection over disposable FFP3 masks due to design characteristics. They are more likely to provide reliable fit due to increased seal surface area (half face $10 \mathrm{~mm}$, full face $20 \mathrm{~mm}$ ). As they are designed to be decontaminated between patients and after each shift they are both economically and ecologically advantageous whilst also reducing fit testing burden and negating reliance upon precarious supply chains. There are factories in the UK which already make reusable respirators and MedSupplyDrive have been contacted by UK manufacturers looking to retool to meet this demand. Although some NHS Trusts remain reluctant to use reusable respirators, others have already adopted them routinely, using manufacturer decontamination and filter change advice. One NHS Trust has supplied every member of their workforce with a reusable respirator as a sustainable plan for ongoing pandemic waves.

It is apparent that healthcare workers are unable to access sufficient quantities of high quality respiratory protection. Reusable respirators provide adequate protection from SARS-CoV-2 as well as being eminently suitable for a wide range of users, tasks and environment. We call on those reviewing decontamination and filter policy for reusable respirators to appreciate the urgency of the situation and expedite the process to enable all health and social care workers to access the respiratory protection that they need.

\section{References}

1. England PH. Recommended PPE for healthcare workers by secondary care inpatient clinical setting, NHS and independent sector. London: PHE; 2020.
2. Jessop ZM, Dobbs TD, Ali SR, Combellack E, Clancy R, Ibrahim N, et al. Personal Protective Equipment (PPE) for Surgeons during COVID-19 Pandemic: A Systematic Review of Availability, Usage, and Rationing. British Journal of Surgery 2020.

3. Semple S, Cherrie JW. COVID-19: protecting worker health. Annals of Work Exposures and Health 2020.

4. Memorial of Health \& Social Care Workers taken by COVID-19 Nursing Notes 2020 [cited 2020 08.06.2020]. Available from: https: / / nursingnotes.co.uk/covid-19- memorial/?fbclid=<?PMU ?)IwAR2ZqY_t5xcDBjA-c2R4o-YplOpr52cKLujlOP4vC4zyAVkvw2i wiD1VneU.

5. Hart A. Covid-19. Journal of Plastic, Reconstructive \& Aesthetic Surgery 2020;73(5):811-14.

G.C. Higgins*, E. Robertson Canniesburn Plastic Surgery and Burns Unit, Glasgow Royal Infirmary

C. Horsely, N. McLean Georope Geo-technical and Rope Access solutions, West Quarry, Ballachulish

J. Douglas GP and Occupational Health Specialist, Tweeddale Practice, Fort William Health Centre, Fort William

*Corresponding author. E-mail address: gillianhiggins@nhs.net (G.C. Higgins)

(C) 2020 Published by Elsevier Ltd on behalf of British Association of Plastic, Reconstructive and Aesthetic Surgeons.

https://doi.org/10.1016/j.bjps.2020.06.002 